The Dissertation Committee for Cheryl Lynn Olson certifies that this is the approved version of the following dissertation:

\title{
Determination of the Internal Exposure Hazard from Plutonium Work in an Open Front Hood
}

\author{
Committee:
}

Sheldon Landsberger, Supervisor

Steven Biegalski

Richard Corsi

Ofodike Ezekoye

Murray E. Moore, Co-Supervisor 


\title{
Determination of the Internal Exposure Hazard from Plutonium Work in an Open Front Hood
}

by

Cheryl Lynn Olson, B.S.; M.S.

\author{
Dissertation \\ Presented to the Faculty of the Graduate School of \\ The University of Texas at Austin \\ in Partial Fulfillment \\ of the Requirements \\ for the Degree of \\ Doctor of Philosophy
}

The University of Texas at Austin

December 2006 


\section{Dedication}

To my Father and Mother - I know you are in heaven looking down on me and I hope you are proud. 


\section{Acknowledgements}

I would like thank Dr. Sheldon Landsberger for his support and guidance of my work at the University of Texas and my dissertation committee for reviewing my work. My dream of obtaining a $\mathrm{PhD}$ would not have been possible without the distance learning program offered by the University of Texas.

I would like to thank the professors of all my classes for their wonderful instruction and understanding of personal issues that affected my work. In addition,

everyone I had contact with at the University of Texas and the Nuclear Engineering Teaching Laboratory were wonderful.

I also thank my leaders and co-workers at Los Alamos National Laboratory, specifically Luiz Bertelli, Jim Bland, Megan Bliss, Art Crawford, Bill Eisele, and Murray Moore. I had the unique benefit of working with so many knowledgeable persons who patiently guided me through my research.

A special thanks to my husband, who tolerated me while I was going through this endeavor. There is a special place in heaven for men like him. 


\title{
Determination of the Internal Exposure Hazard from Plutonium Work in an Open Front Hood
}

\author{
Publication No. \\ Cheryl Lynn Olson, Ph.D. \\ The University of Texas at Austin, 2006 \\ Supervisor: Sheldon Landsberger \\ Co-Supervisor Murray E. Moore
}

Work with hazardous substances, such as radioactive material, can be done safely when engineered controls are used to maintain the worker effective dose below the International Commission on Radiological Protection ICRP 60 recommendation of 0.02 $\mathrm{Sv} / \mathrm{year}$ and reduce the worker exposure to material to as low as reasonably achievable (ALARA). A primary engineered control used at a Los Alamos National Laboratory facility is the open-front hood. An open-front hood, also known as an open-front box, is a laboratory containment box that is fully enclosed except for a $15-\mathrm{cm}$ opening along the front of the box.

This research involved collection of the aerosol escaping an open-front hood while $\mathrm{PuO}_{2}$ sample digestion was simulated. Sodium chloride was used as a surrogate to mimic the behavior of $\mathrm{PuO}_{2}$. The $\mathrm{NaCl}$ aerosol was binned as a function of median aerodynamic diameter using a Micro-orifice Uniform Deposit Impactor (MOUDI, MSP Corporation, Shoreview, MN) cascade impactor. Using neutron activation analysis (NAA) to measure the mass of material in each of the nine bins of the MOUDI, the mass median diameter of the escaping aerosol was determined. Using the mass median 
diameter and the total mass of the particle distribution, dose was calculated using ICRP 60 methodology.

Experimental conditions mimicked a stationary worker and a worker moving her hands in and out of the open front hood. Measurements were also done in the hood for comparison. The effect of the hands moving in and out of the box was modeled. Information necessary for Computational Fluid Dynamics (CFD) modeling is given, such as volumetric flow rates out of the open front hood and into the experimental room, detailed sketches of the experimental set-up, and energy provided by the hot plate and worker.

This research is unique as it measures particle size distribution from routine working conditions. Current research uses tracer gases or describes non-routine conditions. It is important to have results that mimic routine conditions to allow for quantitative measurement of worker exposure and determination of the adequacy of the open front hood for this type of work. This work is important as it quantifies the effectiveness of the open front hood for controlling inhalation hazards. This information is crucial for managing the risk to workers.

The mass median diameter of particles escaping the hood when a stationary worker sits in front of the hood is $0.54 \pm 3.7 \mu \mathrm{m}$. The mass median diameter of particles escaping the hood when a worker performs work in the hood is $0.35 \pm 5.1 \mu \mathrm{m}$. These particle sizes are in the range of those seen in the published liturature. (Raabe, et al., 1978; Dorrian and Bailey, 1995; and Cheng, et al., 2004)

The effective dose from digestion of $\mathrm{PuO}_{2}$ in an open-front hood while a worker is moving her hands in and out of the hood was estimated to be $5 \mathrm{mSv}$. Based on the experimental error, this value could be low by a factor of 4 . There was little difference 
between the dose calculated for a worker in motion and a stationary worker. The calculated dose while work was being performed is $5 \%$ higher.

Comparison of these results to measured worker doses and continuous air monitoring results showed the experimental results may be somewhat higher. The lower limit of detection for urine bioassay is $0.002 \mathrm{~Sv}$ (Inkret, et al., 1999). Workers performing the activity mimicked in this experiment are routinely monitored and do not have measurable internal doses. The most likely reason for the high experimental results is the placement of the sample digestion apparatus. For this experiment, the material was placed $10 \mathrm{~cm}$ from the hood opening. In practice, the material is typically further back in the hood; placing the material further back in the hood likely decreases the amount of material escaping the hood.

The cost-benefit analysis showed the use of the open-front hood as a reasonable protective measure. Although worker exposure may approach the ICRP limit, the cost of previously observed ergonomic injuries caused by work in a glove box is five thousand times greater than the dose received by the worker. Protective measures such as respiratory protection should be evaluated on a case by case basis to keep worker exposure as low as reasonably achievable. 


\section{TABLE OF CONTENTS}

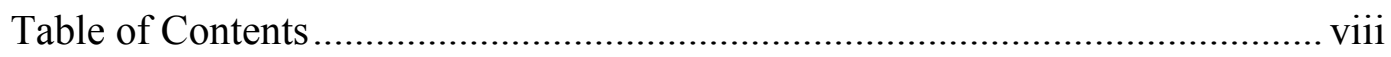

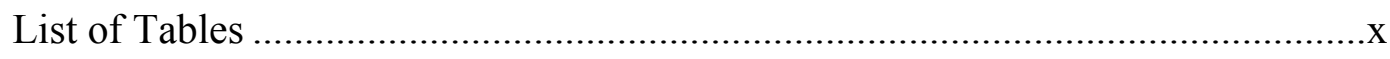

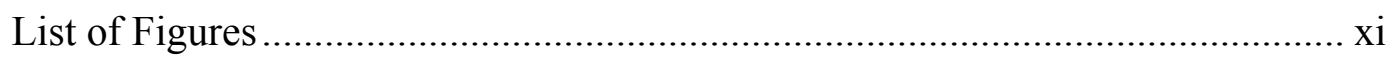

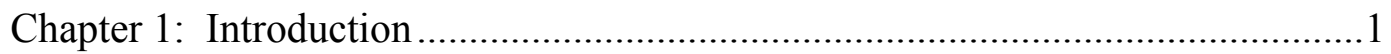

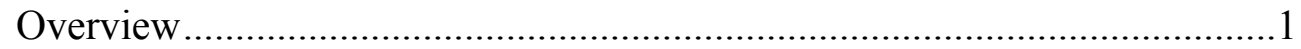

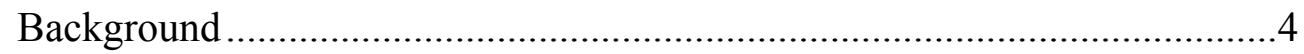

Studies of Leakage of material from hood......................................................

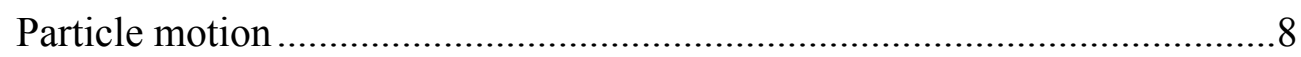

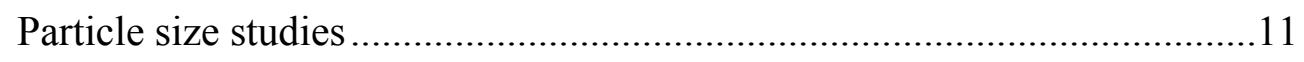

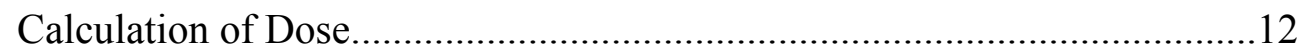

Chapter 2: Material and Methods ..................................................................22

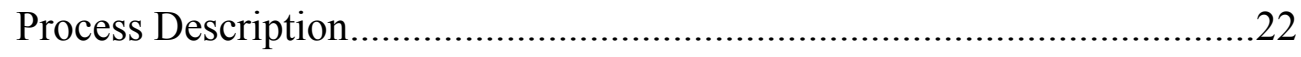

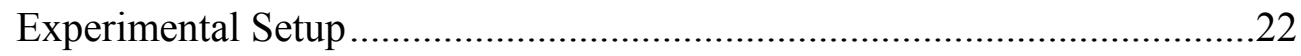

Selection of Surrogate Material and Analysis Method ........................22

Selection of Sampling Apparatus.........................................................23

Experimental Facility Description .....................................................27

Sample Preparation and Collection....................................................31

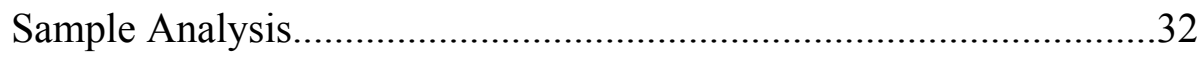

Evaluation of Particle Size Distribution Data .........................................34

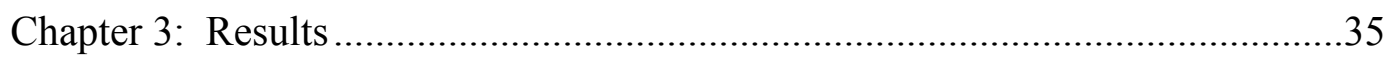

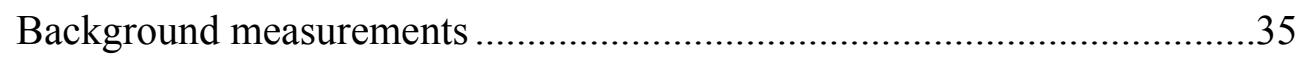

Measurements of material escaping while no work is being performed ......38

Measurements of material escaping while work is being performed ............43

Measurements of material escaping with MOUDI in Hood ..........................49

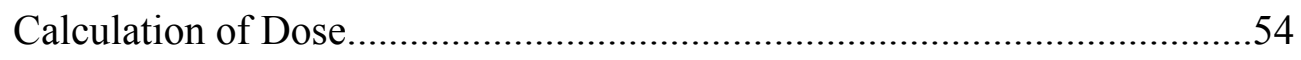

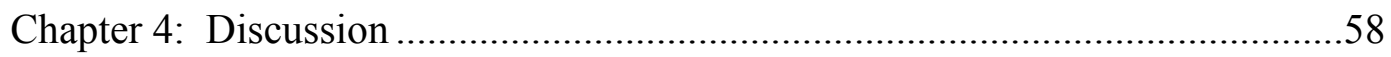

Capture Efficiency and Hood Leakage ........................................................58 
Effect of Hand Motion on Hood Leakage......................................................59

Modeling of Hood Leakage ..........................................................................60

Statistical Significance of Measurements ......................................................61

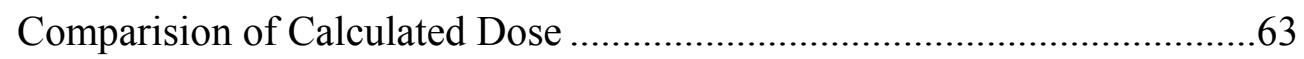

Chapter 5: Conclusions and Recommendations .................................................67

Appendix A - Diagram of Experimental Setup ....................................................70

Appendix B - Los Alamos Program Output.......................................................74

Appendix C - Sample Calculation for $1 \mu$ particles .............................................78

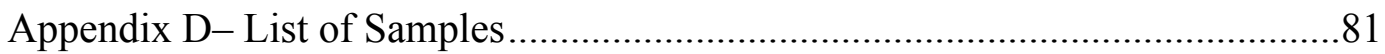

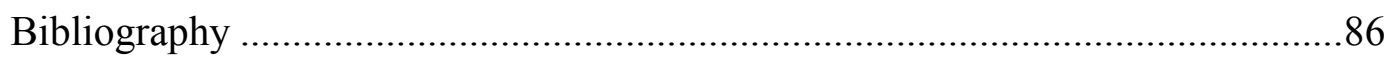

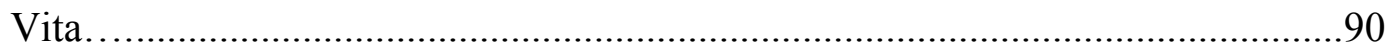




\section{LIST OF TABLES}

Table 1: Regional Percent Deposition in Reference Worker (ICRP 66, 1993) ....16

Table 2: Calibrated Cut Points for Each Stage ..................................................25

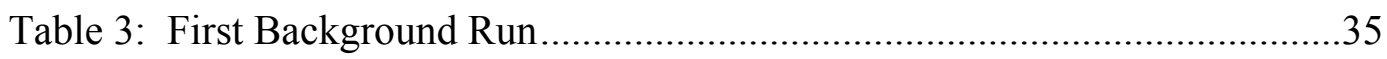

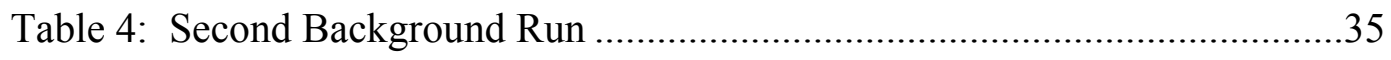

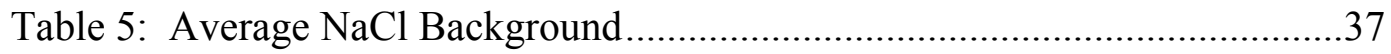

Table 6: First no-motion $\mathrm{NaCl}$ mass collected ................................................39

Table 7: Second no-motion $\mathrm{NaCl}$ mass collected ...........................................40

Table 8. Third no-motion $\mathrm{NaCl}$ mass collected ...............................................41

Table 9: Average $\mathrm{NaCl}$ Mass for Stationary Worker......................................42

Table 10. First motion $\mathrm{NaCl}$ mass collected ..................................................44

Table 11. Second motion $\mathrm{NaCl}$ mass collected ............................................45

Table 12. Third motion $\mathrm{NaCl}$ mass collected ..................................................46

Table 13. Fourth motion $\mathrm{NaCl}$ mass collected................................................47

Table 14: Average $\mathrm{NaCl}$ Mass for Worker in Motion ......................................48

Table 15. First MOUDI in hood $\mathrm{NaCl}$ mass collected.......................................50

Table 16. Second MOUDI in hood $\mathrm{NaCl}$ mass collected ..................................51

Table 17. Third MOUDI in hood $\mathrm{NaCl}$ mass collected .....................................52

Table 18: Average $\mathrm{NaCl}$ Mass for MOUDI in Hood.........................................53

Table 19. Comparison of $\mathrm{Sv} / \mathrm{Bq}$ results using AIDE and Hand Calculation .........56

Table 20. Activity Inhaled for each Experimental Condition............................57

Table 21. Activity Inhaled for each Experimental Condition...........................57

Table 22. Fan Power for varying box capture efficiencies ..............................60 


\section{LIST OF FIGURES}

Figure 1. Typical open front hood and glove box.............................................

Figure 2. Contamination events by year for open front hood operations ................3

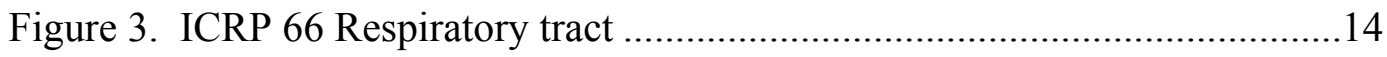

Figure 4. Fractional deposition for reference worker .....................................15

Figure 5. Particle size distribution with Spraytec ...........................................24

Figure 6. Frame of box prior to powder coating ...........................................27

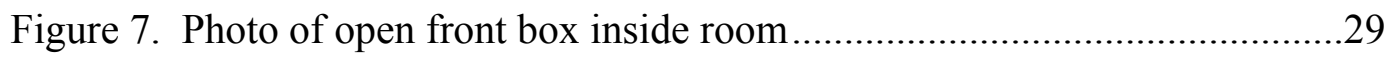

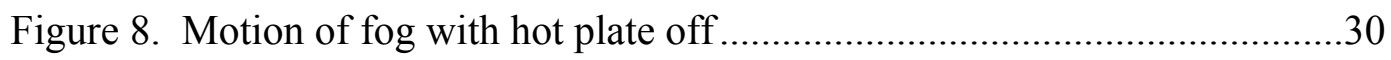

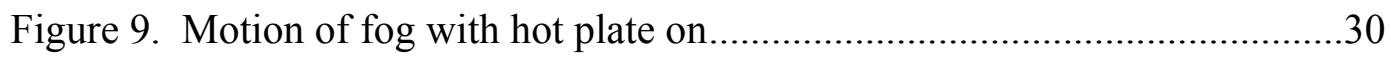

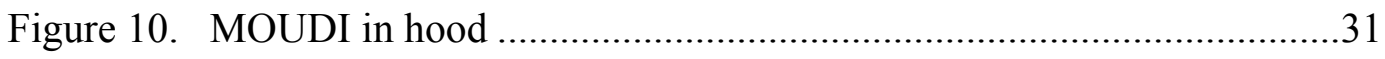

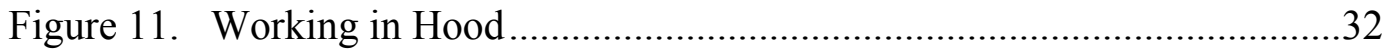

Figure 12. Background mass as a function of particle size.................................38

Figure 13. Mass as a function of particle diameter with no work......................42

Figure 14. Particle diameter distribution - with no work occurring...................43

Figure 15. Work mass as a function of particle diameter. ...............................48

Figure 16. Particle diameter when work is being performed ............................49

Figure 17. Particle diameter distribution with the MOUDI in hood....................53

Figure 18. Mass as a function of particle diameter with the MOUDI in the hood54

Figure 19. Relationship between volumetric flow rate and capture efficiency ....59

Figure 20. Comparison of gross particle size distribution to background ............62

Figure 21. Comparison of net particle size distribution...................................63

Figure 22. Dose conversion factor as a function of particle size .......................64 


\section{CHAPTER 1: INTRODUCTION}

\section{OVERVIEW}

Work with hazardous substances, such as radioactive material, can be done safely when engineered controls are used to reduce the worker exposure to material to as low as reasonably achievable (ALARA). The primary exposure route associated in working with un-encapsulated plutonium is inhalation. Therefore, a confinement device such as the open-front hood or glove box shown in Figure 1 is used when working with unencapsulated plutonium.
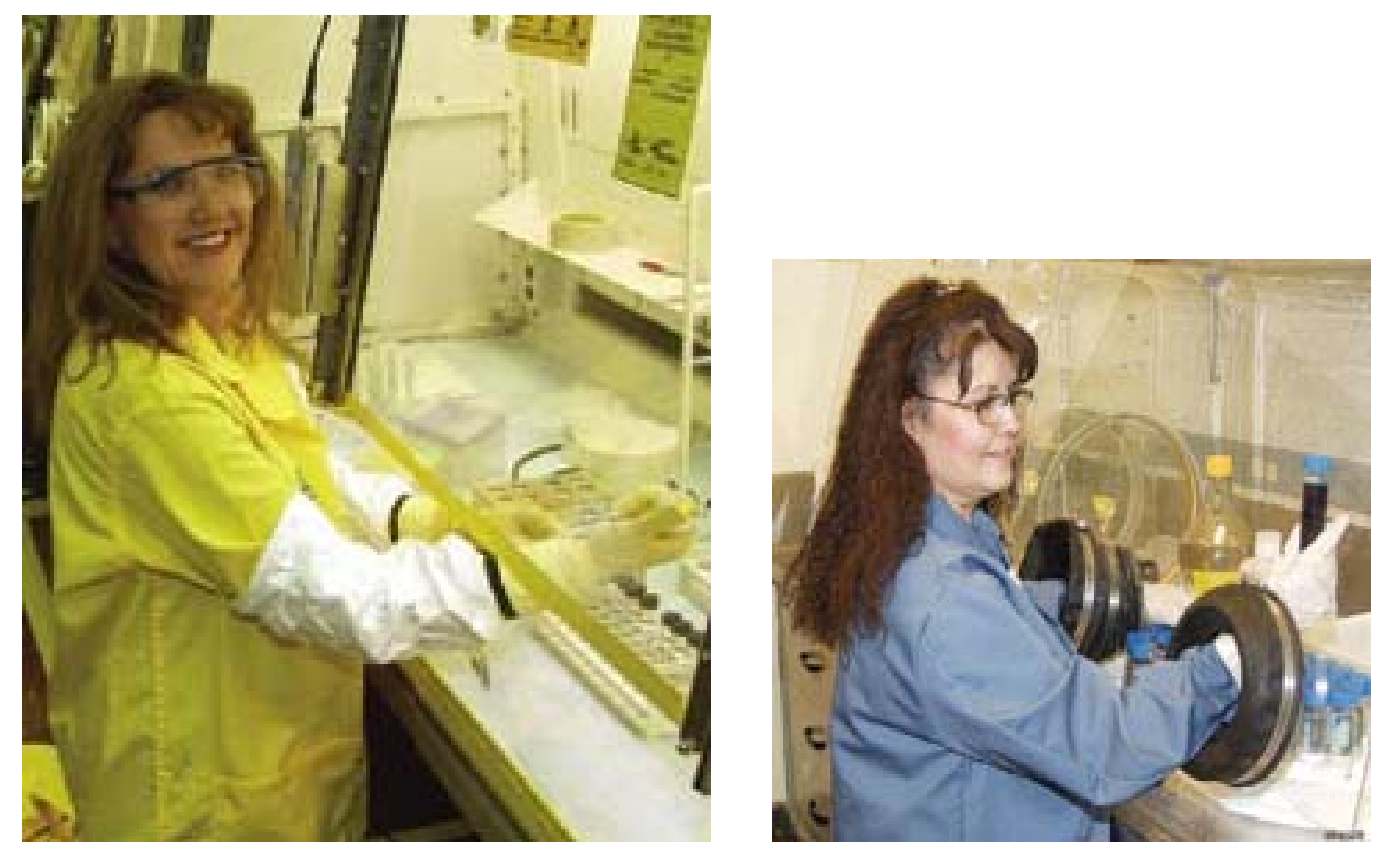

Figure 1. Typical open front hood and glove box

An open-front hood, also known as an open-front box, is a laboratory containment box that is fully enclosed except for a $15-\mathrm{cm}$ opening along the front of the box. Openfront hoods increase worker comfort by providing ease of use compared to working in a 
glove box. Open-front hoods have been used for over fifty years. The confinement for these hoods is based on an imposed airflow through the opening. The analyst stands approximately $10 \mathrm{~cm}$ from the opening and performs tasks by reaching through the opening with their hands and forearms to access the contents of the box. Under routine conditions, air enters the opening at an average velocity of $0.5 \mathrm{~m} / \mathrm{s}$. The analyst wears personal protective equipment on his or her hands, arms, and body.

By comparison, the glove box totally encloses the hazardous material. The glove box is ventilated and kept at a lower pressure than the laboratory air, however the primary engineered control is the box itself. Even if there were a failure of the ventilation, the material would remain in the box. Only a failure of the structure, such as a hole in the glove, would allow material to escape. However, it is more difficult to work in glove boxes as the gloves decrease dexterity and apply stress on joints that may cause ergonomic injuries.

To determine if the open front hood provides a safe level of containment of the material, one must know how much material escapes the hood and the consequence, or resulting worker exposure, from inhalation of the material. There is evidence from past events that indicates some material escapes the hood. A review of Los Alamos National Laboratory radiological incident data (LANL, 2004) over the past eleven years at a facility using primarily open-front hoods shows radioactive material escapes the hoods over one hundred times per year, on average. A breakdown of the contamination events by year is shown in Figure 2. Personal clothing contamination occurs when a worke's personal clothing becomes contaminated while working. PPE contamination, or personnel protective clothing contamination occurs when a labcoat or coveralls become contaminated. Skin contamination refers to contamination on a worker's skin. Area contamination is contamination found in the work area. Positive CAM alarms occur 
when the concentration of airborne radioactivity exceeds a preset level. A literature search to find how much material escapes an open front hood showed only qualitative findings; however, it has been verified that contaminants do escape.

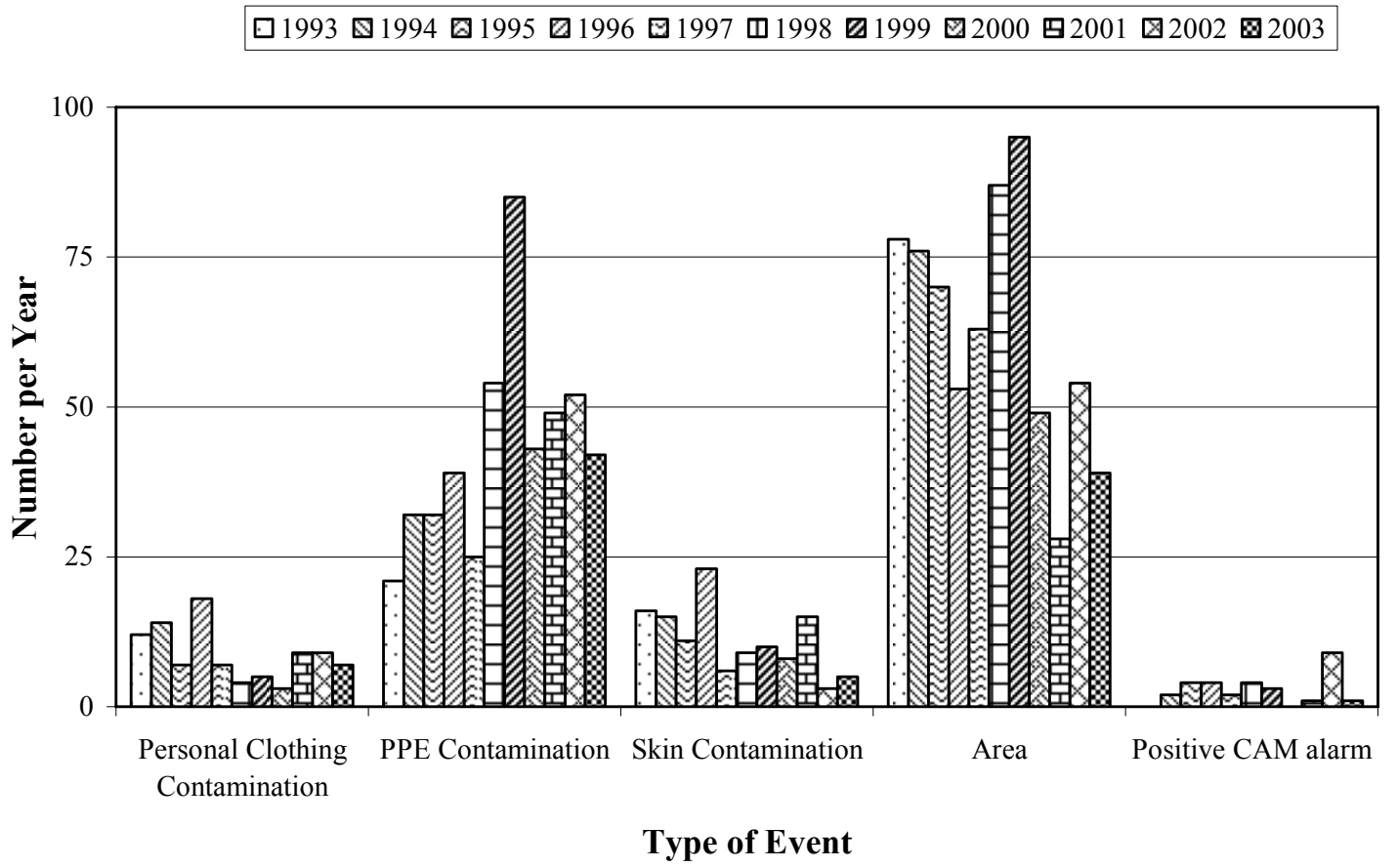

Figure 2. Contamination events by year for open front hood operations

Calculation of worker exposure from inhalation of radioactive material is based on the median particle diameter and the amount of material inhaled. A literature search on particle size distribution for work in an open front hood or glove box revealed quantitative data; however, none of the studies investigated the particle size distribution to a worker performing routine work in an open-front hood.

In this research, the amount and median particle size of material escaping the open-front hood during routine work was quantitatively measured. From these data, the resulting dose to an exposed worker was estimated. The worker protection effectiveness 
of an open-front hood was then evaluated. CFD modeling of the experimental results was not included. However, numerous references that have performed modeling of parts of the experimental method are cited.

\section{BACKGROUND}

There have been numerous studies investigating the leakage of material from hoods. However, these studies were qualitative in nature. Other investigations used tools such as CFD software, but the results of these studies have not been validated by field measurements. There have been quantitative studies investigating the physical characteristics of radioactive material in the workplace. However, these studies are generally retrospective and do not mimic the routine working conditions.

Knowledge of physical characteristics such as particle size and mass of the material is vital in determining how much material the worker may inhale. Particle size plays a key role in worker inhalation dose, as smaller particles tend to be readily inhaled into the deep lung where they tend to remain, while larger particles may be deposited in the nose and throat then swallowed. Once particle size and the mass of the material inhaled is known, the dose resulting from inhalation of the material can be determined.

\section{STUDIES OF LEAKAGE OF MATERIAL FROM HOOD}

Although there are no quantitative data regarding the amount of material that escapes from an open-front hood, there have been numerous qualitative studies demonstrating that material does indeed escape. Leakage has been shown to increase when a worker or heated manikin is in front of the hood. The results of studies relating face velocity to leakage vary. At least one study shows maximum leakage at lower face velocities. Other studies show maximum leakage at higher flows. 
Leakage from an open-front hood as a function of face velocity was investigated by Johnson and Fletcher (Johnson and Fletcher, 1996). The opening of the box was 120 $\mathrm{cm}$ wide and $39 \mathrm{~cm}$ high. The tracer gas sulfur hexafluoride $\left(\mathrm{SF}_{6}\right)$ was released along a plane $15 \mathrm{~cm}$ from the centerline of the sash at a volumetric flow rate of $2.5 \mathrm{~L} / \mathrm{m}$. Leakage measurements were taken along the plane of the sash opening. The face velocity was varied from 0.1 to $1.4 \mathrm{~m} / \mathrm{s}$. The maximum leakage occurred at face velocities between 0.4 and $0.6 \mathrm{~m} / \mathrm{s}$. The amount of leakage caused by the obstruction of the face of the box by the worker was also measured. A series of tests were carried out with heated and unheated manikins at temperatures of $25^{\circ} \mathrm{C}, 30^{\circ} \mathrm{C}, 33^{\circ} \mathrm{C}$, and $37^{\circ} \mathrm{C}$ and with a human subject. Little to no leakage was seen with the unheated manikin. In general, leakage increased as the temperature of the manikin increased. Leakage seen with the human operator was comparable to that seen with a manikin heated to $30^{\circ} \mathrm{C}$. Measurements of leakage as a function of operator distance from the opening were also made. The amount of leakage falls rapidly with increasing separation distance and is negligible for separation distance greater than $60 \mathrm{~cm}$.

Research has been done to quantify the air movement around a worker by measuring the velocity vectors of the air around the human and heated manikin (Johnson and Fletcher, 1996b). The human and heated manikin was placed in front of an exhaust register pulling air at a velocity of $0.5 \mathrm{~m} / \mathrm{s}$. The heat of the manikin and human caused a heated boundary layer moving upward with a velocity on the order of $0.2 \mathrm{~m} / \mathrm{s}$.

Myers et a.l evaluated the airflow conditions around the human body and characterized the interaction of the human thermal plume (Meyers et al., 1998). The baseline case, effects of blockage of the air-flow, as well as the thermal effects of a heated manikin were evaluated. The experiments demonstrated an upward motion of the air into the breathing zone. 
Brohus and Nelson evaluated the thermal boundary layer caused by the human thermal plume (Brohus and Nielsen, 1994). The authors found that the boundary layer caused by human body temperature compared with the temperature of room air allows for air to entrain from below the breathing zone. This moves contamination below the breathing zone into the breathing zone.

Brohus (1997) performed some numerical modeling of the human plume phenomena for his Ph.D. dissertation (Brohus, 1997). Using CFD modeling, Brohus developed a personnel exposure model using the breathing zone as an "exhaust opening" (the ventilation effectiveness experienced by a person in a ventilated room) and entrainment effectiveness (ability of material to be entrained by the human thermal plume boundary layer) as boundary conditions. The model takes into account the concentration gradient within a room and influence of the human thermal boundary layer.

Eli Lilly and Company (Maupins and Hitchings, 1998) conducted a study to determine how well a hood contains hazardous chemicals. Thirty-nine fume hoods were tested using the tracer gas $\mathrm{SF}_{6}$ to measure leakage. Face velocity for the hoods ranged from 0.4 to $0.6 \mathrm{~m} / \mathrm{s}$. The gas was released inside the hood at a volumetric flow rate of 4.0 $\mathrm{L} / \mathrm{m}, 15 \mathrm{~cm}$ from the plane of the hood opening. An unheated manikin was placed $7.6 \mathrm{~cm}$ in front of the hood and samples were taken at the breathing zone of the manikin, $66 \mathrm{~cm}$ above the floor of the hood. Thirty-four of the thirty-nine hoods (87\%) were found to have leakage greater than the American Conference of Governmental Industrial Hygienists recommended maximum control level of $0.10 \mathrm{ppm}$.

In an investigation done at the University of Washington (Guffey and Barnea, 1994), the effects of face velocity and position on exposure to a manikin standing at the face of hood were studied. Face velocities were varied from 0.3 to $0.86 \mathrm{~m} / \mathrm{s}$. The tracer gas $\mathrm{SF}_{6}$ was released at a volumetric flow rate of $1 \mathrm{~L} / \mathrm{m}, 15 \mathrm{~cm}$ inside the hood, $37 \mathrm{~cm}$ 
from the breathing zone of the manikin. Measurements taken at the breathing zone of the manikin showed exposure was greatest at the lowest face velocity and decreased dramatically as face velocity increased. When the manikin's hands were placed inside the hood, the exposure was twice that seen with the manikin's hands at the manikin's sides.

The United Kingdom Atomic Energy Research Establishment (Bull et al., 1987) investigated the variation in aerosol concentration around a phantom using diethylhexylphosphate (DOP) released in the breathing zone of the phantom to simulate a puff release from a confinement box. DOP particle concentrations on the order of $10^{10}$ $/ \mathrm{m}^{3}$ were released at $20 \mathrm{~L} / \mathrm{min}$. The geometric median diameter of the particles was 0.26 $\mu \mathrm{m}$ with a density of $1 \mathrm{~g} / \mathrm{cm}^{3}$. The confinement box was simply a platform holding the nebulizer. The distance between the face of the box and the front of the phantom varied between 30 and $100 \mathrm{~cm}$. The study showed only a "weak trend" in the decrease of DOP concentration as a function of distance from the box.

Research on contaminant dilution (Welling, et al., 2000) used acetone as the contaminant and measured the concentration as a function of distance from the source, free stream velocity, body temperature, and source geometry (point vs line). Comparison was made between a stationary worker and worker a moving her arms. Air flowing from the back to the front of the worker resulted in the maximum observed dilution. Other observations included dilution as a function of distance from the source and the increase of contaminant concentration when the worker moved her arms.

A Los Alamos study (Jordan et al., 2001) presented a method to perform qualitative dose prediction for accidental releases of material from an enclosure. The model uses two different laboratory airflow conditions, instantaneous and gradual, and Department of Energy (DOE) release fractions. The DOE release fractions quantify the 
fraction of material released into the air and are based on experimental data and historical observations (DOE, 1994). The instantaneous model assumes the release from a glove box is instantaneous and the released material spreads instantaneously and homogeneously throughout the room that houses the glove box. The gradual-mixing model assumes an instantaneous leak that disperses in all directions causing the airborne concentration to decrease as the cloud disperses. Most releases fit neither of these models. The report noted the difficulty in making predictions, even qualitatively.

When hood leakage is investigated using CFD models the results vary. Lan and Viswanathan (2001) used CFD to study the effect of face velocity on flow patterns in the area of a person standing in front of the hood. The model had a hood opening of $300 \mathrm{~cm}$ wide and $64 \mathrm{~cm}$ high with a manikin positioned $20 \mathrm{~cm}$ from the opening. The model simulated injection of the tracer gas $\mathrm{SF}_{6}$ at a volumetric flow rate of $0.6 \mathrm{~L} / \mathrm{m}, 15 \mathrm{~cm}$ behind the plane of the center of the opening with a face velocity across the opening of $0.3 \mathrm{~m} / \mathrm{s}$. The model predicted no contamination leakage.

The National Institute of Health (NIH) (Memarzadeh, 1997) used CFD to investigate hood performance. The NIH model used a hood with an opening $96 \mathrm{~cm}$ wide by $20 \mathrm{~cm}$ high. The leakage was analyzed using average face velocities of $0.25 \mathrm{~m} / \mathrm{s}$ and $0.5 \mathrm{~m} / \mathrm{s}$. A simulation of a contaminant released inside the hood was modeled. Results showed the lower sash velocity produced less leakage and the amount of leakage increased with the presence of a heated manikin $10 \mathrm{~cm}$ from the front of the hood.

\section{PARTICLE MOTION}

Particle motion can be described using Stokes's law-which is a solution of the Navier-Stokes equations describing fluid motion. Stokes assumes (Hinds, 1999): 
1. The fluid is incompressible. The air does not compress significantly near the particle as the particle moves through the air, which is true for particle sizes less than $10 \mu \mathrm{m}$.

2. The inertial forces are negligible compared with the viscous forces. This is true for particle Reynolds number less than 1 .

3. There are no walls or other particles nearby. The presence of a wall within ten diameters of the particle will modify the drag force on the particle. However, due to the small particle size, only a tiny fraction of the particles will be within 10 particle diameters of the wall.

4. The motion of the particle is constant.

5. The fluid velocity at the particle's surface is zero. The assumption of zero fluid velocity at the particle's surface is not met for small particles less than $1 \mu \mathrm{m}$ in diameter and is addressed by use of a correction factor. The factor is called the Cunningham correction factor or slip factor. This factor is expressed as:

$$
\begin{array}{ll}
C_{c}=1+\frac{2.52 \lambda}{d} & \text { Equation } 1
\end{array}
$$

where $\lambda$ is the mean free path of the particle and $d$ is the particle diameter.

Stokes's law describes terminal settling velocity of a particle with respect to particle diameter and density.

$$
V_{T S}=\frac{\rho_{p} d^{2} g}{18 \eta} \quad \text { Equation } 2
$$


Equation 2 can be written in terms of an equivalent diameter that is useful in aerosol lung deposition studies such as this study. This diameter, $d_{a}$, is called the aerodynamic diameter and is defined as the diameter of a spherical particle of density 1 $\mathrm{g} / \mathrm{cm}^{3}$ that has the same settling velocity as the particle of interest.

$$
V_{T S}=\frac{\rho_{o} d_{a}^{2} g}{18 \eta} \quad \text { Equation } 3
$$

Taking into account the density and shape of the particle as well as correcting for slip, if the particle is less than $1 \mu \mathrm{m}$ in diameter, particle size and aerodynamic size are related as follows:

$$
d_{p}=d_{a} \sqrt{\frac{\chi \rho_{o} C_{c}\left(d_{a}\right)}{\rho_{p} C_{c}\left(d_{p}\right)}} \quad \text { Equation } 4
$$

where $d_{a}$ is the aerodynamic diameter, $d_{p}$ is the particle diameter, $\rho_{p}$ is the density of the particle, $\rho_{o}$ is the unit density, $\chi$ is the shape factor, $C_{c}\left(d_{a}\right)$ is the slip factor for the aerodynamic diameter and $C_{c}\left(d_{p}\right)$ is the slip factor for the physical diameter.

Particle deposition in the lung is described by three phenomena: gravitational sedimentation, inertial impaction, and diffusion. Sedimentation and impaction are "aerodynamic" effects and are predominant when the median aerodynamic diameter of the particle distribution is greater than $1 \mu \mathrm{m}$. If the median aerodynamic diameter is less than $0.1 \mu \mathrm{m}$, diffusion (Brownian motion) predominates and particle behavior is represented using the thermodynamic equivalent diameter, $d_{t h}$. The thermodynamic equivalent diameter is the diameter of a spherical particle that has the same diffusion coefficient as the particle of interest. The thermodynamic equivalent diameter does not depend on particle density and is the physical or geometric diameter of the particle. The 
thermodynamic equivalent diameter is the physical or geometric diameter of the particle, according to the International Commission on Radiological Protection. (ICRP, 2003)

\section{PARTICLE SIZE STUDIES}

Studies have been done to characterize particle size in the workplace, inside enclosures, and under accident conditions. However, there are no studies showing the particle-size distribution of material that escapes an open-front hood during routine work.

Raabe, et al., (1978) measured the particle size and activity of aerosols formed inside a glove box during $\mathrm{PuO}_{2}$ mixing and grinding. In the powder mixing operations, the airborne aerosol size distributions had activity median aerodynamic diameters (AMADs) of $1.9 \pm 0.4 \mu \mathrm{m}$ and geometric standard deviation of $1.59 \pm 0.08 \mu \mathrm{m}$. The amount of activity in the air was log-normally distributed with a median value of 45 nCi/L. For the grinding operation, the airborne aerosol size distributions had activity median aerodynamic diameters of $2.3 \pm 0.3 \mu \mathrm{m}$ and geometric standard deviation of $1.6 \pm$ $0.1 \mu \mathrm{m}$. The amount of activity in the air was log-normally distributed with a median value of $7 \mu \mathrm{Ci} / \mathrm{L}$. The $\mathrm{PuO}_{2}$ particle density for both operations was calculated to be 7.5 $\mathrm{g} / \mathrm{cm}^{3}$.

A review of published values of AMAD that included over 52 publications was presented by Dorrian and Bailey (1995). The reported values of AMAD for $\mathrm{PuO}_{2}$ operations ranged from $0.16-15 \mu \mathrm{m}$. The sub-micron particles were produced primarily from high temperature operations.

Los Alamos National Laboratory (Cheng et al., 2004) analyzed air filters collected from fixed air samplers and continuous air monitors after an accidental release of $\mathrm{PuO}_{2}$ from a glove box. Transmission electron microscopy was done on the filters and from the number of alpha tracks detected from each particle; the volume equivalent diameter of the particles was calculated, assuming a $50 \%$ counting efficiency and 
spherical particles. The aerodynamic diameter of the particle was then calculated using the relationship in Equation 4. Since the true dynamic shape factor was not known, two calculations were made using a dynamic shape factor of 1 and 1.5. The calculated value from the two different shape factors were compared using aerodynamic particle size determination by resuspension and aerosolization of the particles on the filters. These experimental results agreed well with the calculated value using a dynamic shape factor of 1. The AMAD for an accidental release of $\mathrm{PuO}_{2}$ particles was determined to be 4.8 $\mu \mathrm{m}$ with a geometric standard deviation of $1.5 \mu \mathrm{m}$.

\section{Calculation of Dose}

Dose is a generic term to describe the amount of radiation received. ICRP 60 provided more descriptive terms such as effective dose and equivalent dose to help describe the effect of the radiation on the tissue or human body. The effects of radiation can be described as stochastic, or random, and deterministic. For stochastic effects, it is thought the probability of the effect increases with increasing exposure. For deterministic effects, there is thought to be threshold below which no effect is seen. Above this threshold, the severity of the effect increases with increasing dose.

Equivalent dose $\left(\mathrm{H}_{T}\right)$ is a measure of the amount of average dose $\left(\mathrm{D}_{T, \mathrm{R}}\right)$ over a tissue or organ and varies as a function of the type of radiation $\left(\mathrm{w}_{\mathrm{R}}\right)$.

$$
H_{T}=\sum_{R} w_{R} \bullet D_{T, R}
$$

For internal dose, alpha particles are assigned a weighting factor of 20. For comparison, the weighting factor of a beta particle is 1 . This weighting factor takes into account the amount of damage the differing types of radiation cause. An alpha particle is very large, compared to a beta particle, and has twice the ionization effect as the beta particle. The 
damage an alpha particle causes is 20 times that of the beta particle, all other things being equal.

The effective dose (E) quantifies the combination of different dose from several different organs. The effective dose is the sum of tissue weighted equivalent dose. The tissue weighting factor $\left(\mathrm{w}_{\mathrm{T}}\right)$ represents relative effect the irradiation of each organ has on the overall deleterious effect of the whole body.

$$
E=\sum_{T} w_{T} \bullet H_{T}
$$

The calculation of equivalent dose uses models developed by the ICRP. Much research (ICRP78, 1997) has been done on internal deposition of plutonium and the resulting dose. The current dosimetric model for inhalation dose considers the respiratory tract as five anatomical regions (ICRP66, 1993), shown in Figure 3:

(1) the anterior nose $\left(\mathrm{ET}_{1},\right)$;

(2) the posterior nasal passages, larynx, pharynx, and mouth $\left(\mathrm{ET}_{2},\right)$;

(3) the bronchial region (BB), consisting of the trachea and bronchi from which deposited material is cleared by ciliary action;

(4) the bronchiolar region (bb) consisting of the bronchioles and terminal bronchioles; and

(5) the alveolar-interstitial region (AI), consisting of the respiratory bronchioles (bronchioles with some alveoli apposed), the alveolar ducts and sacs with their alveoli, and the interstitial connective tissue. 


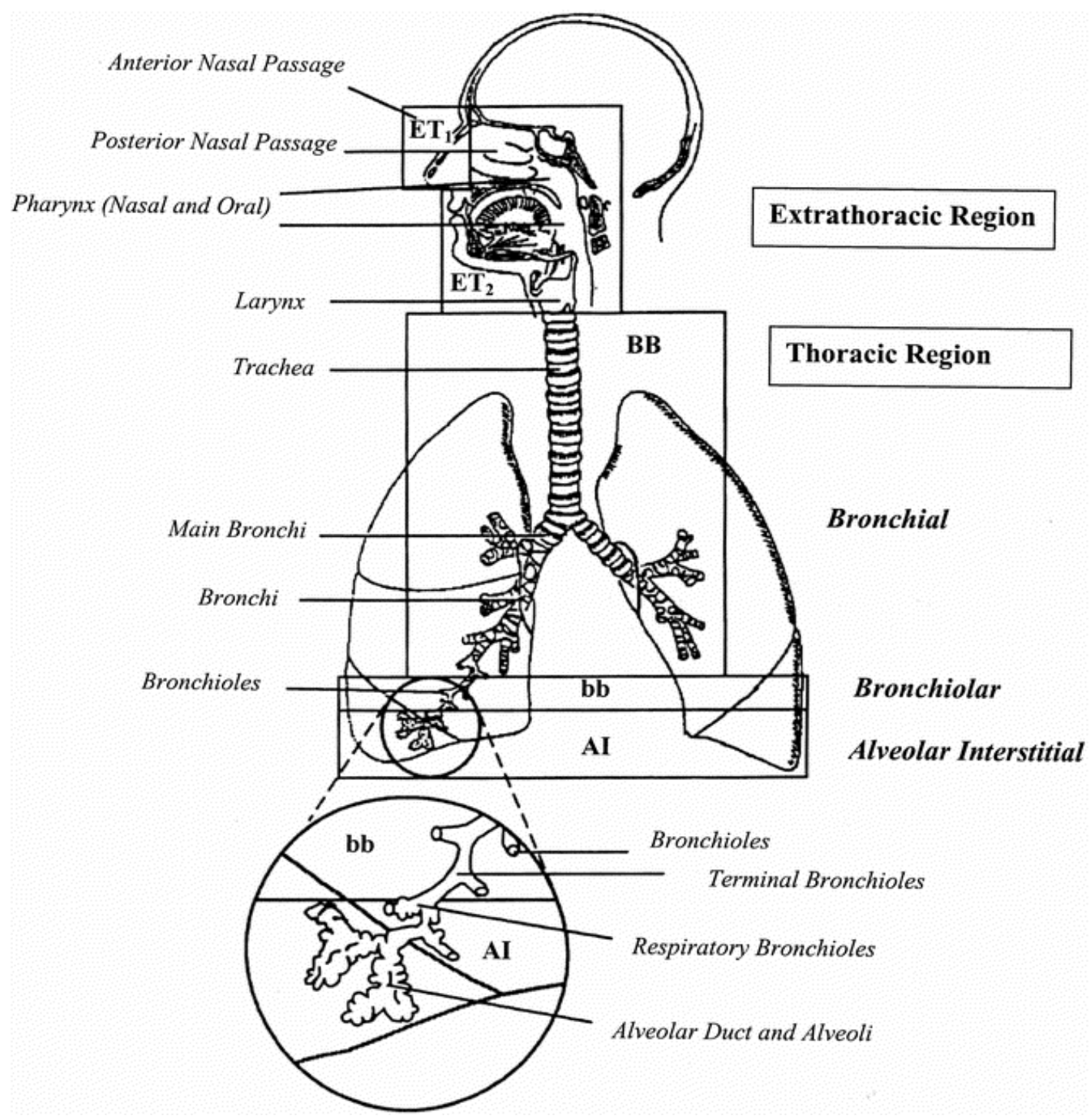

Figure 3. ICRP 66 Respiratory tract

This respiratory tract model separates the individual models for deposition, clearance, absorption, and dosimetry. Deposition includes the use of both thermodynamic and aerodynamic particle motion. The thermodynamic equivalent diameter is the diameter of a spherical particle that has the same diffusion coefficient as the particle of interest and describes diffusion behavior prevalent for particles less than 
$0.1 \mu \mathrm{m}$ in size. Sedimentation and impaction are "aerodynamic" effects and are predominant when the median aerodynamic diameter of the particle distribution is greater than $1 \mu \mathrm{m}$.

Other factors influencing deposition are hygroscopicity of the aerosol and breathing habits of the worker. Hygroscopic material readily absorbs water and can grow rapidly to many times the original size. However, for $\mathrm{PuO}_{2}$ this is not an issue. Breathing habits affect the amount of inhaled material that deposits in the lung. The nose is a much better filter and "nose breathers" have less material deposit in the lung than "mouth breathers". The ICRP model reflects the differences in deposition rate. A normal nose breather was selected as the reference worker in this study. The fractional deposition by respiratory tract region for the mean diameters of the MOUDI stages was calculated and is shown in Figure 4.

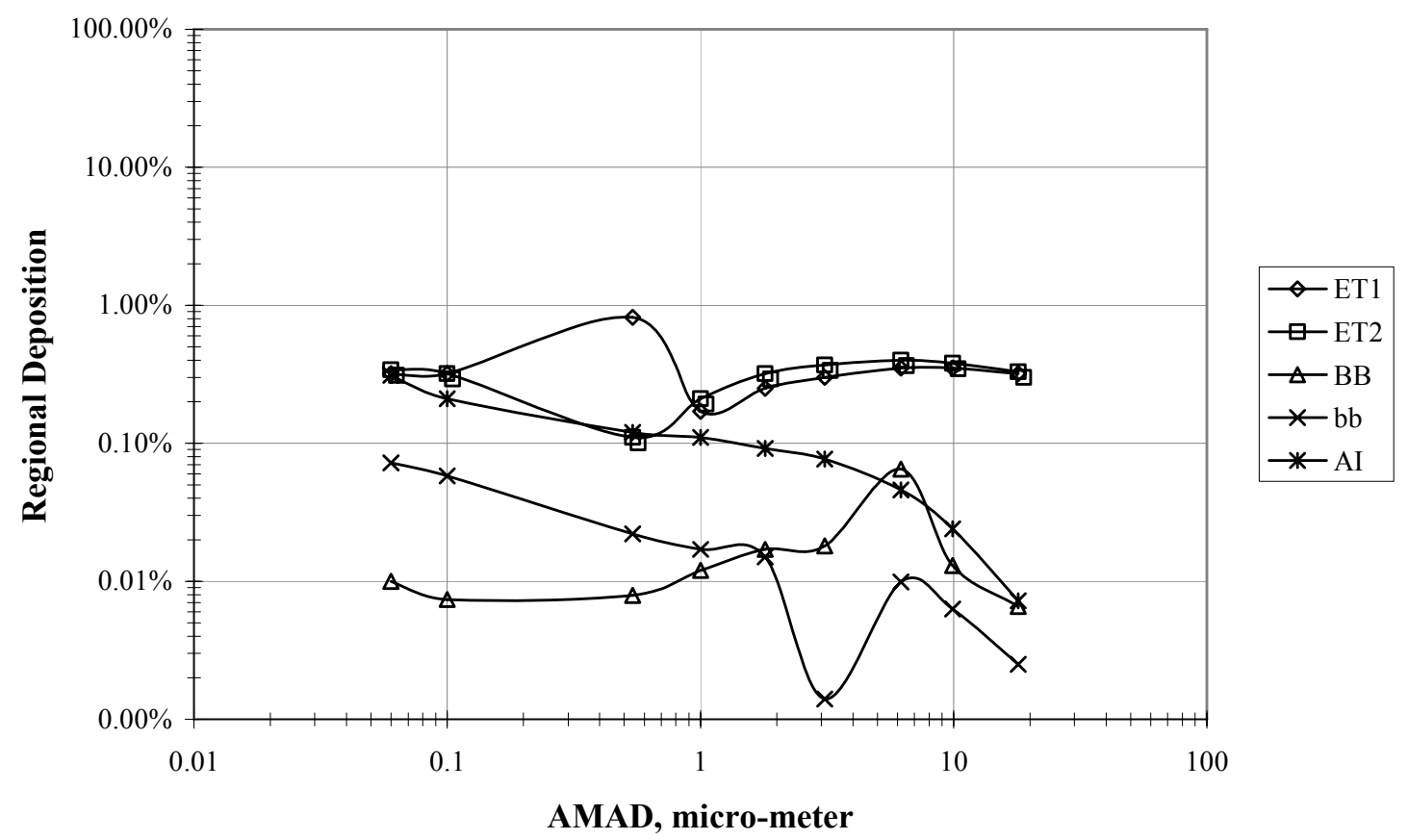

Figure 4. Fractional deposition for reference worker 
Other factors in deposition include type of breathing, nose vs. mouth, and breathing rate. Deposition data for the reference worker are shown in Table 1. A reference worker is assumed to breathe through the nose and to be performing light work activity.

Table 1: Regional Percent Deposition in Reference Worker (ICRP 66, 1993)

\begin{tabular}{lccc}
\hline Region & $\mathbf{0 . 1} \boldsymbol{\mu} \mathbf{m}$ & $\mathbf{1} \boldsymbol{\mu m}$ & $\mathbf{5} \boldsymbol{\mu \mathbf { m }}$ \\
$\mathrm{ET}_{1}$ & 3.20 & 16.52 & 33.85 \\
$\mathrm{ET}_{2}$ & 3.20 & 21.12 & 39.91 \\
$\mathrm{BB}$ & 0.74 & 1.24 & 1.78 \\
$\mathrm{bb}$ & 0.48 & 1.65 & 1.10 \\
$\mathrm{Al}$ & 21.00 & 10.66 & 5.32 \\
Total & 33.00 & 51.19 & 81.96 \\
\hline
\end{tabular}

When the activity median aerodynamic diameter (AMAD) is $0.1 \mu \mathrm{m}$, only $33 \%$ of material inhaled is deposited in the lung. However, $21 \%$ of the material inhaled is deposited in the Alveolar Interstitial area of the lung. As discussed in more detail below, this material will tend to stay in the lung. If the AMAD is $5 \mu \mathrm{m}$, over $80 \%$ of the material inhaled will deposit in the lungs. However, most of the material will move to the GI tract or bloodstream.

The movement of material from the lung is described using a compartment model. A compartment model is used to represent time-dependent particle clearance from each region. Lung clearance generally involves three processes: movement of particles into blood, movement of particles toward the GI tract, and absorption of material by the lymphatic system.

Material deposited in $\mathrm{ET}_{1}$ region is removed by nose blowing. In other regions, the movement of particles into the GI tract competes with absorption into the blood and 
lymphatic system. The fraction of material absorbed into the blood by each process is a function of the chemical composition of the material and particle size. Absorption is assumed to occur at the same rate in all regions except $\mathrm{ET}_{1}$, where it is assumed none occurs. The ICRP (ICRP 78, 1997) has identified three types of material absorption rates: F, M, and $\mathrm{S}$.

For type $\mathrm{F}$ aerosols, half of the material deposited in the $\mathrm{BB}, \mathrm{bb}$ and $\mathrm{AI}$ is absorbed every 10 min. Fifty percent of the material deposited in $\mathrm{ET}_{2}$ is cleared to the GI tract, the rest is absorbed at a half-time of 10 minutes.

For type $\mathrm{M}$ material there is rapid absorption ( $\mathrm{T}_{1 / 2}$ of 10 minutes) of about ten percent from the $\mathrm{BB}$ and $\mathrm{bb}$ regions and five from the $\mathrm{ET}_{2}$ region. The remaining material from these regions and the $\mathrm{Al}$ region is absorbed at a half-time of 140 days.

There is very little absorption into the blood stream with type S material. The half-time for the material is approximately 7000 days, with little absorption from the $\mathrm{ET}_{2}$, $\mathrm{BB}$, or bb regions. Only about ten percent of the material deposited in AI reaches the bloodstream.

As an example, if 1 gram of type $\mathrm{S}$ material with an average particle size of 0.1 $\mu \mathrm{m}$ is inhaled, $0.67 \mathrm{~g}$ of the material is exhaled. The $0.03 \mathrm{~g}$ deposited in $\mathrm{ET}_{1}$ is removed by nose blowing or wiping. Of the $0.04 \mathrm{~g}$ deposited in $\mathrm{ET}_{2}, \mathrm{BB}$, and $\mathrm{bb}, 0.03$ is absorbed in the blood. Of the $0.21 \mathrm{~g}$ deposited in the AI region, $0.021 \mathrm{~g}$ is absorbed in the blood. Two hundred fifty milligrams remain in the lung.

Calculation of the dose to the lung requires:

1. determination of particle size distribution which relates to the amount of activity inhaled and the regional deposition fractions; 
2. calculation of the number of disintegrations for each compartment of the lung which is a function of compartmental residence times and the amount of activity deposited

3. calculation of equivalent doses to regions of the respiratory tract which is a function of the specific effective energy absorbed in each target tissue from the radiations emitted by each source;

4. determination of the detriment-weighted equivalent dose by weighting the equivalent doses to account for the radio-sensitivity of the different regions of the lungs; and

5. summing the equivalent doses to obtain the total equivalent dose to the lung.

Annex F of ICRP 66 provides values of fractional deposition for each region of the lung median thermodynamic and aerodynamic diameters. The fractions relate to nominal intake - they already include the loss of particle before entry into the respiratory tract.

Using the deposition fraction, clearance rate, and absorption rate in coupled differential equations, the number of radioactive atoms per compartment can be determined. (Potter, 2005)

$$
\begin{aligned}
& \frac{d N_{1}(t)}{d t}=k_{2,1} N_{2}(t)-k_{1} N_{1}(t) \\
& \frac{d N_{2}(t)}{d t}=k_{1,2} N_{1}(t)-k_{2} N_{2}(t)
\end{aligned}
$$

\section{Equation 5}

where $N_{i}(t)$ are the number of atoms in compartment $i, k_{i j}$ are rate constants describing the movement of material from $\mathrm{i}$ to $\mathrm{j}$, and $k_{i}$ is the effective removal constant.

The number of transformations per compartment is: 


$$
\begin{array}{ll}
U_{i}=N(0) \sum_{j=1}^{n} \frac{a_{i, j}}{\gamma_{i, j}}\left[1-e^{-\gamma_{j}(50 y)}\right] \quad \text { Equation } 6
\end{array}
$$

where $U_{i}$ is the number of transformations in compartment $\mathrm{i}, \mathrm{N}(0)$ is the initial number of atoms at time $\mathrm{t}=0, \mathrm{a}_{\mathrm{i}, \mathrm{j}}$ is the replacement function coefficient, and $\gamma$ is the eigenvalue solution to equation 5 .

There are conservative simplifying assumptions that can be made to calculate the number of transformation per compartment. Multiplying default compartmental depositions fractions and approximate residence times from ICRP 66 provides results that are quite close to results derived using a computer to solve the differential equations. However, the conservation assumptions used lead to an overestimate of dose contribution from the lymph nodes.

The specific effective energy (SEE) from source to target is calculated as follows:

$$
\operatorname{SEE}(T \leftarrow S)=\sum \frac{Y_{i} E_{i} w_{r} A F(T \leftarrow S)_{i}}{M_{T}} \quad \text { Equation } 7
$$

where $Y_{i}$ is the yield of radiation $\mathrm{i}$; $\mathrm{E}_{\mathrm{i}}$ is the average energy of radiation $\mathrm{i} ; w_{r}$ is the radiation weighting factor, $A F(T \leftarrow S)_{i}$ is the absorbed fraction of energy for radiation $\mathrm{i}$ in target organ $T$ emitted from source organ $S$; and $M_{T}$ is the mass of target organ $T$. For $\mathrm{PuO}_{2}$ each radioactive disintegration emits an alpha particle of $5.14 \mathrm{MeV}$. The radiation weighting factor for alpha radiation is 20. (ICRP, 1997) There are other radiations emitted, low-energy x-rays for example, but the mean energies of these radiations are low compared with the alpha emission. The weighted equivalent dose in each target tissue, $T$, from the radiation emitted in the source tissue, $S$, is determined by multiplying the total number of disintegrations (dis.) in the source tissue by the SEE - energy absorbed per unit mass in the target tissue, modified by the radiation weighting factor. The energy 
absorbed per unit mass in the target tissue is the product of the radiation weighting factor $\left(w_{R}\right)$, the absorbed fraction $(A F)$, the energy of the radiation $\left(E_{R}\right)$, and the yield of the radiation $\left(Y_{R}\right)$ divided by the mass of the tissue. Equation 8 shows equation for SEE for $\mathrm{Pu}$.

$$
\begin{aligned}
\operatorname{SEE}\left(\frac{S v}{\text { dis. }}\right) & =\frac{A F(T \leftarrow S)_{\alpha} \times E_{R} \times Y_{R} \times w_{R}}{M_{T}} \\
& =\frac{1.65 \times 10^{-11}\left(A F(T \leftarrow S)_{\alpha}\right)}{M_{T}}
\end{aligned}
$$

Equation 8

Multiply the number of disintegrations/Bq by the SEE (Sv/dis) to get Sv/Bq in each compartment.

The equivalent dose to each compartment in the lung is the product of Equation 6 and 7. However, some regions of the lung are more radio-sensitive than other regions. The apportionment of the detriment is accomplished using tissue weighting factors for regions of the lung. The detriment weighted, or effective dose, for each compartment is the produce of the dose for that compartment and the detriment weighting factor. The sum of the doses to each compartment is the equivalent lung dose.

The stochastic dose limit recommended by ICRP 60 is $0.02 \mathrm{~Sv} /$ year. This limit is based on weighted equivalent dose to the whole body and is the sum of all of the weighted organ doses. The weighting factor for the lung is given in ICRP 60 as 0.12 . Weighting the effect of the dose in each organ represents the relative contribution of that organ to the total detriment of the whole body, not just each organ. The equivalent lung dose is multiplied by the weighting factor and then added to the other organ equivalent doses to give the effective dose.

Effective dose will be calculated using a computer program used at Los Alamos National Laboratory. The computer program is called Activity and Internal Dose 
Estimates (AIDE) and uses the methodology described above to calculate dose. The program calculated internal doses for a wide range of conditions and the user can change almost all the parameters involved, although values recommended by the ICRP are present as defaults. The program includes radionuclide decay data and the biokinetic models presented in ICRP Publication 66. A comparison of the calculated dose to the dose limit of $0.02 \mathrm{~Sv} / \mathrm{year}$ will be made. 


\section{CHAPTER 2: MATERIAL AND METHODS}

\section{PROCESS DESCRIPTION}

The process investigated in these experiments was the digestion of $\mathrm{PuO}_{2}$ (Chemistry, 2002). $\mathrm{PuO}_{2}$ is mixed with a liquid of approximately the same density as water and heated on a hot plate until dry. The hot plate is generally at the maximum temperature of $550^{\circ} \mathrm{C}$ during the process. A stirring rod is placed in the beaker and the mixture was stirred continuously. When heated to this high temperature $\mathrm{PuO}_{2}$ enters the delta phase. In this phase, the material changes shape and density. The shape of the material is a face entered cubic (Wick, 1980). A study done at ITRI (Kotrappa, et al., 1975) measured a $\mathrm{PuO}_{2}$ dynamic shape factor of 1.8 .

\section{EXPERIMENTAL SETUP}

\section{Selection of Surrogate Material and Analysis Method}

The literature cited many investigations where tracer gas was observed leaking from a safety enclosure, such as an open-front hood. Therefore, it was important to choose a non-hazardous surrogate material. In addition, the amount of material observed in these studies was on the order of ppm. Therefore, the method used to quantify the material must be able to detect these low levels and the material selected had to be compatible with the method selected. Neutron activation analysis (NAA) was selected; it is capable of detecting extremely low levels of material by measuring the induced radioactivity. Exposing the sample to a neutron flux induces radioactivity.

Sodium chloride was selected as the surrogate material. It is not hazardous and when irradiated with neutrons, both the sodium and the chloride become radioactive and give a fairly strong signal. Sodium chloride can be used in place of DOP to test filters 
use in $\mathrm{PuO}_{2}$ operations. (Shibata et al., 1990). A study done at the University of Cincinnati proved the efficacy of $\mathrm{NaCl}$ for particulate respirator fit testing. (Qian et al., 1998). Sodium chloride aerosols were used to test proper operation of instruments and obtain correct instrument settings for measurement of biological organisms (Brosseau, et al., 2000).

Sodium chloride is the same shape as delta phase $\mathrm{PuO}_{2}$ (face centered cubic) and has a dynamic shape factor of approximately 1.5. (Kramer et al., 2000) The default dynamic shape factor used by ICRP 66 is 1.5 . Since the sampling is done using an aerodynamic sampler, the particles will be collected based on aerodynamic diameter and the effect of particle shape on particle collection is negated.

When either the $\mathrm{PuO}_{2}$ or $\mathrm{NaCl}$ solutions are heated, the aerosol formed is initially a droplet. The droplet dries almost immediately and a solid particle remains. The ratio of the size of the particle to the size of the droplet is the cube root of the ratio of the concentration of the solution to the density of the solution. The particle size distribution will vary as a function of the solution concentration. A 4\% solution of $\mathrm{NaCl}$ was used. This concentration will give the same particle size distribution as the $\mathrm{PuO} 2$ solution routinely digested at Los Alamos.

$$
\frac{V_{\mathrm{NaCl}}}{V_{\mathrm{NaCl}+\mathrm{H}_{2} \mathrm{O}}}=\frac{V_{\mathrm{PuO}_{2}}}{V_{\mathrm{PuO}_{2}+\text { solution }}}=\left[\frac{d_{p}}{d_{d}}\right]^{3} \quad \text { Equation } 9
$$

\section{Selection of Sampling Apparatus}

In order to determine the range of liquid droplet sizes created by heating the sodium chloride solution, a simulation of the experiment was performed, and a Malvern Spraytec was used to measure the size of the droplets that were generated (Malvern Instruments, Worcestershire, UK). By measuring the angular intensity of light scattered 
by striking a particle, the particle size distribution is calculated using a patented multiple scattering algorithm. As shown in Figure 5, a 4\% solution of sodium chloride was placed on a hot plate and heated to dryness. Baseline measurements were also taken using distilled water.

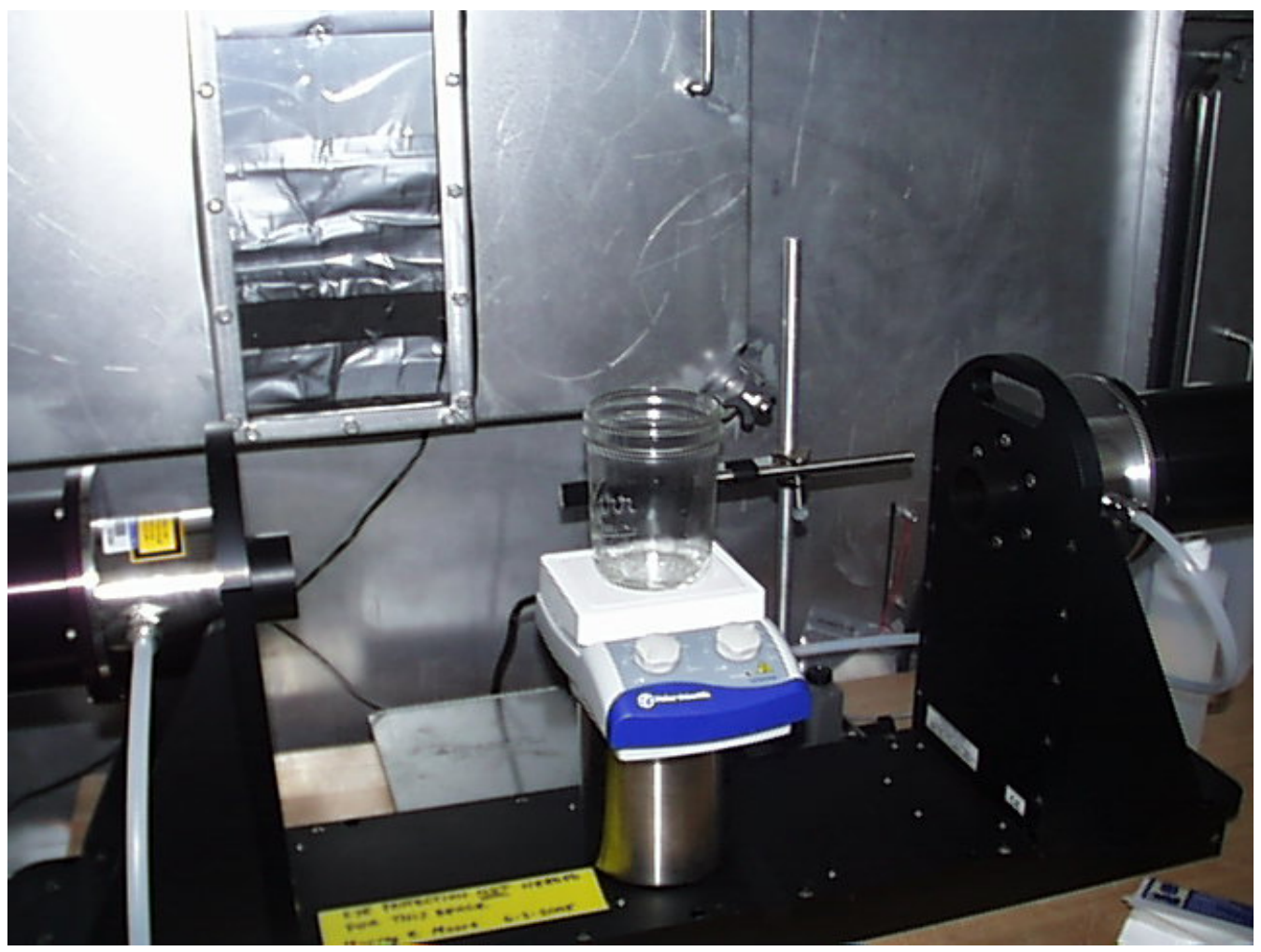

Figure 5. Particle size distribution with Spraytec

Twelve measurements were taken. The room air currents affected the results, so a wooden framed plastic shrouded enclosure shaped like an open front hood was placed around the instrument. Using this configuration, four measurements were taken of a $4 \%$ salt solution and two measurements were taken of distilled water. The mass median particle size for the four measurements of a $4 \%$ salt solution was $14 \mu \mathrm{m}$. 
The amount of material escaping the beaker was also measured by comparing the weight of salt in the beaker before heating to the weight of salt in the beaker after heating. An average of $3 \%$ of the salt escaped the beaker. Using NAA for analysis of the samples requires at least micro gram quantities of material. So in order to reliably see the aerosol, there needed to be milligram quantities of $\mathrm{NaCl}$ in the beaker.

Since particle size distribution by mass must be measured, a Micro-orifice Uniform Deposit Impactor (MOUDI) capable of separating the aerosol particles by size was selected. This apparatus is an eight-stage cascade impactor with nine cut-sizes from 0.19 to $18 \mu \mathrm{m}$. The calibrated cut points for each stage are shown in Table 2. A tenth filter is used as a "backstop" to collect all particles smaller than the last stage, but is not calibrated to specific cut-size. It operates at a flow rate of $28.3 \mathrm{~L} / \mathrm{min}$.

Table 2: Calibrated Cut Points for Each Stage

\begin{tabular}{|l|c|}
\hline \multicolumn{1}{|c|}{ Stage } & Cut Point \\
\hline Inlet & 18 \\
\hline 1 & 9.9 \\
\hline 2 & 6.2 \\
\hline 3 & 3.1 \\
\hline 4 & 1.8 \\
\hline 5 & 1 \\
\hline 6 & 0.54 \\
\hline 7 & 0.32 \\
\hline 8 & 0.19 \\
\hline
\end{tabular}

The principle of the MOUDI operation utilizes inertial separation of particles from the air stream in a classical impactor geometry (Hinds, 1999). An aerosol is passed 
through a nozzle and the output stream of air is directed toward a collection media. These flat plates deflect the flow and particles larger than a certain aerodynamic size, or cut point, are removed from the air stream and smaller particles remain airborne. Aerodynamic size, rather than geometric size, determines the trajectory of particles in the air stream and accounts for all three major aerodynamic factors: size, shape, and mass density.

By placing several impactors in series, arranged in order of decreasing cutoff size, the distribution of particles is divided into a series of nine contiguous groups according to their aerodynamic diameter. The aerodynamic diameter is defined as the size of a spherical particle of mass density $1 \mathrm{~g} / \mathrm{cm}^{3}$ that has the same terminal settling velocity as the sampled particle. Aerodynamic diameter is important in particle work because it determines the penetration of particles in the human lung. This is the method used by the pharmaceutical companies to evaluate the efficacy of inhalers (Thiel, 2002).

Particle collection efficiency, or the ability of the MOUDI to capture particles of the appropriate size for each stage, is influenced by particle size, interstage losses, and particle bounce (Marple, 1991). Particle bounce occurs when particles rebound off the collection media, re-enter the air stream, and move to the next stage of the impactor. The collection media used in this experiment was a Millipore ${ }^{\mathrm{TM}}$ filter rinsed in isopropyl alcohol with $5 \%$ by volume silicon oil. After evaporation of the alcohol, the remaining oil causes the particles to adhere to the filter, reducing particle bounce.

The MOUDI has several features to overcome issues associated with sub-micron particle collection and interstage losses. By using very small nozzles the MOUDI collects small particles at low jet velocities and consequently low pressure drops. Minimizing sharp bends in the interstage flow path reduces interstage losses. The interstage particle loss for the MOUDI is less than $2 \%$. 


\section{Experimental Facility Description}

The experiment was designed to mimic the conditions of the workplace. A mockup of an open-front hood was constructed. The dimensions of the hood are $76 \mathrm{~cm}$ deep by $91 \mathrm{~cm}$ wide and $75 \mathrm{~cm}$ tall. There is a $15-\mathrm{cm}$ opening across the front of the hood. There are two exhaust ports in the rear of the box. One of the ports is $10 \mathrm{~cm} \times 25$ $\mathrm{cm}$ and the other is $5 \mathrm{~cm} \times 36 \mathrm{~cm}$. A detailed drawing is shown in Figures $1-3$ of Appendix A.

The box was constructed using steel tubing for a frame. The tubing was welded to meet the dimensions shown in Figure 5. Sheet metal was used for the floor and back of the box. The metal was then powder coated to protect the metal from rusting or flaking. Figure 6 shows the frame of the box prior to powder coating.

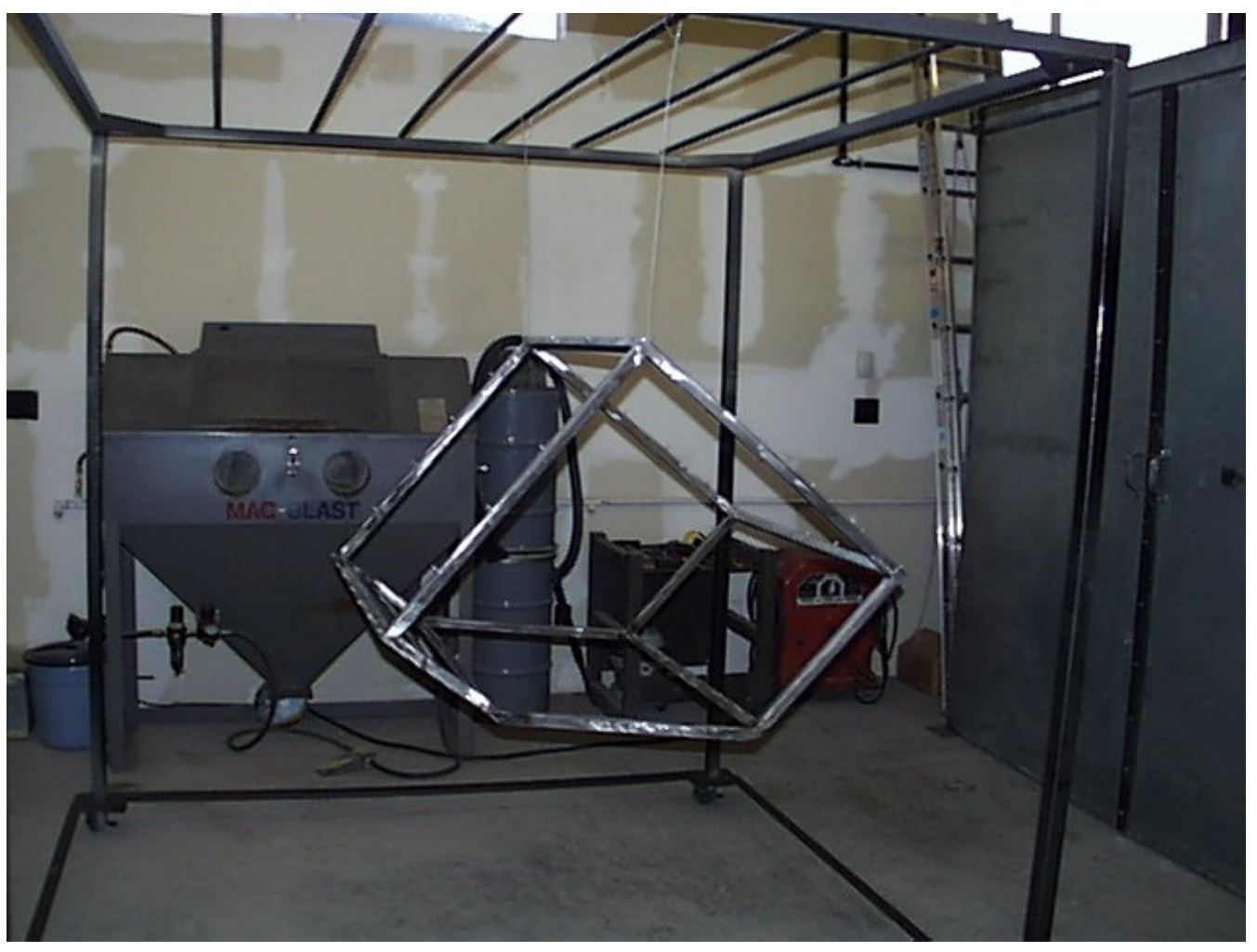

Figure 6. Frame of box prior to powder coating 
Plexiglass was then attached to the front and sides of the box. Next the sheet metal on the back of the box was cut and four inch diameter circular ducting attached.

The open-front hood was placed in a room, as shown in Figure 7. The hood was connected to exhaust ventilation to provide the typical linear velocity of between 0.4 to $0.6 \mathrm{~m} / \mathrm{s}$ (80 to $120 \mathrm{fpm}$ ) across the opening of the open front hood. The velocity through the $25 \times 10 \mathrm{~cm}$ exhaust port was $300 \mathrm{ft} / \mathrm{min}$. The velocity through the $36 \times 5 \mathrm{~cm}$ exhaust port is $520 \mathrm{ft} / \mathrm{min}$ Filtered supply ventilation was provided to the room to reduce the amount of nuisance dust and mimic the air quality conditions seen in laboratory settings. The room was kept at a positive pressure of $0.25 \mathrm{~cm} \mathrm{H}_{2} \mathrm{O}$. 


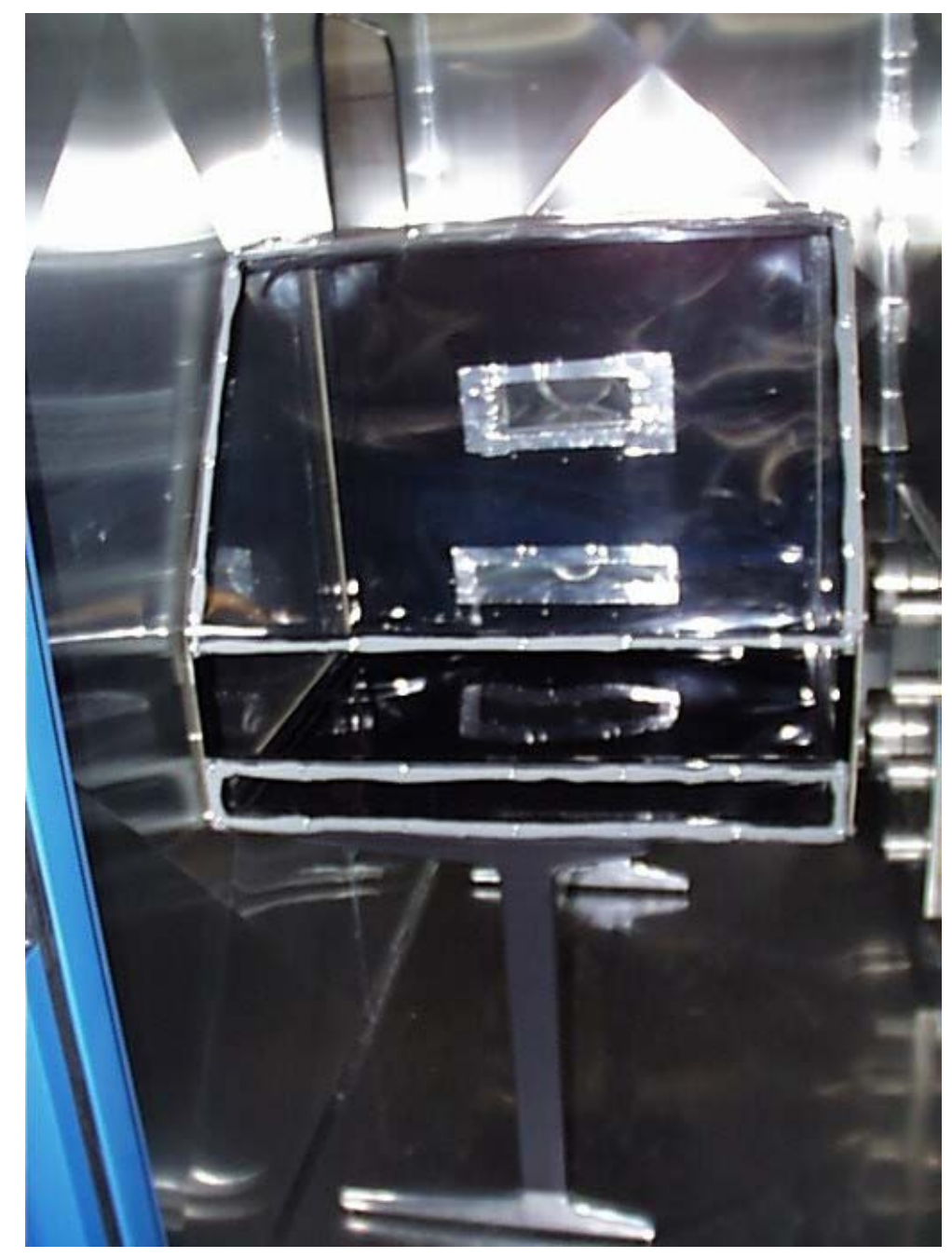

Figure 7. Photo of open front box inside room

A hot plate was placed in the hood. The center of the hot plate was $15 \mathrm{~cm}$ from the front face of the hood and in the center of hood. Flow visualization was done using a fog generator. The fog was introduced into the box and motion of the fog recorded. First the box was tested with the hot plate off. As shown in Figure 8, the fog flowed from the opening straight back to the exhaust ports. 


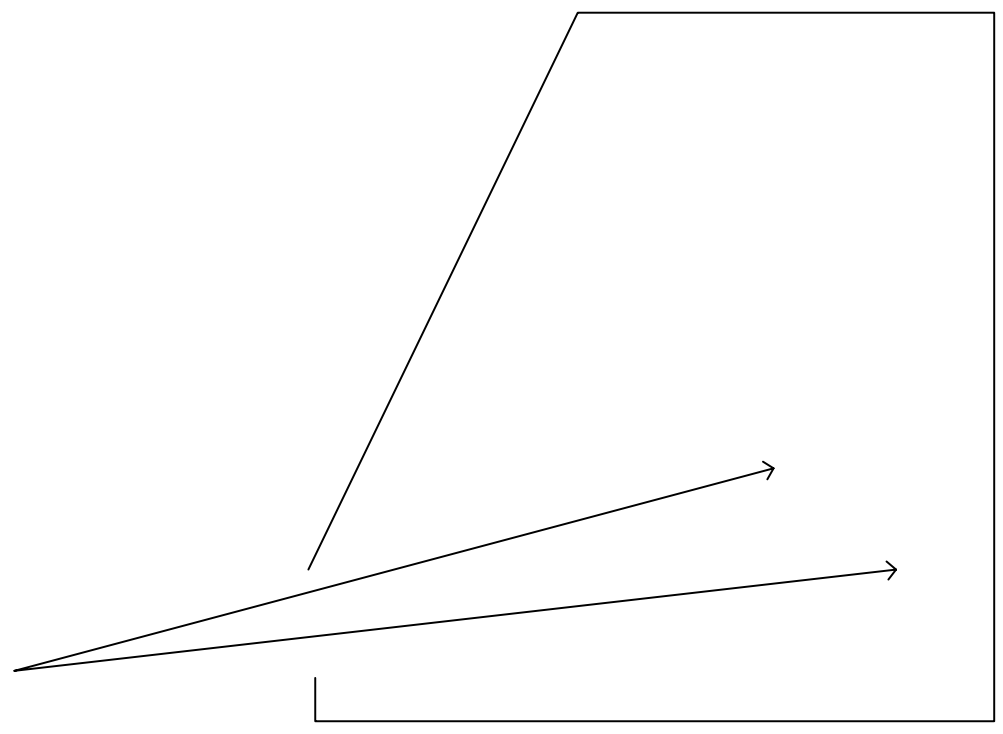

Figure 8. Motion of fog with hot plate off

Next the hot plate was heated to $550^{\circ} \mathrm{C}$. As shown in Figure 9, the fog then tended to swirl around the hot plate in an outward motion before moving slowly toward the exhaust.

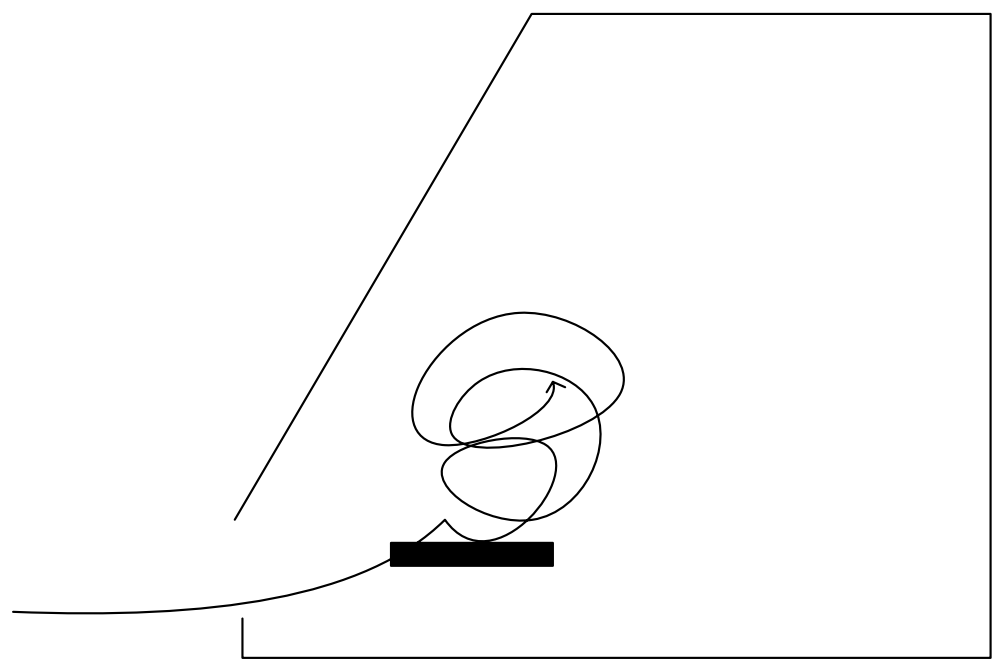

Figure 9. Motion of fog with hot plate on 


\section{Sample Preparation and Collection}

A solution of $\mathrm{NaCl}$ dissolved in distilled water was prepared in a $10 \mathrm{~cm}$ high beaker with a $7 \mathrm{~cm}$ diameter opening. The beaker was placed on the hot plate and heated to dryness. The resulting aerosol was collected by the MOUDI. A total of 13 measurements were done. Each measurement took 2 hours. Three measurements were done to determine the background level of $\mathrm{NaCl}$ present in the experimental area. Three measurements were done with the MOUDI placed inside the hood, as shown in Figure 10. Three measurements were done with the MOUDI placed outside the hood between a stationary worker and the opening of the hood. Four measurements were taken with the MOUDI placed between a worker simulating work and opening of the hood, as shown in Figure 11. Work was simulated by having the worker move her hands in and out of the hood at a rate of $30 \mathrm{~cm} / \mathrm{sec}$.

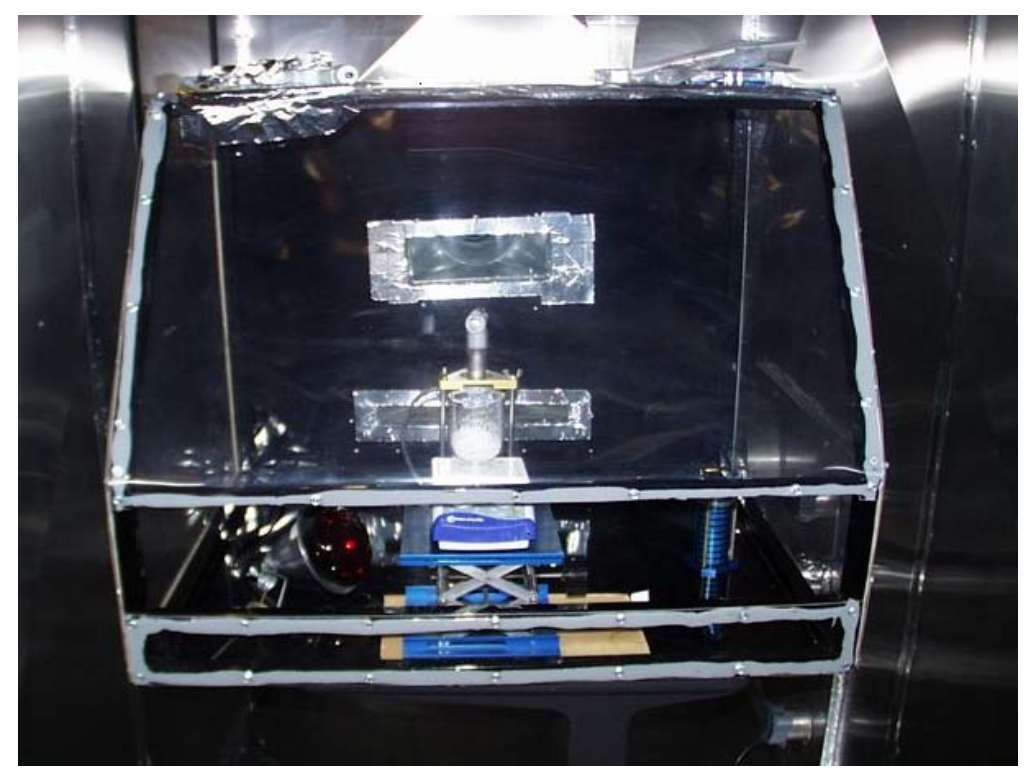

Figure 10. MOUDI in hood 


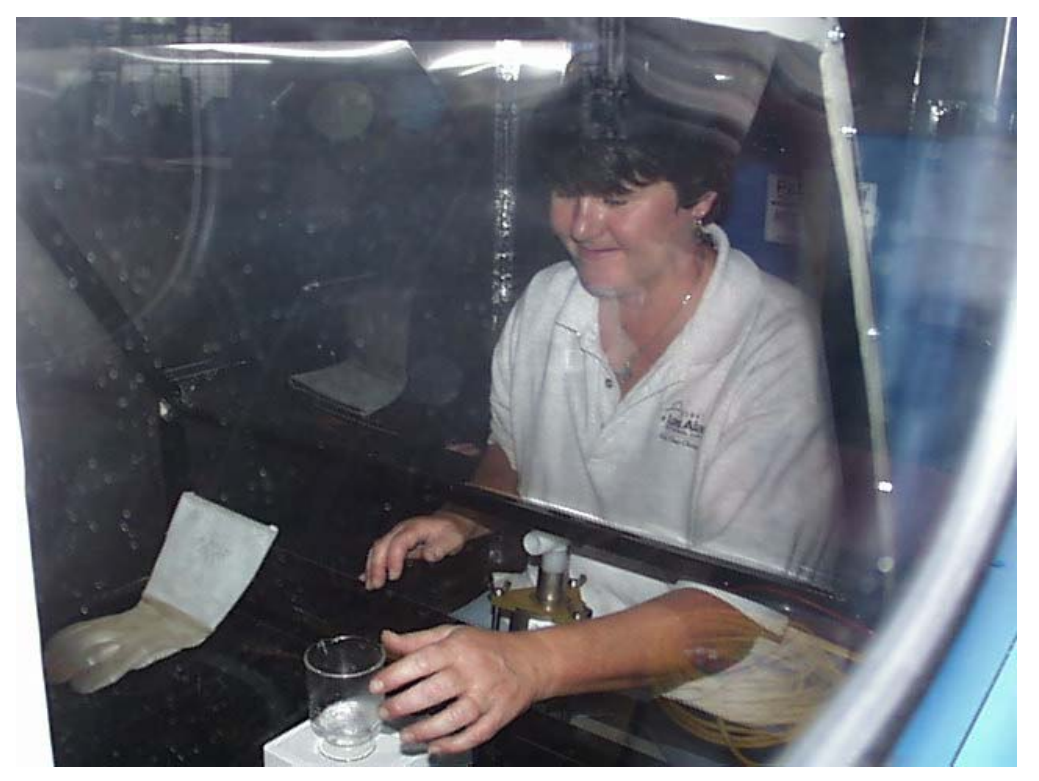

Figure 11. Working in Hood

\section{Sample Analysis}

The amount of material collected on each stage of the MOUDI was determined by measuring the amount of radioactivity induced by exposing the sample to a neutron field. The amount of induced radioactivity is based on the reaction rate between material and the probability of neutron absorption. The probability of neutron absorption, or crosssection, is an isotopic, energy-dependent quantity that has been experimentally measured and quantified. The reaction rate, or rate of formation the radioactive species at thermal energies, is obtained by integrating the product of the cross-section $\sigma(E)$, the neutron flux $\varphi(E)$, and the number of target atoms $\left(N_{o}\right)$ over the energy range of the incident neutrons.

$$
R_{t}=N \int_{o}^{\infty} \sigma_{i}(E) \Phi(E) d E=N \sigma_{a c t} \Phi \quad \text { Equation } 10
$$

The net change in the number of radioactive atoms formed by this reaction is expressed as: 


$$
\frac{d N}{d t}=\sigma_{a c t} \Phi N_{o}-\lambda N
$$

Equation 11

where $\lambda$ is the decay constant for radioactive atoms and $t_{i}$ is the irradiation time. Upon integration, equation 11 yields

$$
N=\frac{\sigma_{a c t} \Phi N_{o}}{\lambda}\left(1-e^{-\lambda t_{i}}\right) \quad \text { Equation } 12
$$

To measure the number of radioactive atoms present it is necessary to measure the radioactivity emitted from the decay of these atoms. This is done using a high-purity Germanium Detector (HPGe) gamma spectrometer connected to a multi-channel analyzer. The number of atoms present can be calculated using the following relationship:

$$
N_{o}=\frac{N \lambda}{\phi \sigma\left(1-e^{-\lambda t_{i}}\right) e^{-\lambda t_{d}}\left(1-e^{-\lambda t_{c}}\right) \varepsilon} \quad \text { Equation } 13
$$

where, $N$ is the number of radioactive atoms, $\lambda$ is the decay constant for radioactive atoms, $t_{d}$ is the decay time (time between removal of the sample from the reactor and time the analysis begins), $t_{c}$ is the count time, $t_{i}$ is the irradiation time, and $\varepsilon$ is the efficiency of the instrument for detecting the gamma radiation.

Once the number of atoms present is calculated, the mass of sample can be calculated as follows:

$$
m\left(N_{o}\right)=\frac{N_{o}(\text { atoms }) \times A\left(\frac{g}{\text { mole }}\right)}{6.02 \times 10^{23}\left(\frac{\text { atoms }}{\text { mole }}\right)}
$$




\section{Evaluation of Particle Size Distribution Data}

The background data for each particle size were averaged. A mass corresponding to a $90 \%$ confidence level (CL) was calculated from these data, using the formula in Equation 15.

$$
90 \% C L=1.282 \times \sigma_{\text {avg } b k g}+a v g \text { bkg } \quad \text { Equation } 15
$$

The three sets of data collected when the MOUDI was placed in the hood, the three sets of data collected with the MOUDI between a stationary worker and the opening to the hood and the four sets of data collected with the MOUDI between a worker working in hood and the hood opening were compared to the $90 \%$ confidence level. Results above the $90 \%$ confidence level were then corrected for background and averaged. The mass and cumulative mass as a function of particle size was plotted. A Kolmogorov-Smirnov (KS) test was performed to determine the nature of the data distribution and to confirm that the averaged sample data was statistically different from the background data (Press, 1992).

The KS test is applicable to unbinned distributions that are a function of a single independent variable, such as mass to particle size. This non-parametric test can compare two different distribution types (i.e., log normal and bi-modal). It is based on cumulative distributions and measures if one distribution is significantly different from another distribution. 


\section{CHAPTER 3: RESULTS}

\section{BACKGROUND MEASUREMENTS}

To measure background in the experiment room, the MOUDI was run for two hours on three separate occasions to collect background particles in the room. The supply and exhaust ventilation was on in both the room and the open-front hood. The hot plate was off, no sample was in the hood, and no one was in the room during the collection of the background sample. The results are shown in Table 4.

Table 3: First Background Run

\begin{tabular}{|c|c|c|c|c|}
\hline \multirow[b]{2}{*}{ Sample ID } & \multicolumn{2}{|c|}{$\mathrm{Na}$} & \multicolumn{2}{|c|}{$\mathrm{Cl}$} \\
\hline & Mass $(\mu \mathrm{g})$ & $\pm(\mu \mathrm{g})$ & Mass $(\mu \mathrm{g})$ & $\pm(\mu \mathrm{g})$ \\
\hline 1 & 0.387 & 0.0167 & 2.02 & 0.0436 \\
\hline 2 & 0.563 & 0.0185 & 2.19 & 0.0455 \\
\hline 3 & 0.774 & 0.0224 & 2.29 & 0.0476 \\
\hline 4 & 0.693 & 0.0206 & 1.87 & 0.0414 \\
\hline 5 & 0.592 & 0.0214 & 2.04 & 0.0452 \\
\hline 6 & 0.703 & 0.0206 & 2.12 & 0.0447 \\
\hline 7 & 0.727 & 0.0220 & 2.46 & 0.0497 \\
\hline 8 & 0.993 & 0.0256 & 2.78 & 0.0546 \\
\hline 9 & 0.657 & 0.0213 & 1.98 & 0.0437 \\
\hline 10 & 1.01 & 0.0264 & 4.08 & 0.0729 \\
\hline
\end{tabular}

Table 4: Second Background Run 


\begin{tabular}{|c|c|c|c|c|}
\hline \multirow[b]{2}{*}{ Sample ID } & \multicolumn{2}{|c|}{$\mathbf{N a}$} & \multicolumn{2}{|c|}{$\mathrm{Cl}$} \\
\hline & Mass $(\mu \mathrm{g})$ & $\pm(\mu \mathrm{g})$ & Mass $(\boldsymbol{\mu g})$ & $\pm(\mu \mathrm{g})$ \\
\hline 11 & 0.72 & 0.0219 & 2.13 & 0.0454 \\
\hline 12 & 0.38 & 0.0161 & 1.69 & 0.0385 \\
\hline 13 & 0.63 & 0.0194 & 1.93 & 0.0428 \\
\hline 14 & 1.24 & 0.0295 & 2.67 & 0.0537 \\
\hline 15 & 1.26 & 0.0304 & 2.76 & 0.0549 \\
\hline 16 & 0.913 & 0.0239 & 2.13 & 0.0455 \\
\hline 17 & 0.601 & 0.0200 & 1.72 & 0.0399 \\
\hline 18 & 0.783 & 0.0231 & 2.42 & 0.0505 \\
\hline 19 & 0.775 & 0.0230 & 2.11 & 0.0449 \\
\hline 20 & 1.16 & 0.0287 & 3.65 & 0.0675 \\
\hline 21 & 0.652 & 0.0209 & 2.07 & 0.0444 \\
\hline 22 & 0.600 & 0.0194 & 1.95 & 0.0426 \\
\hline 23 & 0.717 & 0.0219 & 2.19 & 0.0466 \\
\hline 24 & 0.462 & 0.0178 & 1.77 & 0.0405 \\
\hline 25 & 0.430 & 0.0178 & 1.91 & 0.0429 \\
\hline 26 & 0.617 & 0.0189 & 1.79 & 0.0398 \\
\hline 27 & 0.458 & 0.0196 & 1.87 & 0.0415 \\
\hline 28 & 0.536 & 0.0187 & 1.90 & 0.0425 \\
\hline 29 & 0.737 & 0.0211 & 2.09 & 0.0444 \\
\hline 30 & 1.06 & 0.0274 & 2.94 & 0.0573 \\
\hline
\end{tabular}


The sum of the $\mathrm{Na}$ and $\mathrm{Cl}$ masses were averaged, the standard deviation of the sum calculated, and these results tabulated as a function of the particle median aerodynamic diameter. This tabulation is shown in Table 5. Notice there are only nine particle sizes. The tenth sample for each run represents a "backstop" that is not calibrated to a specific cut point. A Kolomogorov-Smirnov (KS) test was run to determine the distribution of the background data. The data were consistent with a log-normal distribution. Using 15 from Chapter 2, the signal mass of a 90\% confidence level was calculated for each stage of the MOUDI was calculated. These results are shown in Table 4. The graphical representation of this tabulation is shown in Figure 12.

Table 5: Average NaCl Background

\begin{tabular}{|c|c|c||c|}
\hline \multirow{2}{*}{ Diameter } & \multicolumn{2}{|c||}{ NaCl } & \multirow{2}{*}{} \\
\cline { 2 - 3 } & Mass $(\boldsymbol{\mu g})$ & $\pm(\mu \mathrm{g})$ & $\mathbf{9 0 \%} \mathbf{C L}(\boldsymbol{\mu g})$ \\
\hline \hline 18 & 2.6587 & 0.0845 & 2.7670 \\
\hline 9.9 & 9.7868 & 2.1096 & 12.4913 \\
\hline 6.2 & 7.6875 & 1.5682 & 9.6979 \\
\hline 3.1 & 5.7583 & 1.1996 & 7.2961 \\
\hline 1.8 & 3.1244 & 0.5862 & 3.8758 \\
\hline 1 & 2.0836 & 0.3060 & 2.4759 \\
\hline 0.54 & 1.1905 & 0.1400 & 1.3699 \\
\hline 0.32 & 1.1866 & 0.1035 & 1.3193 \\
\hline 0.19 & 0.9544 & 0.0642 & 1.0366 \\
\hline
\end{tabular}




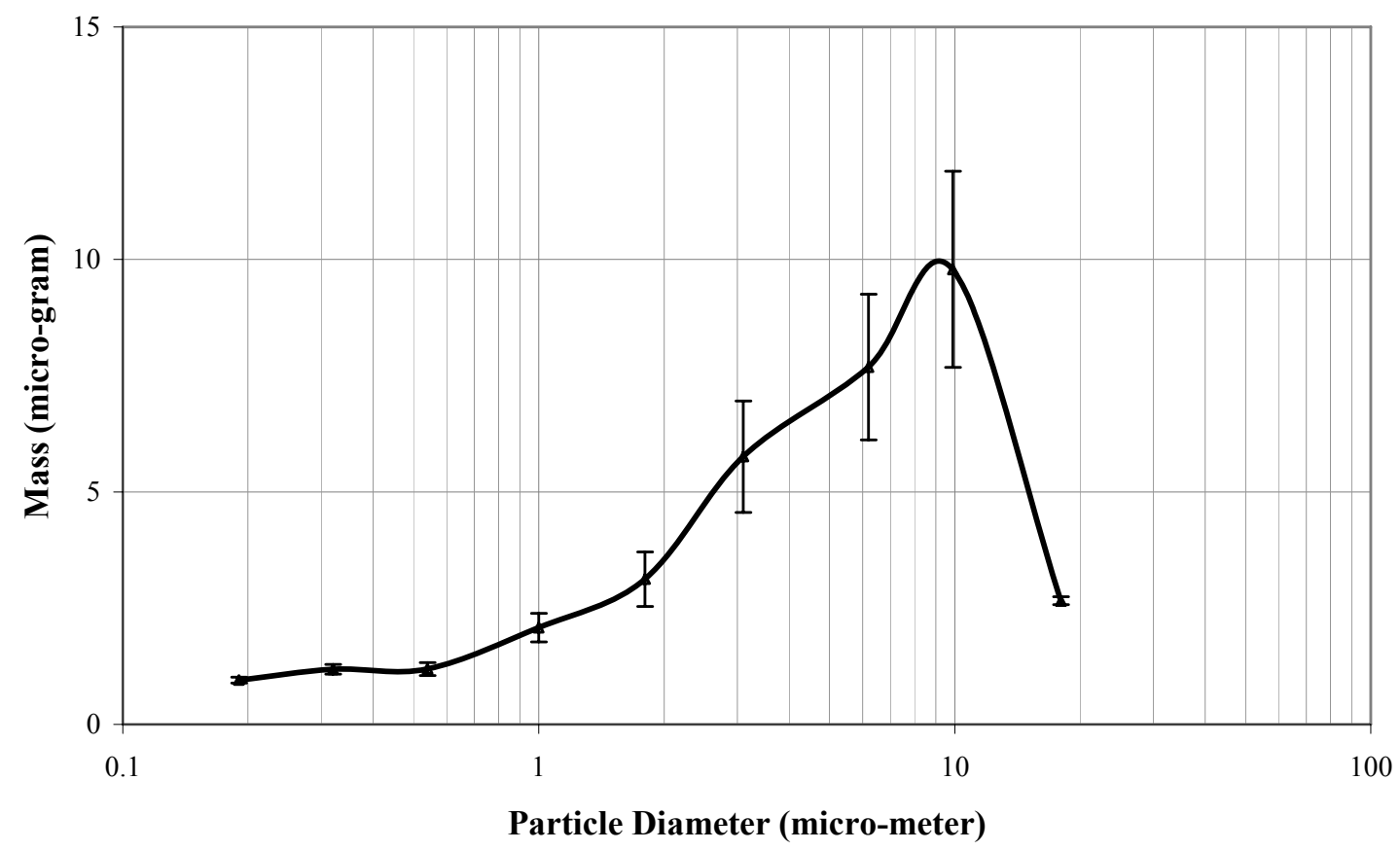

Figure 12. Background mass as a function of particle size

\section{MEASUREMENTS OF MATERIAL ESCAPING WHILE NO WORK IS BEING PERFORMED}

The MOUDI was run for two hours to collect particles escaping from the hood while a worker sat stationary in front of the hood. The supply and exhaust ventilation was on in both the room and the open-front hood. The $\mathrm{NaCl}$ solution was heated on the $550^{\circ} \mathrm{C}$ hot plate. The results of the first run conducted are shown in Table 6 . 
Table 6: First no-motion $\mathrm{NaCl}$ mass collected

\begin{tabular}{|c|c|c|c|c|}
\hline \multirow[b]{2}{*}{ Sample ID } & \multicolumn{2}{|c|}{$\mathbf{N a}$} & \multicolumn{2}{|c|}{ Cl } \\
\hline & $\operatorname{Mass}(\mu \mathrm{g})$ & $\pm(\mu \mathrm{g})$ & Mass $(\mu \mathrm{g})$ & $\pm(\mu \mathrm{g})$ \\
\hline 41 & 0.733 & 0.0244 & 4.25 & 0.0740 \\
\hline 42 & 0.923 & 0.0239 & 2.16 & 0.0445 \\
\hline 43 & 1.83 & 0.0374 & 2.96 & 0.0566 \\
\hline 44 & 1.32 & 0.0305 & 2.91 & 0.0565 \\
\hline 45 & 0.914 & 0.0243 & 2.84 & 0.0550 \\
\hline 46 & 0.983 & 0.0245 & 2.30 & 0.0468 \\
\hline 47 & 1.02 & 0.0255 & 2.76 & 0.0541 \\
\hline 48 & 1.08 & 0.0262 & 2.28 & 0.0472 \\
\hline 49 & 1.28 & 0.0297 & 2.44 & 0.0494 \\
\hline 50 & 1.57 & 0.0338 & 3.19 & 0.0601 \\
\hline
\end{tabular}

While unloading the MOUDI from the run conducted on December 5, I dropped Sample ID 110 on the floor. This sample became contaminated with the dust particles from the floor and therefore this sample result was not included in the data shown in Table 7. 
Table 7: Second no-motion $\mathrm{NaCl}$ mass collected

\begin{tabular}{|c|c|c|c|c|}
\hline \multirow{2}{*}{ Sample ID } & \multicolumn{2}{|c|}{ Na } & \multicolumn{2}{c|}{ Cl } \\
\cline { 2 - 5 } & Mass $(\boldsymbol{\mu g})$ & $\pm(\boldsymbol{\mu g})$ & Mass $(\boldsymbol{\mu g})$ & $\pm(\boldsymbol{\mu g})$ \\
\hline 101 & 1.29 & 0.0298 & 2.62 & 0.0526 \\
\hline 102 & 0.731 & 0.0219 & 2.26 & 0.0478 \\
\hline 103 & 1.03 & 0.0265 & 2.63 & 0.0538 \\
\hline 104 & 0.870 & 0.0236 & 2.41 & 0.0493 \\
\hline 105 & 1.31 & 0.0310 & 3.09 & 0.0601 \\
\hline 106 & 0.879 & 0.0244 & 2.33 & 0.0487 \\
\hline 107 & 0.510 & 0.0181 & 1.80 & 0.0410 \\
\hline 108 & 0.775 & 0.0227 & 2.18 & 0.0467 \\
\hline 109 & 0.642 & 0.0205 & 1.93 & 0.0426 \\
\hline
\end{tabular}

The exhaust fan for the open-front hood failed on third run when samples 121-130 were collected. Therefore, the results shown in Table 8 for these samples are suspect and not included in the data analysis. 
Table 8. Third no-motion $\mathrm{NaCl}$ mass collected

\begin{tabular}{|c|c|c|c|c|}
\hline \multirow[b]{2}{*}{ Sample ID } & \multicolumn{2}{|c|}{$\mathrm{Na}$} & \multicolumn{2}{|c|}{ Cl } \\
\hline & Mass ( $\mu \mathrm{g})$ & $\pm(\mu \mathrm{g})$ & Mass ( $\mu \mathrm{g})$ & $\pm(\mu \mathrm{g})$ \\
\hline 121 & 3.51 & 0.0636 & 6.55 & 0.110 \\
\hline 122 & 2.80 & 0.0537 & 5.39 & 0.0931 \\
\hline 123 & 2.63 & 0.0515 & 5.30 & 0.0922 \\
\hline 124 & 4.04 & 0.0707 & 5.60 & 0.0959 \\
\hline 125 & 3.52 & 0.0641 & 6.43 & 0.109 \\
\hline 126 & 2.14 & 0.0430 & 3.96 & 0.0726 \\
\hline 127 & 1.82 & 0.0380 & 3.64 & 0.0675 \\
\hline 128 & 1.30 & 0.0309 & 3.05 & 0.0592 \\
\hline 129 & 1.632 & 0.0356 & 3.10 & 0.0603 \\
\hline 130 & 2.21 & 0.0445 & 4.92 & 0.0859 \\
\hline
\end{tabular}

Results above the $90 \%$ confidence level were background-corrected, averaged, and tabulated as a function of the median aerodynamic diameter. This tabulation is shown in Table 9. The graphical representation of this tabulation is shown in Figure 13. 
Table 9: Average $\mathrm{NaCl}$ Mass for Stationary Worker

\begin{tabular}{|c|c|c|}
\hline Diameter & Mass $(\boldsymbol{\mu g})$ & $\pm(\boldsymbol{\mu g})$ \\
\hline 18 & 1.7895 & 0.1299 \\
\hline 1.8 & 0.9508 & 0.5931 \\
\hline 1 & 1.1619 & 0.3153 \\
\hline 0.54 & 1.8564 & 0.1587 \\
\hline 0.32 & 1.9725 & 0.1278 \\
\hline
\end{tabular}

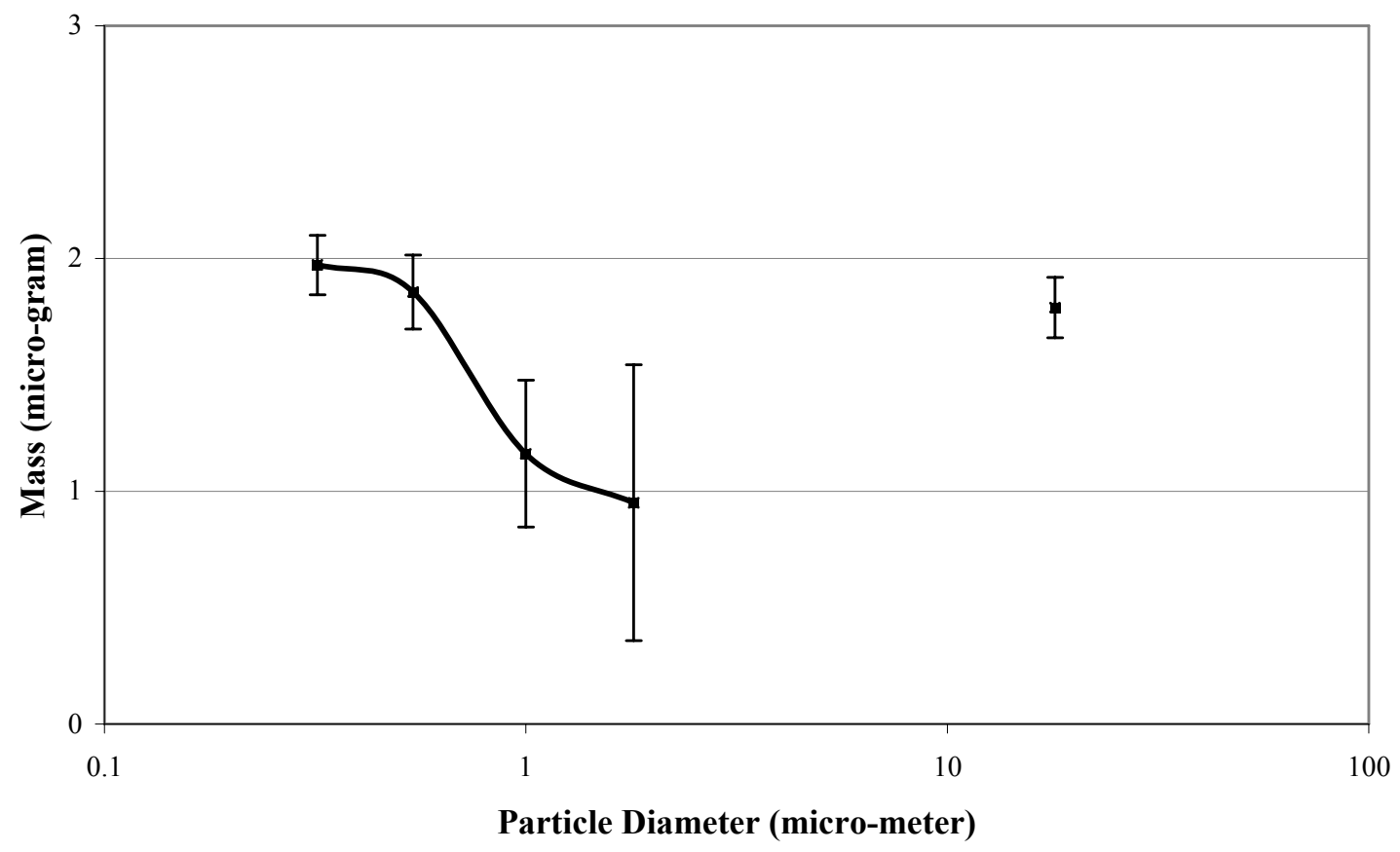

Figure 13. Mass as a function of particle diameter with no work

A KS test was run to determine the distribution of the data. The data were consistent with a log-normal distribution. The KS test was also used to compare the 
experimental data with the background data. The experimental data was found to be different from the background data with a $90 \%$ probability.

The median particle size for this geometry was determined by plotting the cumulative mass as a function of particle size, as shown in Figure 14. The average particle size was $0.54 \mu \mathrm{m}$ with a geometric standard deviation of $3.7 \mu \mathrm{m}$.

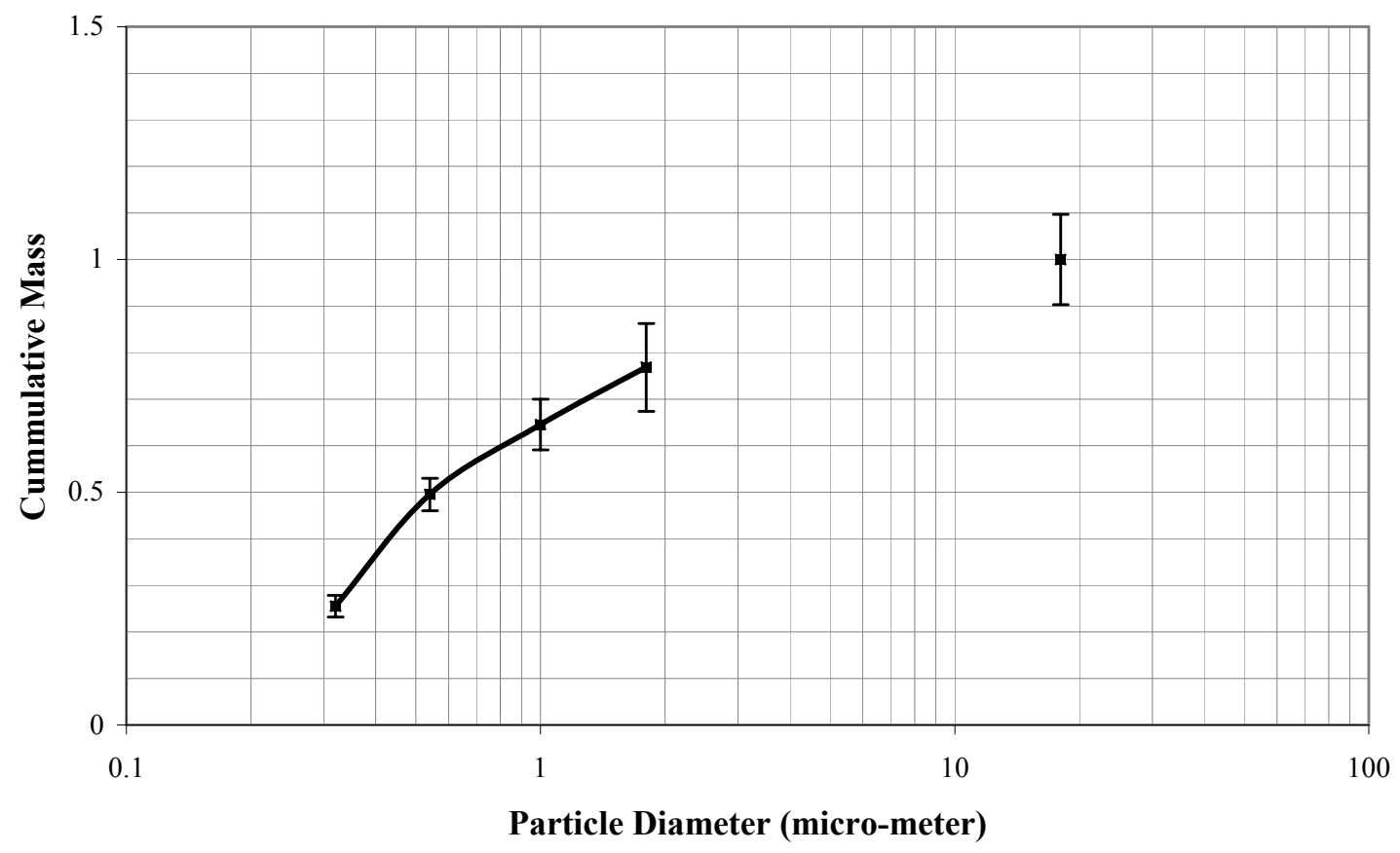

Figure 14. Particle diameter distribution - with no work occurring

\section{MEASUREMENTS OF MATERIAL ESCAPING WHILE WORK IS BEING PERFORMED}

The MOUDI was run for two hours to collect particles escaping from the hood while a worker seated in front of the hood moved her hands in and out of the hood opening at an average rate of $0.3 \mathrm{~m} / \mathrm{s}$. The supply and exhaust ventilation was on in both the room and the open-front hood. The $\mathrm{NaCl}$ solution was heated on the $550^{\circ} \mathrm{C}$ hot plate. During the first run, the hot plate failed while collecting the samples. The results for the 
samples are shown in Table 10; however, these results were not included in the data analysis.

Table 10. First motion $\mathrm{NaCl}$ mass collected

\begin{tabular}{|c|c|c|c|c|}
\hline \multirow{2}{*}{ Sample ID } & \multicolumn{2}{|c|}{ Na } & \multicolumn{2}{c|}{ Cl } \\
\cline { 2 - 5 } & Mass $(\boldsymbol{\mu g})$ & $\pm(\mu \mathrm{g})$ & Mass $(\boldsymbol{\mu g})$ & $\pm(\boldsymbol{\mu g})$ \\
\hline \hline 31 & 0.733 & 0.0244 & 4.25 & 0.0740 \\
\hline 32 & 0.923 & 0.0239 & 2.16 & 0.0445 \\
\hline 33 & 1.83 & 0.0374 & 2.96 & 0.0566 \\
\hline 34 & 1.32 & 0.0305 & 2.91 & 0.0565 \\
\hline 35 & 0.914 & 0.0243 & 2.84 & 0.0550 \\
\hline 36 & 0.983 & 0.0245 & 2.30 & 0.0468 \\
\hline 37 & 1.02 & 0.0255 & 2.76 & 0.0541 \\
\hline 38 & 1.08 & 0.0262 & 2.28 & 0.0472 \\
\hline 39 & 1.28 & 0.0297 & 2.44 & 0.0494 \\
\hline 40 & 1.57 & 0.0338 & 3.19 & 0.0601 \\
\hline
\end{tabular}

Results for motion of runs 2 - 4 are shown in Tables 11, 12, and 13; respectively. 
Table 11. Second motion $\mathrm{NaCl}$ mass collected

\begin{tabular}{|c|c|c|c|c|}
\hline \multirow[b]{2}{*}{ Sample ID } & \multicolumn{2}{|c|}{$\mathrm{Na}$} & \multicolumn{2}{|c|}{ Cl } \\
\hline & Mass $(\mu \mathrm{g})$ & $\pm(\mu \mathrm{g})$ & Mass $(\mu \mathrm{g})$ & $\pm(\mu \mathrm{g})$ \\
\hline 71 & 1.02 & 0.0318 & 2.31 & 0.0560 \\
\hline 72 & 1.57 & 0.0349 & 3.36 & 0.0641 \\
\hline 73 & 2.81 & 0.0531 & 4.62 & 0.0819 \\
\hline 74 & 0.714 & 0.0216 & 1.71 & 0.0395 \\
\hline 75 & 1.33 & 0.0323 & 3.29 & 0.0623 \\
\hline 76 & 1.59 & 0.0344 & 3.01 & 0.0584 \\
\hline 77 & 0.705 & 0.0211 & 2.19 & 0.0462 \\
\hline 78 & 0.876 & 0.0236 & 2.18 & 0.0462 \\
\hline 79 & 1.13 & 0.0286 & 2.54 & 0.0522 \\
\hline 80 & 1.64 & 0.0356 & 3.44 & 0.0648 \\
\hline
\end{tabular}


Table 12. Third motion $\mathrm{NaCl}$ mass collected

\begin{tabular}{|c|c|c|c|c|}
\hline \multirow{2}{*}{ Sample ID } & \multicolumn{2}{|c|}{ Na } & \multicolumn{2}{c|}{ Cl } \\
\cline { 2 - 5 } & Mass $(\boldsymbol{\mu g})$ & $\pm(\boldsymbol{\mu g})$ & Mass $(\boldsymbol{\mu g})$ & $\pm(\boldsymbol{\mu g})$ \\
\hline 81 & 1.32 & 0.0314 & 2.8 & 0.0552 \\
\hline 82 & 1.86 & 0.0394 & 3.42 & 0.0643 \\
\hline 83 & 1.52 & 0.0344 & 2.92 & 0.0571 \\
\hline 84 & 2.83 & 0.0532 & 4.97 & 0.0866 \\
\hline 85 & 1.59 & 0.0350 & 3.03 & 0.0593 \\
\hline 86 & 1.50 & 0.0344 & 2.72 & 0.0549 \\
\hline 87 & 1.42 & 0.0321 & 2.74 & 0.0545 \\
\hline 88 & 1.27 & 0.0306 & 2.45 & 0.0509 \\
\hline 89 & 0.814 & 0.0231 & 2.35 & 0.0489 \\
\hline 90 & 1.07 & 0.0266 & 2.76 & 0.0553 \\
\hline
\end{tabular}


Table 13. Fourth motion $\mathrm{NaCl}$ mass collected

\begin{tabular}{|c|c|c|c|c|}
\hline \multirow{2}{*}{ Sample ID } & \multicolumn{2}{|c|}{ Na } & \multicolumn{2}{c|}{ Cl } \\
\cline { 2 - 5 } & Mass $(\boldsymbol{\mu g})$ & $\pm(\mu \mathrm{g})$ & Mass $(\boldsymbol{\mu g})$ & $\pm(\boldsymbol{\mu g})$ \\
\hline 91 & 2.19 & 0.0442 & 4.00 & 0.0725 \\
\hline 92 & 1.15 & 0.0289 & 2.43 & 0.0502 \\
\hline 93 & 1.05 & 0.0272 & 2.64 & 0.0536 \\
\hline 94 & 0.803 & 0.0237 & 2.34 & 0.0491 \\
\hline 95 & 0.834 & 0.0238 & 2.05 & 0.0442 \\
\hline 96 & 0.682 & 0.0217 & 1.77 & 0.0405 \\
\hline 97 & 1.24 & 0.0298 & 2.50 & 0.0518 \\
\hline 98 & 0.912 & 0.0235 & 1.56 & 0.0370 \\
\hline 99 & 0.953 & 0.0248 & 2.09 & 0.0452 \\
\hline 100 & 2.10 & 0.0440 & 3.79 & 0.0701 \\
\hline
\end{tabular}

Results above the $90 \%$ confidence level were corrected for background, averaged, and tabulated as a function of the median aerodynamic diameter. This tabulation is shown in Table 14. The graphical representation of this tabulation is shown in Figure 15. 
Table 14: Average $\mathrm{NaCl}$ Mass for Worker in Motion

\begin{tabular}{|c|c|c|}
\hline Diameter & Mass $(\boldsymbol{\mu g})$ & $\pm(\boldsymbol{\mu g})$ \\
\hline \hline 18 & 1.8926 & 0.1501 \\
\hline 1.8 & 0.9182 & 0.5965 \\
\hline 1 & 1.6740 & 0.3233 \\
\hline 0.54 & 2.4071 & 0.1725 \\
\hline 0.32 & 1.8976 & 0.1373 \\
\hline 0.19 & 2.3372 & 0.1151 \\
\hline
\end{tabular}

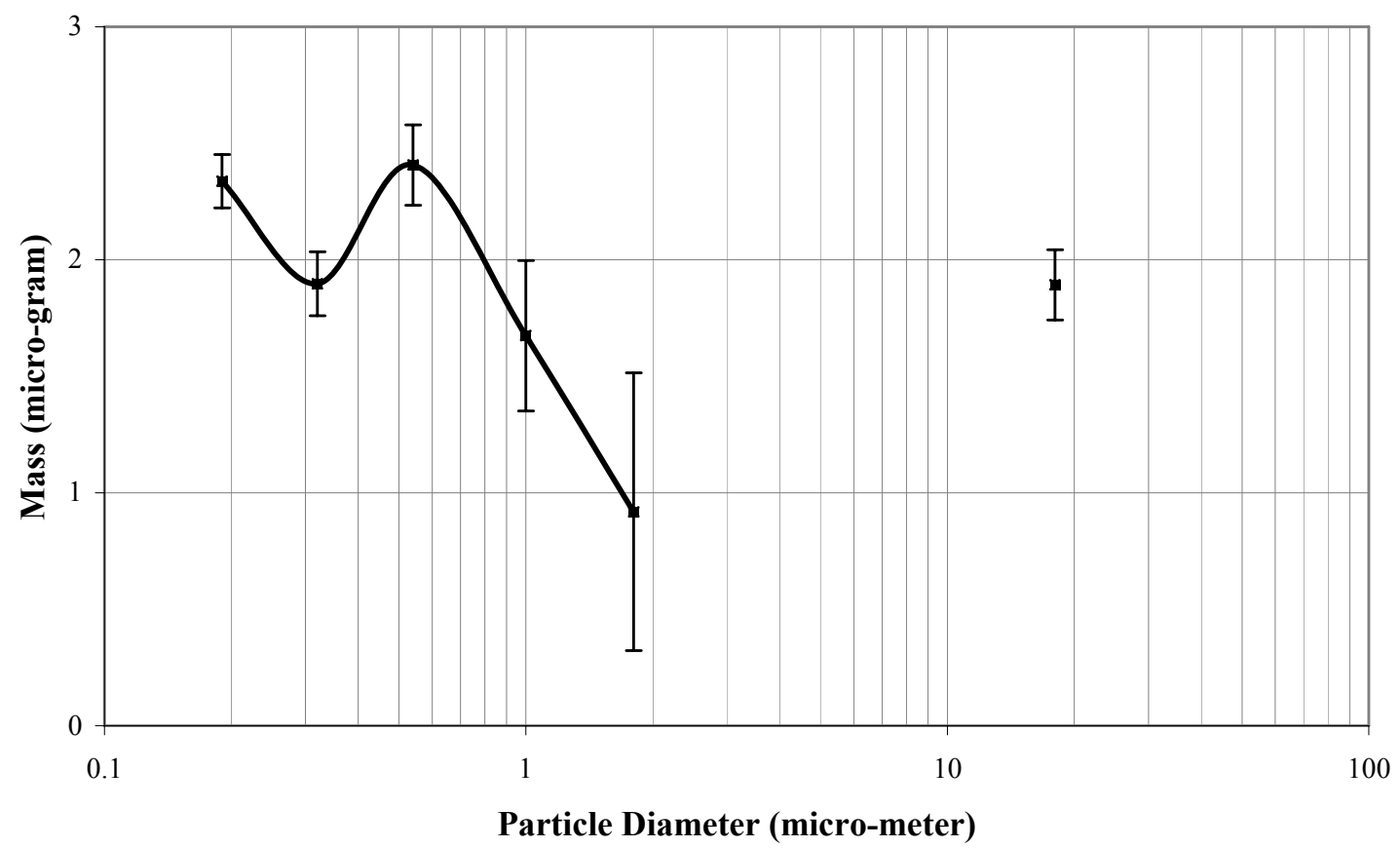

Figure 15. Work mass as a function of particle diameter.

The data appears bi-modal or maybe even tri-modal. The KS test was run on the data for particle size less than $10 \mu \mathrm{m}$ to determine the distribution of the data. This sub- 
set of the data was consistent with a log-normal distribution. The KS test was also used to compare the experimental data with the background data. The experimental data was found to be different from background data with $97 \%$ probability. The KS test was used to compare these data with the data collected with a stationary worker in front of the hood. The data sets are different with a probability of $90 \%$.

The median particle size for this geometry was determined by plotting the cumulative mass as a function of particle size, as shown in Figure 16. The median mass diameter was $0.35 \mu \mathrm{m}$, with a geometric standard deviation of $5.1 \mu \mathrm{m}$.

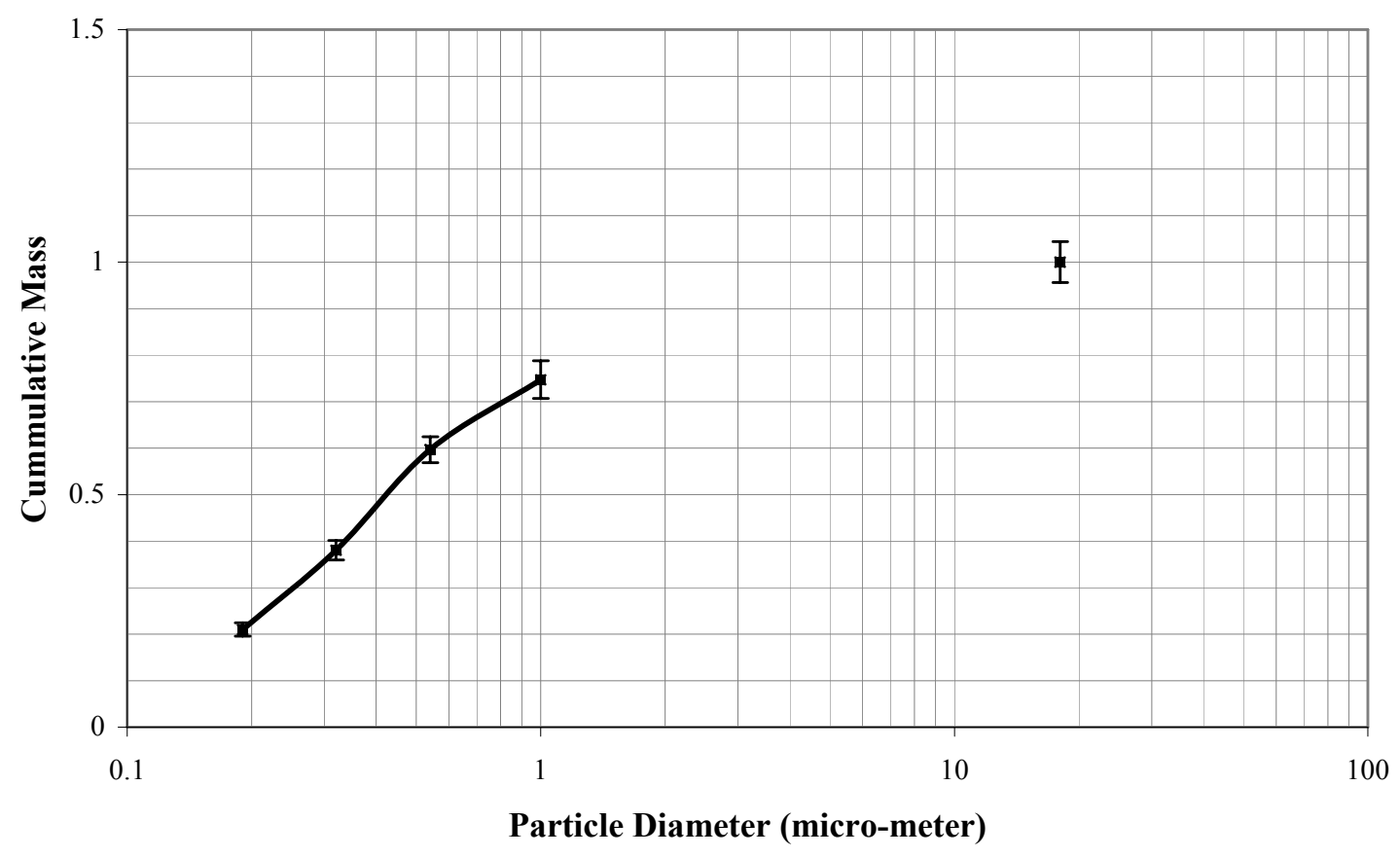

Figure 16. Particle diameter when work is being performed

\section{MEASUREMENTS OF MATERIAL ESCAPING WITH MOUDI IN HOOD}

The MOUDI was run for two hours to collect particles in the hood. The supply and exhaust ventilation was on in both the room and the open-front hood. The $\mathrm{NaCl}$ 
solution was being heated on the $550^{\circ} \mathrm{C}$ hot plate. The results of the three runs are shown Tables 15, 16, and 17.

Table 15. First MOUDI in hood $\mathrm{NaCl}$ mass collected

\begin{tabular}{|c|c|c|c|c|}
\hline \multirow[b]{2}{*}{ Sample ID } & \multicolumn{2}{|c|}{$\mathrm{Na}$} & \multicolumn{2}{|c|}{ Cl } \\
\hline & Mass $(\mu \mathrm{g})$ & $\pm(\mu \mathrm{g})$ & Mass $(\mu \mathrm{g})$ & $\pm(\mu \mathrm{g})$ \\
\hline 51 & 19.2 & 0.284 & 30.7 & 0.440 \\
\hline 52 & 2.3 & 0.0437 & 4.40 & 0.0777 \\
\hline 53 & 1.22 & 0.0284 & 2.42 & 0.0494 \\
\hline 54 & 1.04 & 0.0256 & 2.45 & 0.0497 \\
\hline 55 & 1.17 & 0.0273 & 2.26 & 0.0471 \\
\hline 56 & 1.44 & 0.0318 & 2.91 & 0.0561 \\
\hline 57 & 1.30 & 0.0299 & 3.08 & 0.0590 \\
\hline 58 & 1.52 & 0.0332 & 3.66 & 0.0669 \\
\hline 59 & 1.46 & 0.0322 & 2.99 & 0.0576 \\
\hline 60 & 2.30 & 0.0451 & 4.95 & 0.0853 \\
\hline
\end{tabular}


Table 16. Second MOUDI in hood $\mathrm{NaCl}$ mass collected

\begin{tabular}{|c|c|c|c|c|}
\hline \multirow{2}{*}{ Sample ID } & \multicolumn{2}{|c|}{ Na } & \multicolumn{2}{c|}{ Cl } \\
\cline { 2 - 5 } & Mass $(\boldsymbol{\mu g})$ & $\pm(\mu \mathrm{g})$ & Mass $(\boldsymbol{\mu g})$ & $\pm(\boldsymbol{\mu g})$ \\
\hline \hline 61 & 29.2 & 0.429 & 45.20 & 0.640 \\
\hline 62 & 24.6 & 0.363 & 38.19 & 0.545 \\
\hline 63 & 13.8 & 0.217 & 21.38 & 0.324 \\
\hline 64 & 3.97 & 0.0779 & 7.70 & 0.135 \\
\hline 65 & 6.05 & 0.108 & 10.01 & 0.167 \\
\hline 66 & 2.78 & 0.0594 & 4.95 & 0.0953 \\
\hline 67 & 1.84 & 0.0457 & 3.57 & 0.0746 \\
\hline 68 & 1.68 & 0.0431 & 3.19 & 0.0698 \\
\hline 69 & 2.07 & 0.0493 & 4.26 & 0.0853 \\
\hline 70 & 2.95 & 0.0632 & 5.93 & 0.109 \\
\hline
\end{tabular}


Table 17. Third MOUDI in hood $\mathrm{NaCl}$ mass collected

\begin{tabular}{|c|c|c|c|c|}
\hline \multirow{2}{*}{ Sample ID } & \multicolumn{2}{|c|}{ Na } & \multicolumn{2}{c|}{ CI } \\
\cline { 2 - 5 } & Mass $(\boldsymbol{\mu g})$ & $\pm(\boldsymbol{\mu g})$ & Mass $(\boldsymbol{\mu g})$ & $\pm(\boldsymbol{\mu g})$ \\
\hline 111 & 13.6 & 0.206 & 21.5 & 0.315 \\
\hline 112 & 18.1 & 0.271 & 28.7 & 0.414 \\
\hline 113 & 44.9 & 0.649 & 69.9 & 0.980 \\
\hline 114 & 14.9 & 0.224 & 23.6 & 0.344 \\
\hline 115 & 15.9 & 0.237 & 24.8 & 0.360 \\
\hline 116 & 15.2 & 0.229 & 24.5 & 0.356 \\
\hline 117 & 5.59 & 0.0922 & 9.58 & 0.150 \\
\hline 118 & 3.07 & 0.0561 & 5.09 & 0.0881 \\
\hline 119 & 4.89 & 0.0823 & 8.71 & 0.138 \\
\hline 120 & 3.99 & 0.0693 & 7.69 & 0.124 \\
\hline
\end{tabular}

Results above the $90 \%$ confidence level were corrected for background, averaged, and tabulated as a function of the median aerodynamic diameter. This tabulation is shown in Table 18. The graphical representation of this tabulation is shown in Figure 17. 
Table 18: Average $\mathrm{NaCl}$ Mass for MOUDI in Hood

\begin{tabular}{|c|c|c|}
\hline Diameter & Mass $(\boldsymbol{\mu g})$ & $\pm(\boldsymbol{\mu g})$ \\
\hline 18 & 34.99 & 19.85 \\
\hline 9.9 & 46.12 & 11.31 \\
\hline 6.2 & 68.11 & 56.30 \\
\hline 3.1 & 19.93 & 6.94 \\
\hline 1.8 & 17.04 & 18.97 \\
\hline 1 & 14.53 & 18.95 \\
\hline 0.54 & 6.12 & 5.95 \\
\hline 0.32 & 3.60 & 1.82 \\
\hline 0.19 & 6.05 & 4.83 \\
\hline
\end{tabular}

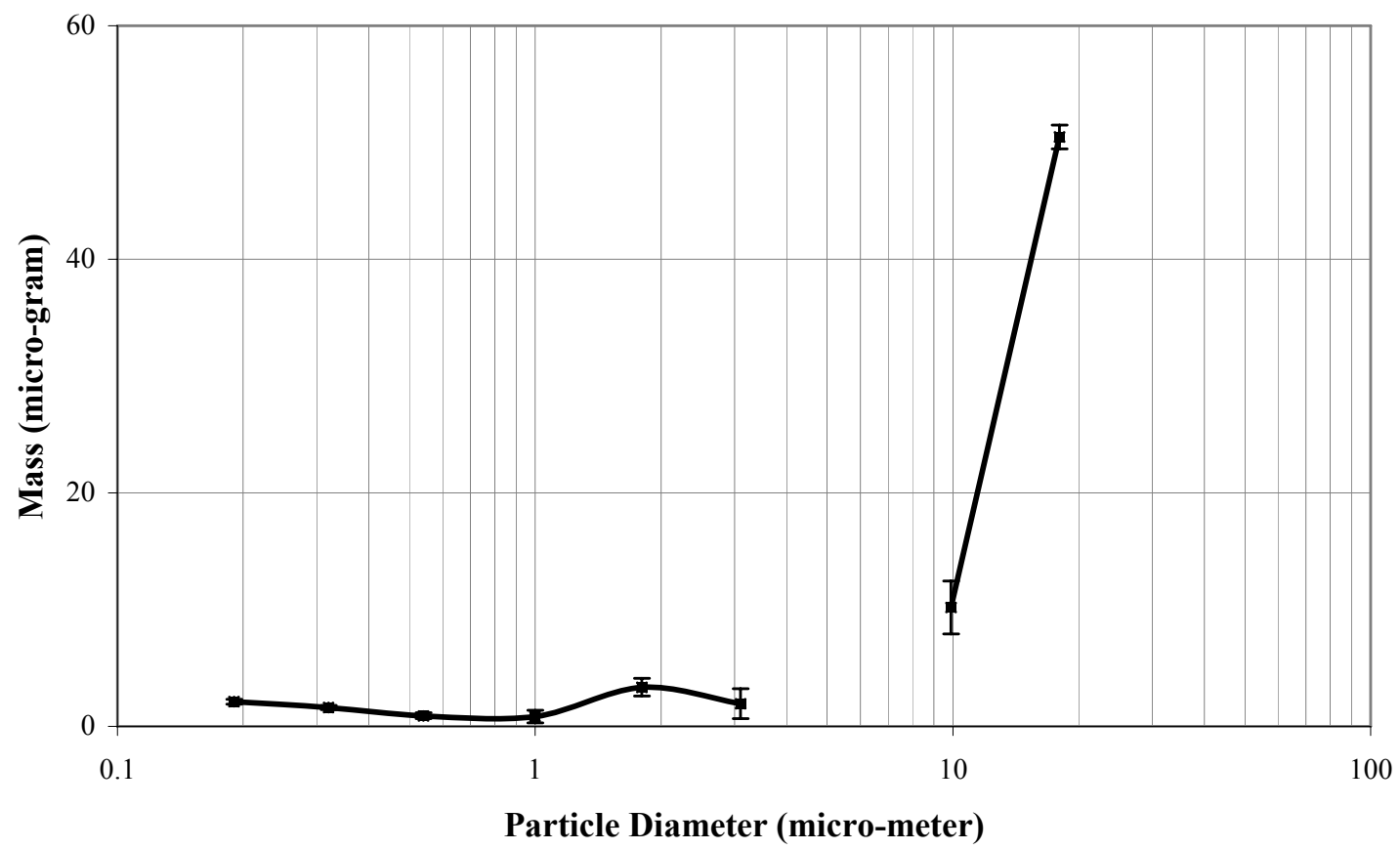

Figure 17. Particle diameter distribution with the MOUDI in hood 
A KS test was run to determine the distribution of the data. The data was consistent with a log-normal distribution. The KS test was also used to compare the experimental data with the background data. The experimental data was found to be different from the background data with $100 \%$ probability.

The median particle size for this geometry was determined by plotting the cumulative mass as a function of particle size, as shown in Figure 18. The average particle size was $13 \mu \mathrm{m}$ with a geometric standard deviation of $4.2 \mu \mathrm{m}$.

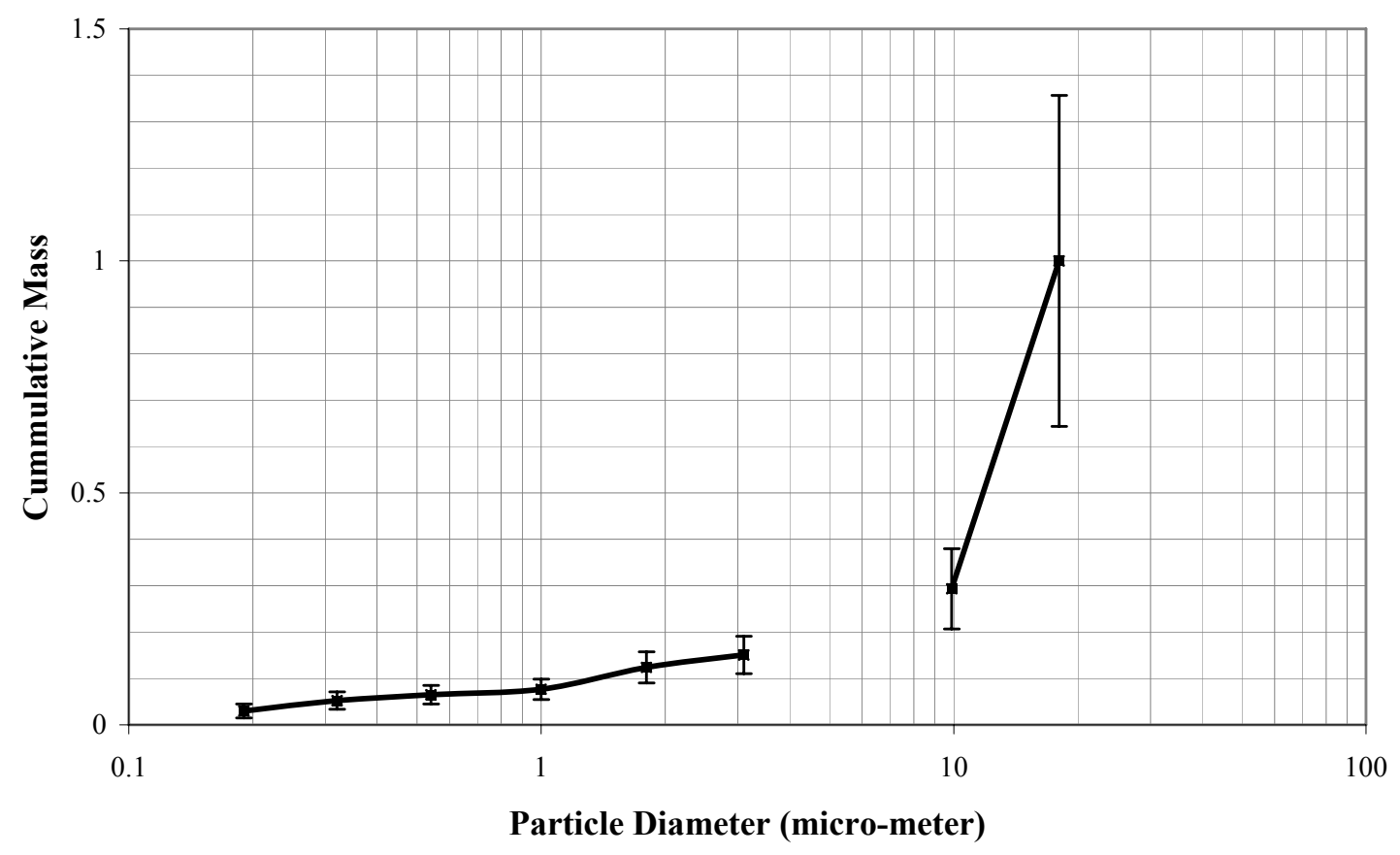

Figure 18. Mass as a function of particle diameter with the MOUDI in the hood

\section{Calculation of Dose}

Now the particle size distribution is known, dose can be calculated. The deposition fraction is given in ICRP 66. Clearance is predominant in region ET. Clearance and absorption are competing processes in regions $\mathrm{BB}, \mathrm{bb}$, and $\mathrm{AI}$. The processes are modeled by coupled differential equations. Plutonium is a Type S material, 
represented by the assumption that $0.1 \%$ of the initially deposited material is absorbed rapidly $\left(\mathrm{s}_{\mathrm{r}}\right.$ of $100 \mathrm{~d}^{-1}$ ) and that $99.9 \%$ of the material is absorbed at a slow rate, $\mathrm{s}_{\mathrm{s}}$, (of $\left.0.0001 \mathrm{~d}^{-1}\right)$ into the lymph nodes $\left(\mathrm{LN}_{\mathrm{TH}}\right.$ and $\left.\mathrm{LN}_{\mathrm{ET}}\right)$. Clearance from the each compartment is based on where the material is deposited. A compartment may be fed activity from several initial deposition compartments. The number of transformations $\left(U_{s}\right)$ in each compartment is the product of the deposition fraction, residence time, mass, the specific activity, and the time constant of $86400 \mathrm{~s} /$ day. The number of disintegrations per $\mathrm{Bq}$ inhaled into each compartment and the dose per $\mathrm{Bq}$ inhaled was calculated both by hand and using a Los Alamos program. The printouts from the AIDE program showing the number of disintegrations per $\mathrm{Bq}\left(U_{s}\right)$ and dose equivalent per $\mathrm{Bq}(\mathrm{Sv} / \mathrm{Bq})$ for each particle size are shown in Appendix A. The comparison of the hand calculation and computer program results for $1 \mu \mathrm{m}$ particles is shown in Table 19 . Note the conservatism that is introduced using approximations given in ICRP 66 instead of solving the coupled differential equations that describe the deposition and clearance of material from the lung. 
Table 19. Comparison of Sv/Bq results using AIDE and Hand Calculation

\begin{tabular}{|c|c|c|}
\hline Compartment & AIDE & Hand \\
\hline $\mathrm{AI}$ & $1.39 \times 10^{-4}$ & $1.40 \times 10^{-4}$ \\
\hline $\mathrm{bb}$ & $6.16 \times 10^{-5}$ & $6.43 \times 10^{-5}$ \\
\hline $\mathrm{BB}$ & $6.91 \times 10^{-5}$ & $6.91 \times 10^{-5}$ \\
\hline $\mathrm{ET}_{1}$ & $4.22 \times 10^{-5}$ & 0 \\
\hline $\mathrm{ET}_{2}$ & $4.22 \times 10^{-5}$ & $4.41 \times 10^{-5}$ \\
\hline $\mathrm{LN}_{\mathrm{TH}}$ & $8.20 \times 10^{-4}$ & $2.51 \times 10^{-2}$ \\
\hline $\mathrm{LN}_{\mathrm{ET}}$ & $7.51 \times 10^{-5}$ & $8.05 \times 10^{-5}$ \\
\hline Total & $1.25 \times 10^{-3}$ & $2.55 \times 10^{-2}$ \\
\hline
\end{tabular}

To calculate the dose due to inhalation of particles with a mass median diameter of $1 \mu \mathrm{m}$, the data in Table 19 are multiplied by the activity inhaled by the worker. The activity inhaled by the worker is calculated by multiplying the mass collected with the MOUDI, and the specific activity for $\mathrm{PuO}_{2}(2400 \mathrm{~Bq} / \mu \mathrm{g})$. This product is then corrected to take into account the deposition fraction for the MMD of the particle distribution and difference between the MOUDI flow rate and the breathing rate of reference man. The MOUDI operates at a flow rate 1.7 times the breathing rate of a reference man performing light work. So, the total activity deposited in the lung is calculated as follows:

$$
\begin{aligned}
B q & =\frac{\operatorname{mass}(\mu g) \times 2400 \mathrm{~Bq} / \mu \mathrm{g} \times \text { deposition fraction }}{1.7} \\
& =1412 \times \operatorname{mass}(\mu \mathrm{g}) \times \text { deposition fraction }
\end{aligned}
$$

The mass collected, MMD measured, the deposition fraction for the measured MMD and the activity inhaled for both work and no work is shown in Table 20. 
Table 20. Activity Inhaled for each Experimental Condition

\begin{tabular}{|l|c|c|c|c|}
\hline $\begin{array}{c}\text { Experimental } \\
\text { Condition }\end{array}$ & $\begin{array}{c}\text { Mass } \\
\text { Collected } \\
(\boldsymbol{\mu g})\end{array}$ & $\begin{array}{c}\text { Measured } \\
\text { MMD }(\boldsymbol{\mu m})\end{array}$ & $\begin{array}{c}\text { Deposition } \\
\text { Fraction }\end{array}$ & $\begin{array}{c}\text { Calculated } \\
\text { Activity } \\
(\mathbf{B q})\end{array}$ \\
\hline Work & $11.13 \pm 0.54$ & $0.35 \pm 5.1$ & 0.32 & $5.00 \times 10^{3} \pm$ \\
No-work & $7.73 \pm 0.46$ & $0.54 \pm 3.7$ & 0.36 & $3.92 \times 10^{3} \pm$ \\
& & & & $2.33 \times 10^{2}$ \\
\hline
\end{tabular}

The potential dose directly in front of the open front hood is now calculated by multiplying the activity $(\mathrm{Bq})$ collected by the MOUDI for each experimental condition by the total dose per activity for the measured mass median diameter. Table 21 shows the results of the calculation.

Table 21. Activity Inhaled for each Experimental Condition

\begin{tabular}{|l|c|c|c|}
\hline $\begin{array}{c}\text { Experimental } \\
\text { Condition }\end{array}$ & Calculated Activity (Bq) & $\begin{array}{c}\text { Dose } \\
\text { Conversion } \\
\text { Factor } \\
\mathbf{( S v / B q )}\end{array}$ & Dose (Sv) \\
\hline Work & $5.00 \times 10^{3} \pm 2.43 \times 10^{2}$ & $1.60 \times 10^{-5}$ & $0.08 \pm 0.01$ \\
\hline No-work & $3.92 \times 10^{3} \pm 2.33 \times 10^{2}$ & $1.89 \times 10^{-5}$ & $0.07 \pm 0.01$ \\
\hline
\end{tabular}

The dose to the worker will be less. Work done by Welling (Welling, et al., 2000) with tracer gas showed a decrease in concentration of contaminant as a function of distance. At a distance of $40 \mathrm{~cm}$, the distance from the MOUDI inlet to the worker breathing zone, the contaminant is diluted by a factor of 36 . Based on this factor, the maximum dose to the worker would be $2 \mathrm{mSv}$. 


\section{CHAPTER 4: DISCUSSION}

\section{CAPTURE EFFICIENCY AND HOOD LEAKAGE}

The larger particles tended to be captured by the exhaust, whereas the smaller particles escaped the hood, becoming available for inhalation. The MMD of the escaping particles was in the range of that observed in other measurements. The MMD of the escaping particles was smaller when work was simulated.

The capture efficiency of the hood can be expressed:

$$
E=1-\frac{\text { mass outside hood }}{\text { total mass }} \quad \text { Equation } 17
$$

When work is performed, the mass observed outside of the hood is $11.13 \mu \mathrm{g}$. The total mass in hood is the sum of the mass observed with the MOUDI in the hood $(71.4 \mu \mathrm{g})$ and the mass observed out of the hood $(11.13 \mu \mathrm{g})$. The collection efficiency is calculated from Equation 17 to be 0.77 . So the box captures $77 \%$ of the contaminants generated when work is performed in the hood. The capture efficiency increases to $90 \%$ when the worker is stationary.

For a "perfect" box, no contaminants would escape and the capture efficiency would be $100 \%$. In this case, the volumetric flow rate out of the box would be zero. A worst case situation could be work on a bench top with a capture efficiency of 0 . In this case, the volumetric flow rate into the box equals the volumetric flow rate out of the box. Mathematically, this is expressed:

$$
\frac{C_{\text {out }}}{C_{\text {in }}}=\frac{Q_{\text {out }}}{Q_{\text {in }}}
$$

Equation 18 
This relationship is shown in Figure 19. The volumetric flow rate out of the box is calculated to be $0.01 \mathrm{~m}^{3} / \mathrm{sec}$ when work is performed, compared to $0.007 \mathrm{~m}^{3} / \mathrm{sec}$ when a worker is stationary.

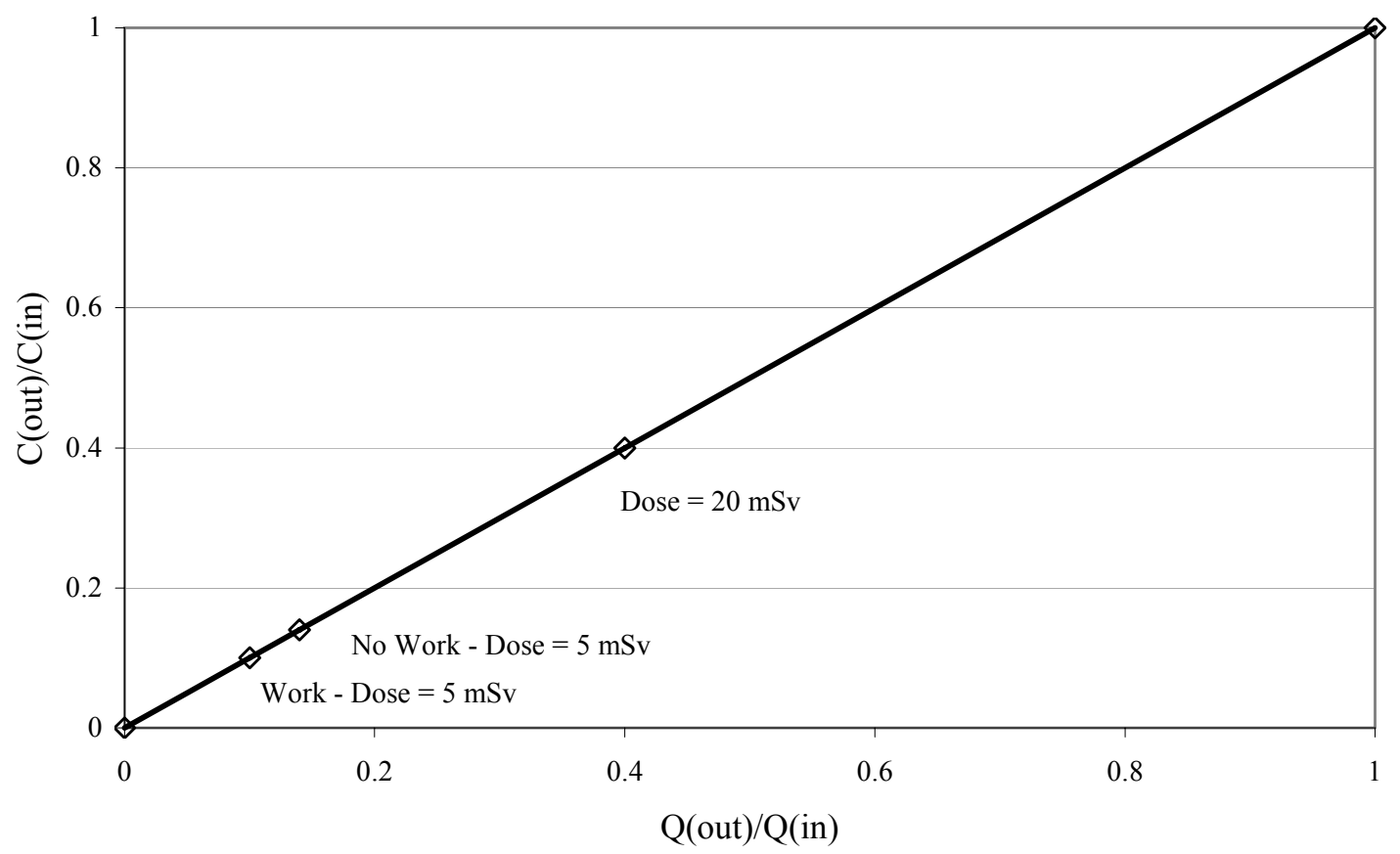

Figure 19. Relationship between volumetric flow rate and capture efficiency

If the concentration outside of the box were 4 times higher than that seen when work is performed, the resulting dose to the worker would approach the dose limit of 0.02 Sv. The capture efficiency for this scenario is $54 \%$. The volumetric flow rate out of the box is calculated to be $0.04 \mathrm{~m}^{3} / \mathrm{sec}$.

\section{EFFECT OF HAND MOTION ON HOOD LEAKAGE}

Hood leakage can be modeled as flow through the rotor of an axial flow fan. The power required to move a volume of air is described mathematically as:

$$
\dot{W}=\omega \bullet T \quad \text { Equation } 19
$$


where $\omega$ is the angular velocity of the shaft of the fan and $\mathrm{T}$ is the torque. For uniform flow, the torque is calculated:

$$
T=\rho \dot{Q} r\left(V_{\text {outlet }}-V_{\text {inlet }}\right) \quad \text { Equation } 20
$$

Assuming the fan operates at $1000 \mathrm{rpm}$, the blade inlet angle is $30^{\circ}$ and the outlet angle is $60^{\circ}$, the density of air at Los Alamos is $0.98 \mathrm{~kg} / \mathrm{m} 3$ and the average radius of the blade is $0.1 \mathrm{~m}$, the velocity at the inlet and out is calculated:

$$
\begin{gathered}
V_{\text {inlet }}=\frac{0.1 \mathrm{~m}\left(1000 \frac{\mathrm{rev}}{\mathrm{min}}\right)\left(2 \pi \frac{\mathrm{rad}}{\mathrm{rev}}\right)\left(\frac{\mathrm{min}}{60 \mathrm{sec}}\right) \cos 30^{\circ}}{\tan 30^{\circ}+\cot 30^{\circ}}=4 \frac{\mathrm{m}}{\mathrm{s}} \\
V_{\text {outlet }}=\frac{0.1 \mathrm{~m}\left(1000 \frac{\mathrm{rev}}{\mathrm{min}}\right)\left(2 \pi \frac{\mathrm{rad}}{\mathrm{rev}}\right)\left(\frac{\mathrm{min}}{60 \mathrm{sec}}\right) \sin 60^{\circ}}{\left(\tan 30^{\circ}+\cot 30^{\circ}\right) \cos 60^{\circ}}=8 \frac{\mathrm{m}}{\mathrm{s}}
\end{gathered}
$$

Table 22. Fan Power for varying box capture efficiencies

\begin{tabular}{|l|c|c|c|}
\hline Condition & $\mathbf{V}_{\text {out }}(\mathbf{m} / \mathbf{s e c})$ & $\dot{Q_{\text {out }}\left(\mathbf{m}^{3} / \mathbf{s e c}\right)}$ & Fan Power $(\mathbf{m W})$ \\
\hline Perfect & 0 & 0 & 0 \\
\hline No Work & 0.05 & 0.007 & 287 \\
\hline Work & 0.08 & 0.011 & 451 \\
\hline No Box & 0.5 & 0.068 & 2790 \\
\hline
\end{tabular}

\section{MODELING OF HOOD LEAKAGE}

CFD modeling could be used to evaluate the experimental results. In order to obtain valid results, the model must reflect the experimental conditions. Therefore, details such as a drawing of the open front box, the room containing the open front box, the position of the hot plate, beaker of solution, and worker with respect to the box and 
the room, exhaust volumetric flow rates out of the box, and heat sources must be known. A detailed drawing of the experimental setup is given in Appendix A.

The region of interest is directly in front of the hood opening. In order to accurately model the influence of the worker in front of the hood, a cube $30 \mathrm{~cm}$ wide, 70 $\mathrm{cm}$ tall and $20 \mathrm{~cm}$ deep can be used. The heat generated by this cube is calculated using American Society of Heating, Refrigerating, and Air Conditioning Engineers (ASHRAE, 1993) and work by Fanger (Fanger, 1992). When a person is stationary, total heat loss from the body averages around $100 \mathrm{~W}$. Moderate activity results in a total body heat loss of around $500 \mathrm{~W}$. The surface area of a cube $30 \mathrm{~cm}$ wide, $70 \mathrm{~cm}$ tall and $20 \mathrm{~cm}$ is 0.82 $\mathrm{m}^{2}$. So the rate of heat loss through the skin is $122 \mathrm{~W} / \mathrm{m}^{2}$ for the stationary worker and $610 \mathrm{~W} / \mathrm{m}^{2}$ when work is performed.

The heat loss from the hot plate at $550^{\circ} \mathrm{C}$ is expressed as:

$$
\frac{W}{m^{2}}=\varepsilon \sigma T^{4}=18.2 \frac{\mathrm{kW}}{\mathrm{m}^{2}}
$$

Where

$$
\begin{array}{ll}
\sigma & =\text { the Stefan-Boltzmann constant }=5.67 \times 10^{-8} \mathrm{~W} /\left(\mathrm{m}^{2} \mathrm{~K}^{4}\right) \\
\varepsilon & =\text { the emissitivity of ceramic }=0.7 \\
\mathrm{~T} & =\text { temperature in Kelvin }=823
\end{array}
$$

\section{STATISTICAL SigNifiCANCE OF MEASUREMENTS}

In Figure 20, the average cumulative particle size distribution of the gross measurement for motion, no-motion, and with the MOUDI in the hood is compared to the background particle size distribution. Figure 21 shows the net cumulative particle size distribution. It is easily seen that each measurement was different from background. The Kolmogorov-Smirnov (K-S) comparison was done using free ware from the College of Saint Benedict, Saint John's University Physics department. The freeware results were 
validated using a known particle size distribution. The KS comparison for motion showed a log-normal distribution for particle sizes smaller than $10 \mu \mathrm{m}$ and the average measurement was different from background with a $97 \%$ probability. The average nomotion measurement was log-normal and different from background with a probability of $90 \%$. The measurement of the average mass collected when the MOUDI is in the hood is log-normal and different from background with a probability of $100 \%$. A comparison of the average measurement for motion and the average measurement for no-motion shows these measurements are different with a $90 \%$ probability.

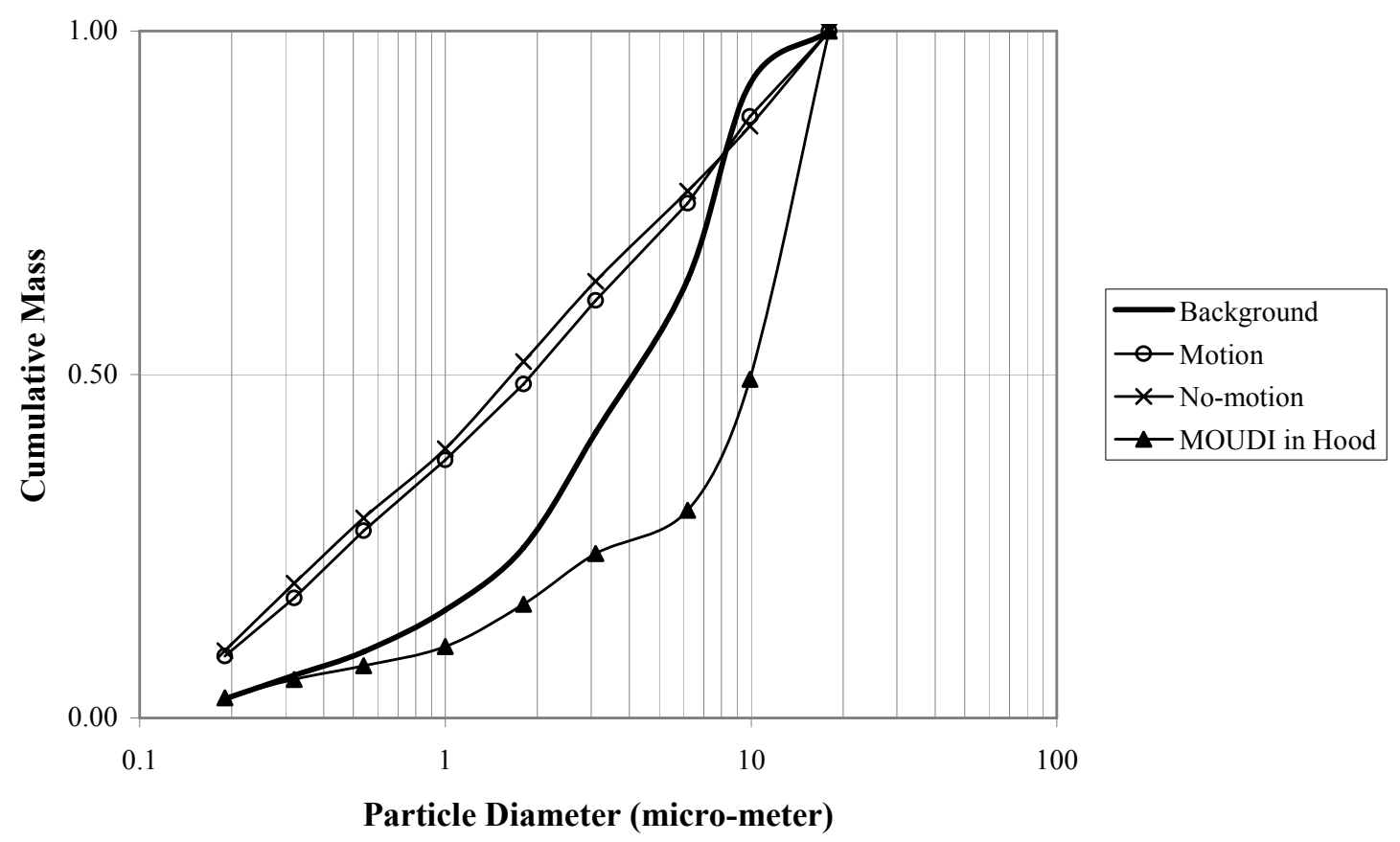

Figure 20. Comparison of gross particle size distribution to background 


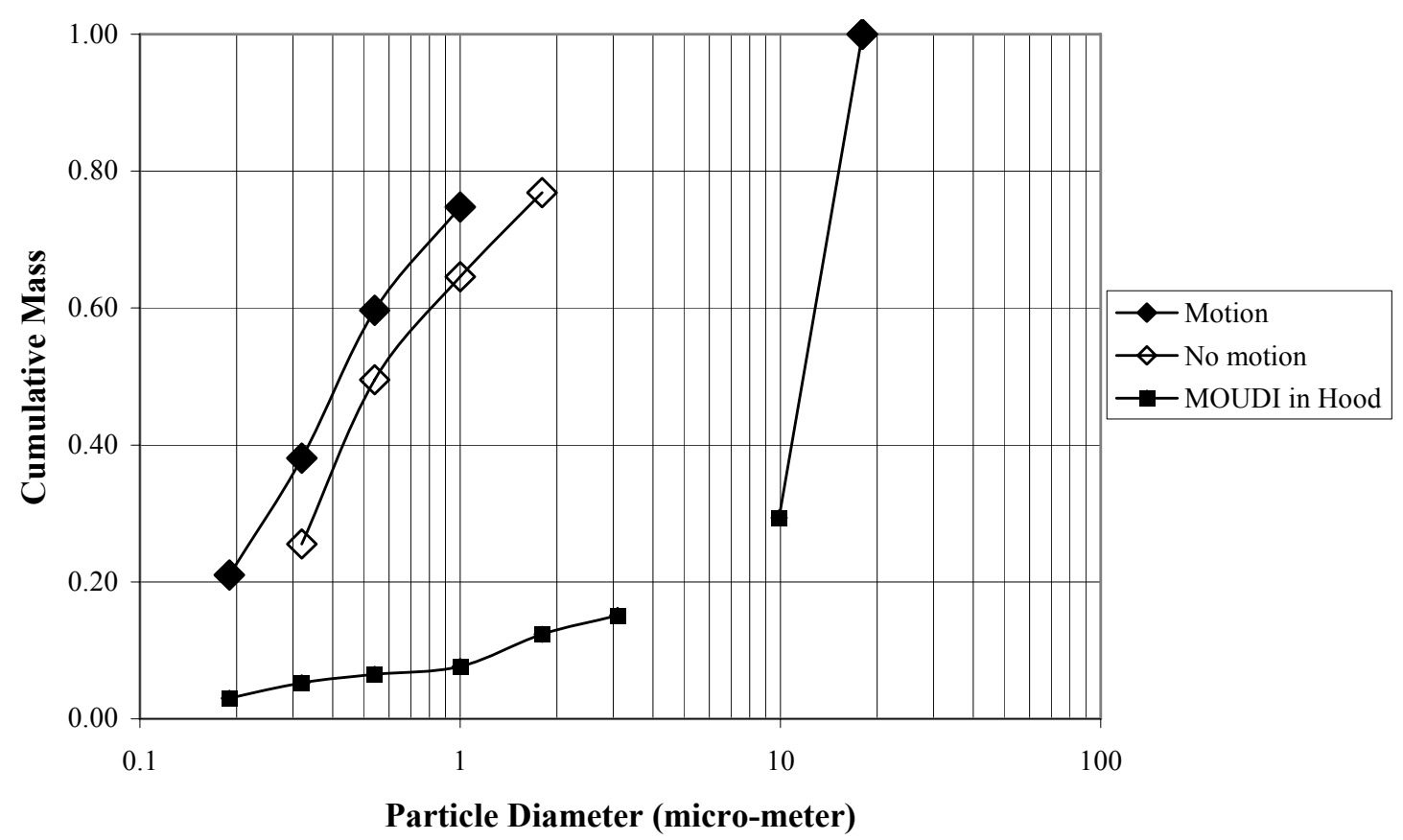

Figure 21. Comparison of net particle size distribution

\section{COMPARISION OF CALCULATED DOSE}

The exposure directly outside of the hood each time a heating process is used to digest a sample was $0.08 \mathrm{~Sv}$. Assuming the worker spent the entire time in front of the hood working, the resulting dose was calculated to be $2 \mathrm{mSv}$. In reality, the worker is in front of the hood only $10 \%$ of the time. Given this operation is performed approximately 24 times a year, the resulting dose to the worker would be $5 \mathrm{mSv}$. This is one quarter of the limit recommended by ICRP.

It is interesting to look at the range of variation of equivalent dose conversion factors as a function of mass median diameter, shown in Figure 22. The dose conversion factor of the measured mass median diameter for a worker in motion and a stationary worker are shown. 


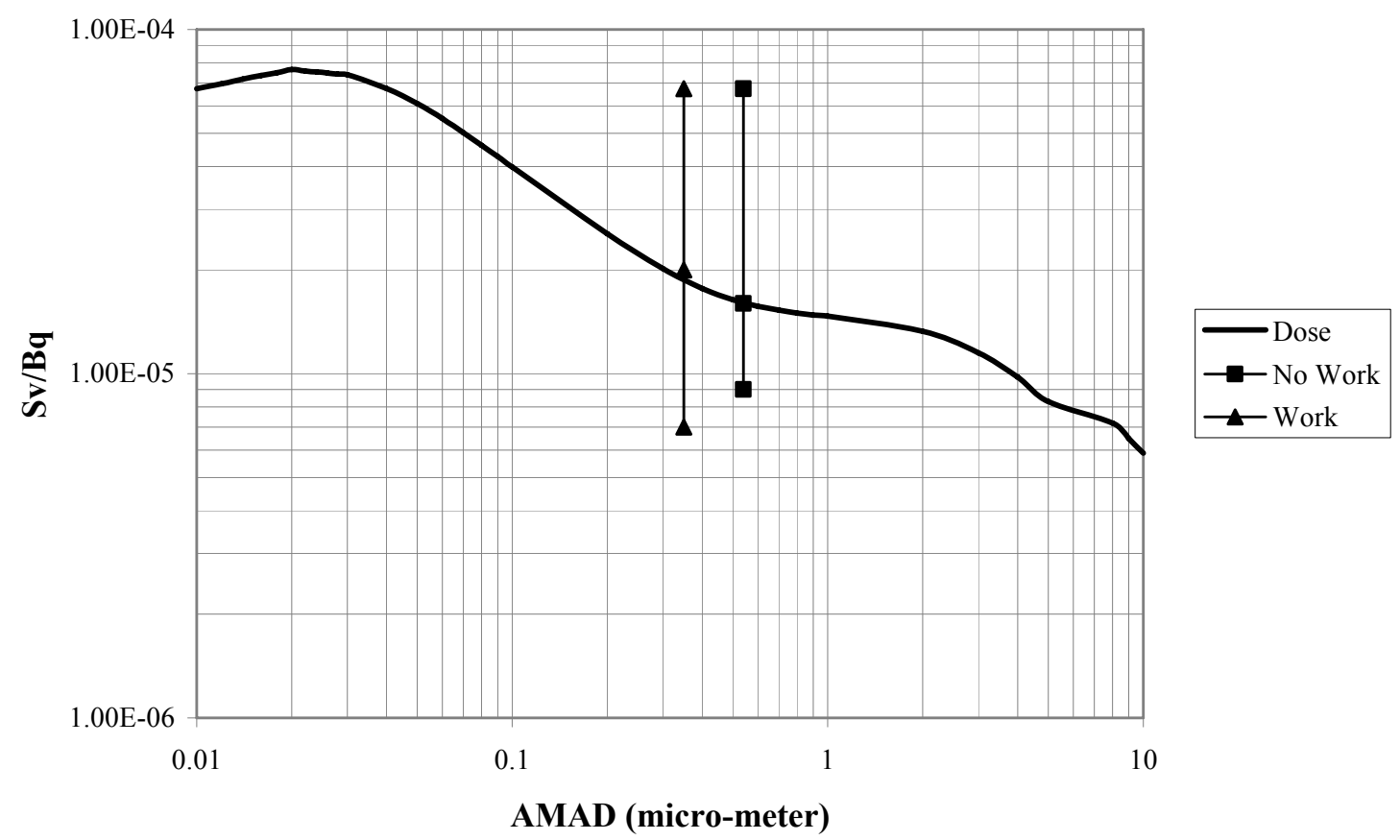

Figure 22. Dose conversion factor as a function of particle size

As shown in Figure 23, the dose estimate could be low by a factor of 4 for a stationary worker and a factor of 3 for a worker in motion. The MMD observed in this research compare to the values seen in the literature search. The Dorrian and Bailey paper gave a range of MMDs for Pu work of $0.16-5 \mu \mathrm{m}$ and noted that for heating operations, such as the operation investigated in this research, the MMD was sub-micron. The Task Group on Lung Dynamics (TGLD, 1966) noted that deposition was relatively insensitive to the geometric standard deviation. The dose estimate for this range of particle sizes could vary as much as a factor of 10 .

In order to verify the measurements made in this research, a comparison to other dose indicators was done. Worker bioassay is used to determine the amount of material inhaled. These measurements are done routinely and after any event that could have resulted in a release of material into laboratory air. The workers are monitored for 64 
internal doses using urine bioassay. The Los Alamos National Laboratory urine bioassay technique is able to detect doses as low as $0.002 \mathrm{~Sv}$ (Inkret et al., 1999). This minimum detectable dose assumes the plutonium is inhaled in a single intake, 180 days prior to the urine sample. For the operation mimicked in this experiment, the inhalation occurs not all at once, but over the entire year. The minimum detectable dose for this situation would be more than $0.002 \mathrm{~Sv}$. The dose calculated for this research is $20 \%$ above the LLD for the bioassay. The workers who perform this type of activity are routinely monitored and do not have measurable internal doses.

The workplace airborne contamination levels are monitored using a continuous air monitor. The alarm set point for the air monitors is $1.2 \mathrm{~Bq} / \mathrm{m}^{3}$. The concentration measured by the MOUDI over the 2 hours while work was performed is the activity divided by the collection efficiency and flow $-39.4 \mathrm{~Bq} / \mathrm{m}^{3}$.

But as discussed earlier, the concentration decreases as a function of distance from the source. The volume of the air seen by the breathing zone was estimated to be 36 times greater than that seen by the MOUDI. So if the CAM were positioned at the breathing zone of the worker, the concentration of contaminant due to the work in the hood would be on the order of $1 \mathrm{~Bq} / \mathrm{m}^{3}$. In fact, the CAMs are located above the breathing zone of the worker. So the concentration of air sampled by the CAM is less than the $1 \mathrm{~Bq} / \mathrm{m}^{3}$ calculated. Indeed, CAM alarms are not observed when this type of work is performed.

In Appendix C, the dose calculated by the Los Alamos program is compared to hand calculation. The hand calculation does not use coupled differential equations but makes simplifying assumptions regarding the competing processes of clearance within the thoracic lymph nodes. The simplifying assumptions overestimate the amount of 
material deposited in the thoracic lymph nodes, thereby overestimating the dose to that region of the lung. 


\section{CHAPTER 5: CONCLUSIONS AND RECOMMENDATIONS}

This research used neutron activation analysis to measure microgram quantities of aerosol. This method allowed for quantitative measurement of the aerosol escaping an open-front hood, including measurement of particle size distribution. The measured mass median diameter ranged from $0.35 \mu \mathrm{m} \pm 5.1 \mu \mathrm{m}$ when a person was moving their hands in and out of the hood to $0.54 \mu \mathrm{m} \pm 3.7 \mu \mathrm{m}$ when a worker simply sat in front of the hood. These values are within the range of measurements done in other research.

The exposure directly outside of the hood each time a heating process is used to digest a sample was $0.08 \pm 0.01 \mathrm{~Sv}$. However, the dose to the worker is 36 times lower than the dose measured at the exit of the hood. Assuming the worker spent the entire time in front of the hood working, the resulting dose was estimated to be $2 \mathrm{mSv}$. In

reality, the worker is in front of the hood only $10 \%$ of the time. Given this operation is performed approximately 24 times a year, the resulting dose to the worker would be $5 \pm$ $0.3 \mathrm{mSv}$. This is a quarter of the limit recommended by ICRP.

Based on the experimental error, this value could be low by a factor of 4 . There was little difference between the dose calculated for a worker in motion and a stationary worker. The dose while work was being performed is $5 \%$ higher. Comparison of these results to measured worker doses and continuous air monitoring results showed the experimental results may be somewhat higher. The lower limit of detection for urine bioassay is $0.002 \mathrm{~Sv}$ (Inkret, et al., 1999). Workers performing the activity mimicked in this experiment are routinely monitored and do not have measurable internal doses. The most likely reason for the high experimental results is the placement of the sample digestion apparatus. For this experiment, the material was place $10 \mathrm{~cm}$ from the hood 
opening. In reality, the material is slightly further back in the hood. Placing the material further back in the hood likely decreases the amount of material escaping the hood.

This research is unique as it measures particle size distribution from routine working conditions. It is important as the results allow for quantitative measurement of worker exposure and determination of the adequacy of the open front hood for this type of work. This work is important as it quantifies the effectiveness of the open front hood for controlling inhalation hazards. This information is key for managing the risk to workers.

Determination of the adequacy of the open front hood is a cost-benefit analysis. Cost-benefit analysis is described in ICRP 37 (ICRP, 1983) and the general concept of optimization of protection is expanded on in ICRP 55 (ICRP 55, 1988). ICRP 37 method compared cost of an engineered control with the detriment associated with the potential health effects, $\$ 10,000$ per Sv and any additional non-health costs associated with dose such as the reduced efficiency of workers. ICRP 55 expanded the comparison to include less quantifiable factors such as worker acceptance.

Assuming a $\mathrm{Sv}$ is worth $\$ 10,000$, the total value of the dose from performing dissolution in an open-front hood 24 times a year is $\$ 50$. If the work was done in a glove box, the internal dose to the worker is assumed to be zero. However, Los Alamos experiences, on average 13 ergonomic injuries per year due to glove box work. The average cost per injury is between $\$ 10,000$ and $\$ 120,000$, based on the joint injured and whether surgery is required. The average annual cost due to ergonomic injuries from glovebox work is estimated to be $\$ 500,000$ (Lawton, 2006). This is 10000 times the cost of the projected worker dose. Therefore, an open-front hood provides reasonable protection to the worker. 
It would be interesting to repeat the experiment varying the concentration of the solution. This change in concentration would likely change the mass median diameter of the particles escaping the hood. As the resulting effective dose is a function of particle size, the worker dose would likely vary as a function of solution concentration. The effect of the location of the hot plate/beaker in the hood on the mass of material released from the hood would be another interesting experiment. Additional measurements along the face of the hood and at the worker's breathing zone would give information about the change in aerosol concentration as a function of distance from the source. 
APPENDIX A - DIAGRAM OF EXPERIMENTAL SETUP 


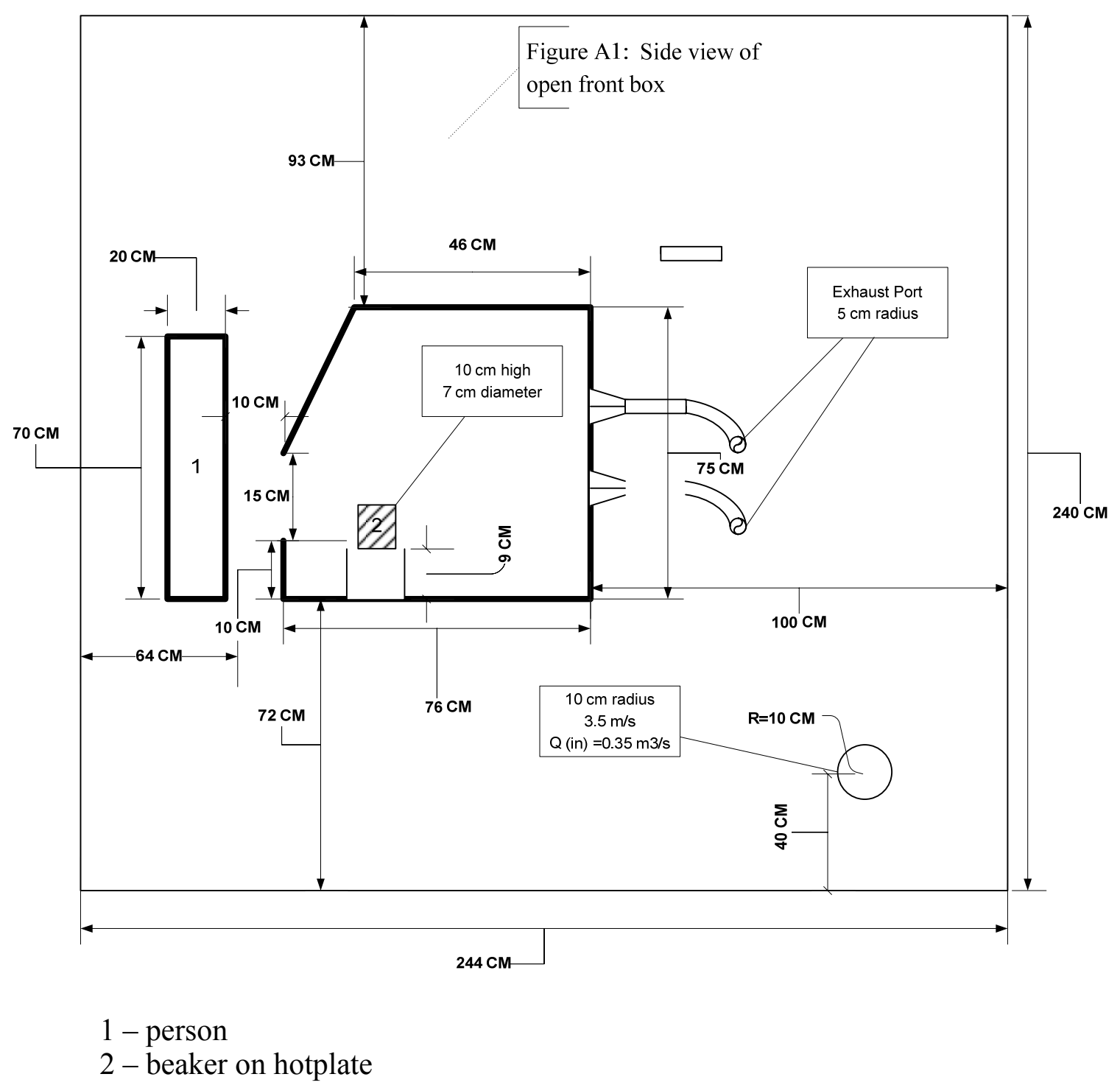


Figure A2: Open Face Glove Box Front View

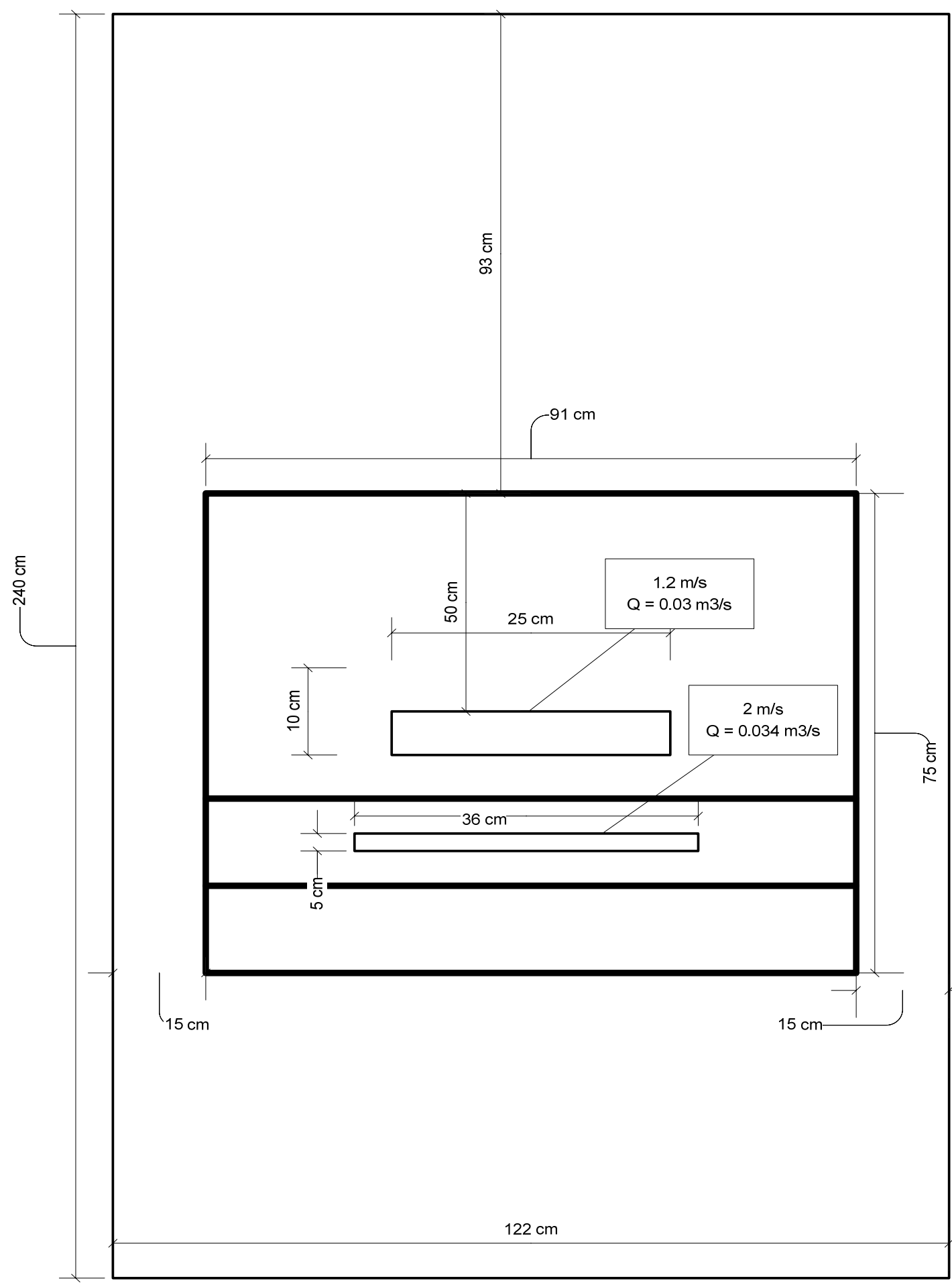


Figure A3: Top View of Open Front Hood

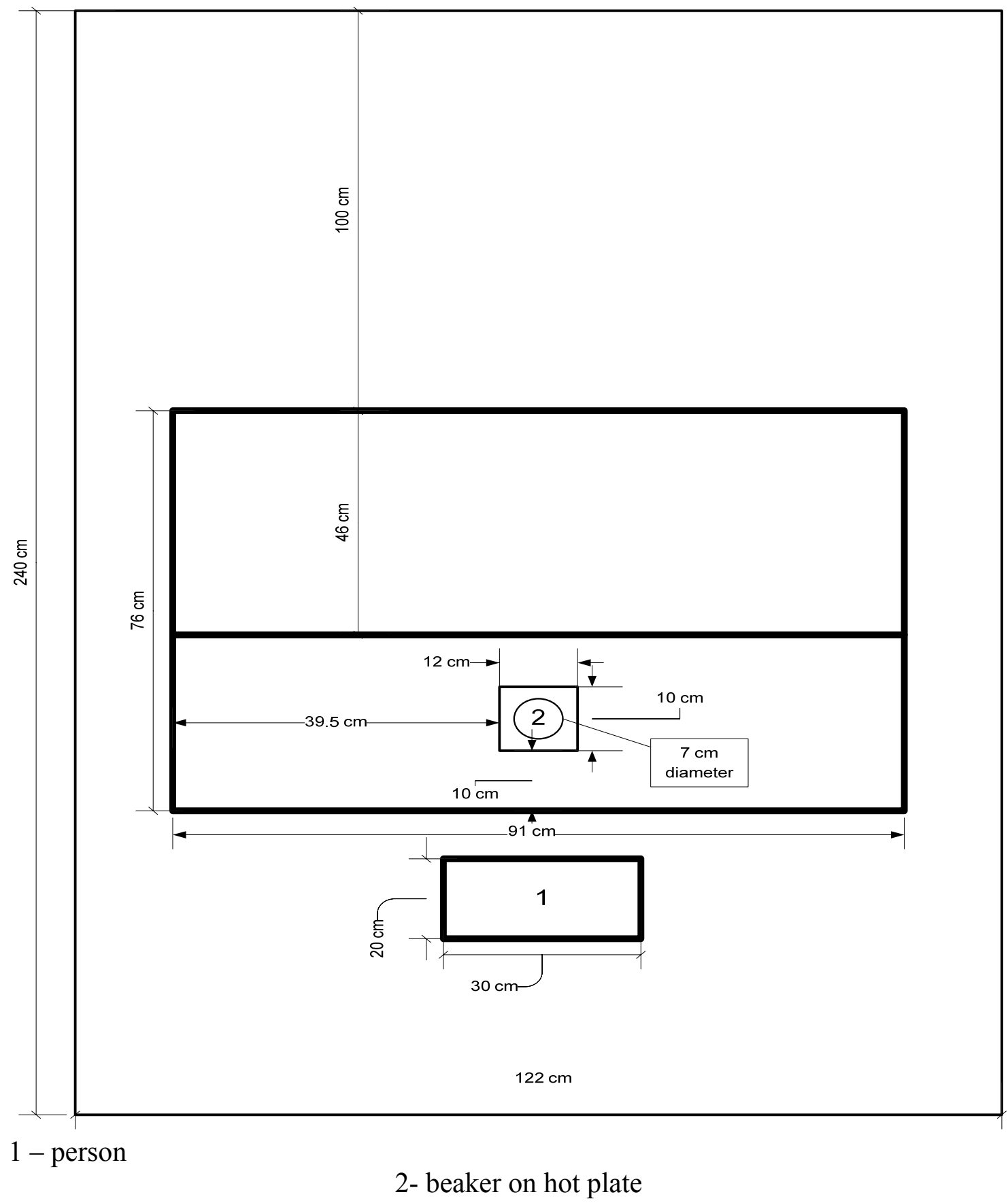




\section{APPENDIX B - LOS ALAMOS PROGRAM OUTPUT}

\section{Exhibit B1: Sv/Bq for 0.54 um}

Series with 1 element(s):

Isotope(s): $\mathrm{Pu}-239$

Model(s): PU

Subject: Standard Worker (Nose Breather)

Intake: Inhalation, Single, without intake of progeny.

Element: Pu-239

Initial or daily activity: $1.000 \mathrm{E}+00 \mathrm{~Bq}$

Inhalation: Respiratory Tract: ICRP-66

Compound: Type $\mathrm{S}$

GI Absorption Fraction: f1 =: 1.000E-05

AMAD (um): 5.400E-01

Dosimetric System: ICRP-60

Committed Equivalent Doses (Sv):

Highest committed equivalent dose: Bone Surface 1.89E-04

Remainder formulation: Default

Time (Years) $\quad 50.00$

$\begin{array}{lc}\text { Adrenals } & 3.19 \mathrm{E}-07 \\ \text { Bladder Wall } & 3.19 \mathrm{E}-07 \\ \text { Bone Surface } & 1.89 \mathrm{E}-04 \\ \text { Brain } & 3.19 \mathrm{E}-07 \\ \text { Breasts } & 3.19 \mathrm{E}-07 \\ \text { Esophagus } & 3.19 \mathrm{E}-07 \\ \text { St Wall } & 3.20 \mathrm{E}-07 \\ \text { SI Wall } & 3.20 \mathrm{E}-07 \\ \text { ULI Wall } & 3.24 \mathrm{E}-07 \\ \text { LLI Wall } & 3.33 \mathrm{E}-07 \\ \text { Colon } & 3.28 \mathrm{E}-07 \\ \text { Kidneys } & 7.99 \mathrm{E}-07 \\ \text { Liver } & 3.93 \mathrm{E}-05 \\ \text { Muscle } & 3.19 \mathrm{E}-07 \\ \text { Ovaries } & 2.45 \mathrm{E}-06 \\ \text { Pancreas } & 3.19 \mathrm{E}-07 \\ \text { Red Marrow } & 9.62 \mathrm{E}-06 \\ \text { ET Airways } & 2.47 \mathrm{E}-05\end{array}$




$\begin{array}{lc}\text { Lungs } & 8.60 \mathrm{E}-05 \\ \text { Skin } & 3.19 \mathrm{E}-07 \\ \text { Spleen } & 3.19 \mathrm{E}-07 \\ \text { Testes } & 2.49 \mathrm{E}-06 \\ \text { Thymus } & 3.19 \mathrm{E}-07 \\ \text { Thyroid } & 3.19 \mathrm{E}-07 \\ \text { Uterus } & 3.19 \mathrm{E}-07\end{array}$

Rem.ICRP-60 3.37E-07

Eff. Dose: 1.60E-05

\begin{tabular}{|c|c|}
\hline ET1-bas & $2.47 \mathrm{E}-05$ \\
\hline ET2-bas & $2.47 \mathrm{E}-05$ \\
\hline LN-ET & 4.39E-05 \\
\hline BBi-bas & $3.19 \mathrm{E}-06$ \\
\hline BBi-sec & 4.75E-05 \\
\hline bbe-sec & 7.63E-05 \\
\hline AI & $1.54 \mathrm{E}-04$ \\
\hline LN-Th & 8.93E-04 \\
\hline
\end{tabular}




\section{Exhibit B2: Sv/Bq for 0.35 um}

Series with 1 element(s):

Isotope(s): $\mathrm{Pu}-239$

Model(s): PU

Subject: Standard Worker (Nose Breather)

Intake: Inhalation, Single, without intake of progeny.

Element: Pu-239

Initial or daily activity: $1.000 \mathrm{E}+00 \mathrm{~Bq}$

Inhalation: Respiratory Tract: ICRP-66

Compound: Type S

GI Absorption Fraction: $\mathrm{f1}=:$ 1.000E-05

AMAD (um): 3.500E-01

Dosimetric System: ICRP-60

Committed Equivalent Doses (Sv):

Highest committed equivalent dose: Bone Surface 2.21E-04

Remainder formulation: Default

Time (Years) $\quad 50.00$

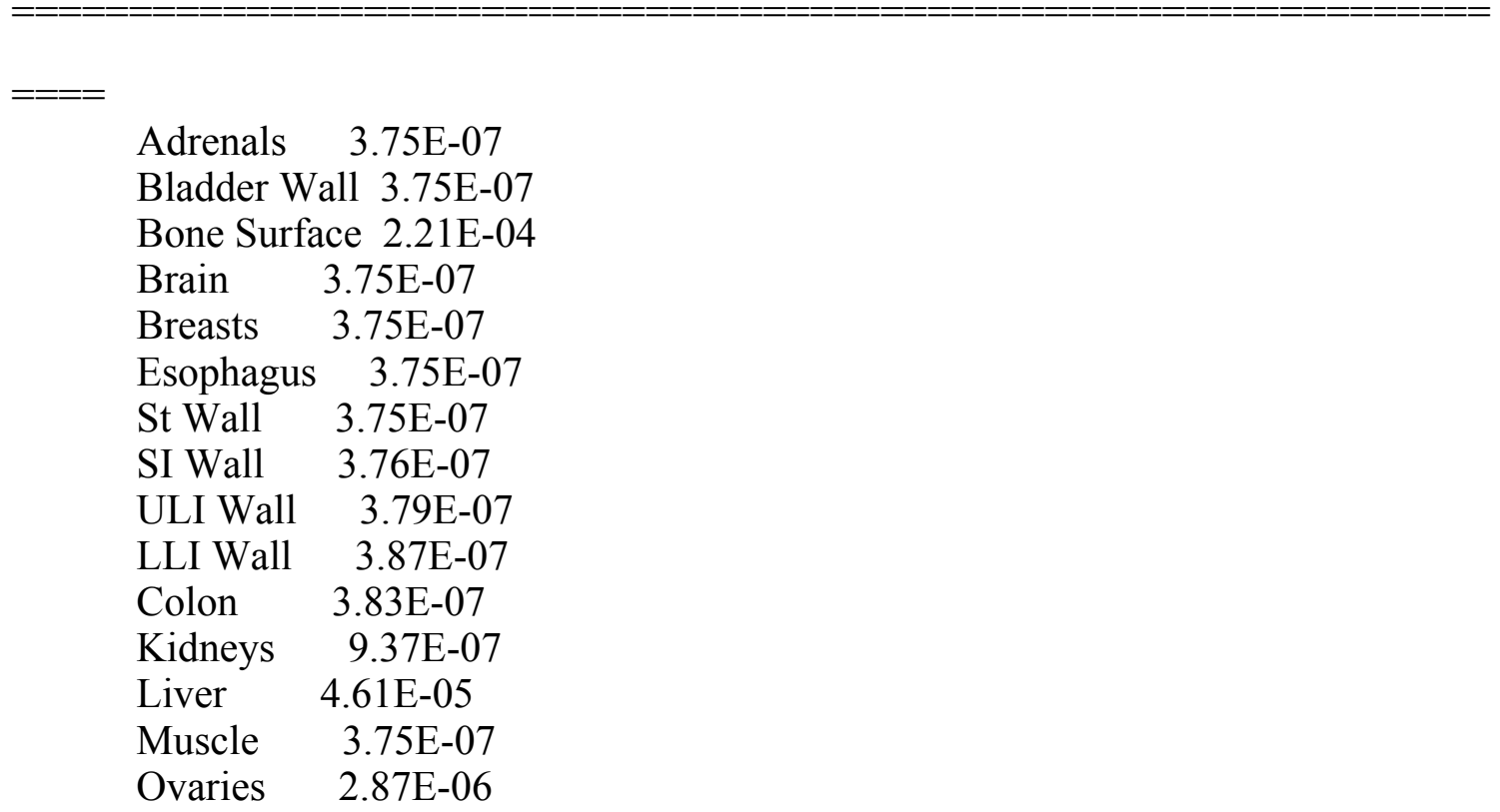


Pancreas 3.75E-07

Red Marrow 1.13E-05

ET Airways $1.46 \mathrm{E}-05$

Lungs 1.02E-04

Skin 3.75E-07

Spleen 3.75E-07

Testes 2.92E-06

Thymus 3.75E-07

Thyroid 3.75E-07

Uterus $\quad 3.75 \mathrm{E}-07$

Rem.ICRP-60 3.88E-07

Eff. Dose: 1.89E-05 


\section{APPENDIX C - SAMPLE CALCULATION FOR $1 \mu$ PARTICLES}

\section{Calculation of Fraction of Deposition in Each Compartment}

\begin{tabular}{lll} 
Region & Initial Deposition & \multicolumn{1}{l}{ Deposition Fraction } \\
ET1 & ET1 & 0.17 \\
ET2 & ET2 & $0.211(0.9995)=2.1 \mathrm{e}-1$ \\
& ETseq & $0.211(0.005)=1.05 \mathrm{e}-4$ \\
BB & BB1 & $0.0124(1-0.47-0.07)=6.49 \mathrm{e}-3$ \\
& BB2 & $0.0124(0.47)=5.83 \mathrm{e}-3$ \\
Bb & BBseq & $0.0124(0.007)=8.68 \mathrm{e}-5$ \\
$0.007)=8.32 \mathrm{e}-3$ & bb1 & $0.0165(1-0.489-$ \\
& bb2 & \\
& bbseq & $0.0165(0.489)=8.07 \mathrm{e}-3$ \\
AI1 & AI2 & $0.0165(0.007)=1.16 \mathrm{e}-4$ \\
& AI3 & $0.107(0.3)=3.21 \mathrm{e}-2$ \\
& & $0.107(0.6)=6.42 \mathrm{e}-2$ \\
& & $0.107(0.1)=1.07 \mathrm{e}-2$ \\
& &
\end{tabular}

These values come out the same as the Los Alamos program 
Calculation of Number of Disintegrations Per Compartment Per Bq Deposited

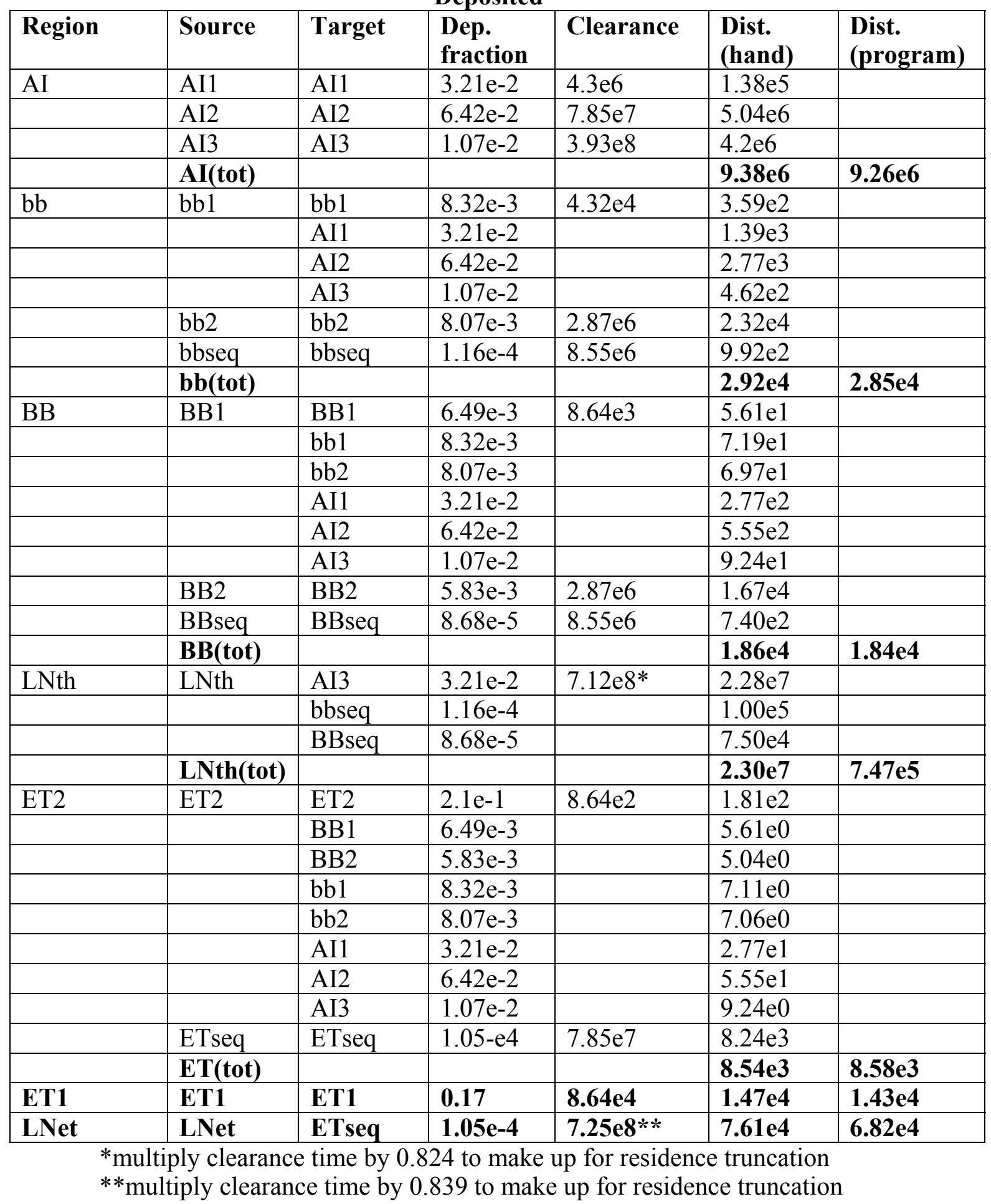




\section{Calculation of $\mathrm{Sv} / \mathrm{Bq}$}

\begin{tabular}{|c|c|c|c|c|c|c|c|}
\hline Target & Source & Dist. & $\mathrm{AF}$ & Mass & SEE* & Sv (hand) & Sv (program) \\
\hline ET1 & ET1 & $1.47 \mathrm{e} 4$ & $\mathbf{0}$ & $2 \mathrm{e} 5$ & $\mathbf{0}$ & 0 & $4.22 \mathrm{e}-5$ \\
\hline \multirow[t]{3}{*}{ ET2 } & ET2 & 300 & 0 & $4.5 \mathrm{e}-4$ & 0 & & \\
\hline & ETseq & 8240 & 0.138 & & $5.03 e-9$ & $4.14 \mathrm{e}-5$ & \\
\hline & ET2(tot) & & & & & $4.14 \mathrm{e}-5$ & $4.22 \mathrm{e}-5$ \\
\hline LNet & LNet & $7.61 \mathrm{e} 4$ & 1 & 0.015 & $1.06 \mathrm{e}-9$ & $8.05 e-5$ & $7.51 e-5$ \\
\hline \multirow{5}{*}{ BBbasal } & BB1 & $1.12 \mathrm{e} 3$ & 0 & $4.3 \mathrm{e}-4$ & 0 & & \\
\hline & BB2 & $1.67 \mathrm{e} 4$ & $5.4 \mathrm{e}-4$ & & $2.06 \mathrm{e}-11$ & $3.44 \mathrm{e}-7$ & \\
\hline & BBseq & 740 & 0.135 & & $5.15 \mathrm{e}-9$ & $3.81 \mathrm{e}-6$ & \\
\hline & $\mathrm{AI}$ & $9.38 \mathrm{e} 6$ & 0 & & 0 & & \\
\hline & Bbbasal(tot) & & & & & $4.15 \mathrm{e}-6$ & $4.46 \mathrm{e}-6$ \\
\hline \multirow[t]{5}{*}{ BBsec } & BB1 & $1.12 \mathrm{e} 3$ & 0.144 & $8.6 \mathrm{e}-4$ & $2.75 \mathrm{e}-9$ & $3.08 \mathrm{e}-6$ & \\
\hline & BB2 & $1.67 \mathrm{e} 4$ & 0.192 & & $3.66 \mathrm{e}-9$ & $6.11 \mathrm{e}-5$ & \\
\hline & Bbseq & 740 & $5.15 \mathrm{e}-2$ & & $9.82 \mathrm{e}-10$ & $7.27 \mathrm{e}-7$ & \\
\hline & $\mathrm{AI}$ & $9.38 \mathrm{e} 6$ & 0 & & 0 & & \\
\hline & BBsec(tot) & & & & & $6.49 \mathrm{e}-5$ & $6.46 \mathrm{e}-5$ \\
\hline \multirow[t]{5}{*}{$\mathrm{bb}$} & bb1 & $4.98 \mathrm{e} 3$ & 0.233 & $1.9 \mathrm{e}-3$ & $2.01 \mathrm{e}-9$ & $1.00 \mathrm{e}-5$ & \\
\hline & bb2 & $2.32 \mathrm{e} 4$ & 0.237 & & $2.05 \mathrm{e}-9$ & $4.76 \mathrm{e}-5$ & \\
\hline & bbseq & $9.92 \mathrm{e} 2$ & 0.111 & & $9.58 \mathrm{e}-10$ & $9.50 \mathrm{e}-7$ & \\
\hline & $\mathrm{AI}$ & $9.38 \mathrm{e} 6$ & $7.06 \mathrm{e}-5$ & & $6.09 \mathrm{e}-13$ & $5.72 \mathrm{e}-6$ & \\
\hline & bb(tot) & & & & & $6.43 e-5$ & $6.16 \mathrm{e}-5$ \\
\hline AI & AI & $9.38 \mathrm{e} 6$ & 1 & 1.1 & $1.49 \mathrm{e}-11$ & $1.40 \mathrm{e}-4$ & $1.39 \mathrm{e}-4$ \\
\hline LNth & LNth & $2.30 \mathrm{e} 7$ & 1 & 0.015 & $1.09 \mathrm{e}-9$ & $2.51 \mathrm{e}-2$ & $8.20 \mathrm{e}-4$ \\
\hline
\end{tabular}

*1.64e11*AF/Mass 


\section{APPENDIX D- LIST OF SAMPLES}




\begin{tabular}{|c|c|c|c|}
\hline Project ID & Description & Date & Cutpoint $(\mu \mathrm{m})$ \\
\hline 1 & First Background Run & $11 / 7 / 2005$ & 18 \\
\hline 2 & First Background Run & $11 / 7 / 2005$ & 9.9 \\
\hline 3 & First Background Run & $11 / 7 / 2005$ & 6.2 \\
\hline 4 & First Background Run & $11 / 7 / 2005$ & 3.1 \\
\hline 5 & First Background Run & $11 / 7 / 2005$ & 1.8 \\
\hline 6 & First Background Run & $11 / 7 / 2005$ & 1 \\
\hline 7 & First Background Run & $11 / 7 / 2005$ & 0.54 \\
\hline 8 & First Background Run & $11 / 7 / 2005$ & 0.32 \\
\hline 9 & First Background Run & $11 / 7 / 2005$ & 0.19 \\
\hline 10 & First Background Run & $11 / 7 / 2005$ & backstop \\
\hline 11 & Second Background Run & $11 / 8 / 2005$ & 18 \\
\hline 12 & Second Background Run & $11 / 8 / 2005$ & 9.9 \\
\hline 13 & Second Background Run & $11 / 8 / 2005$ & 6.2 \\
\hline 14 & Second Background Run & $11 / 8 / 2005$ & 3.1 \\
\hline 15 & Second Background Run & $11 / 8 / 2005$ & 1.8 \\
\hline 16 & Second Background Run & $11 / 8 / 2005$ & 1 \\
\hline 17 & Second Background Run & $11 / 8 / 2005$ & 0.54 \\
\hline 18 & Second Background Run & $11 / 8 / 2005$ & 0.32 \\
\hline 19 & Second Background Run & $11 / 8 / 2005$ & 0.19 \\
\hline 20 & Second Background Run & $11 / 8 / 2005$ & backstop \\
\hline 21 & Third Background Run & $11 / 8 / 2005$ & 18 \\
\hline 22 & Third Background Run & $11 / 8 / 2005$ & 9.9 \\
\hline 23 & Third Background Run & $11 / 8 / 2005$ & 6.2 \\
\hline 24 & Third Background Run & $11 / 8 / 2005$ & 3.1 \\
\hline 25 & Third Background Run & $11 / 8 / 2005$ & 1.8 \\
\hline 26 & Third Background Run & $11 / 8 / 2005$ & 1 \\
\hline 27 & Third Background Run & $11 / 8 / 2005$ & 0.54 \\
\hline 28 & Third Background Run & $11 / 8 / 2005$ & 0.32 \\
\hline 29 & Third Background Run & $11 / 8 / 2005$ & 0.19 \\
\hline 30 & Third Background Run & $11 / 8 / 2005$ & backstop \\
\hline 31 & Worker in Motion - hot plate failed & $11 / 10 / 2005$ & 18 \\
\hline 32 & Worker in Motion - hot plate failed & $11 / 10 / 2005$ & 9.9 \\
\hline 33 & Worker in Motion - hot plate failed & $11 / 10 / 2005$ & 6.2 \\
\hline 34 & Worker in Motion - hot plate failed & $11 / 10 / 2005$ & 3.1 \\
\hline 35 & Worker in Motion - hot plate failed & $11 / 10 / 2005$ & 1.8 \\
\hline 36 & Worker in Motion - hot plate failed & $11 / 10 / 2005$ & 1 \\
\hline 37 & Worker in Motion - hot plate failed & $11 / 10 / 2005$ & 0.54 \\
\hline 38 & Worker in Motion - hot plate failed & $11 / 10 / 2005$ & 0.32 \\
\hline 39 & Worker in Motion - hot plate failed & $11 / 10 / 2005$ & 0.19 \\
\hline 40 & Worker in Motion - hot plate failed & $11 / 10 / 2005$ & backstop \\
\hline
\end{tabular}




\begin{tabular}{|c|c|c|c|}
\hline Project ID & Description & Date & Cutpoint $(\mu \mathrm{m})$ \\
\hline 41 & Person Sitting in Front of Box & $11 / 11 / 2005$ & 18 \\
\hline 42 & Person Sitting in Front of Box & $11 / 11 / 2005$ & 9.9 \\
\hline 43 & Person Sitting in Front of Box & $11 / 11 / 2005$ & 6.2 \\
\hline 44 & Person Sitting in Front of Box & $11 / 11 / 2005$ & 3.1 \\
\hline 45 & Person Sitting in Front of Box & $11 / 11 / 2005$ & 1.8 \\
\hline 46 & Person Sitting in Front of Box & $11 / 11 / 2005$ & 1 \\
\hline 47 & Person Sitting in Front of Box & $11 / 11 / 2005$ & 0.54 \\
\hline 48 & Person Sitting in Front of Box & $11 / 11 / 2005$ & 0.32 \\
\hline 49 & Person Sitting in Front of Box & $11 / 11 / 2005$ & 0.19 \\
\hline 50 & Person Sitting in Front of Box & $11 / 11 / 2005$ & backstop \\
\hline 51 & MOUDI in Hood & $11 / 12 / 2005$ & 18 \\
\hline 52 & MOUDI in Hood & $11 / 12 / 2005$ & 9.9 \\
\hline 53 & MOUDI in Hood & $11 / 12 / 2005$ & 6.2 \\
\hline 54 & MOUDI in Hood & $11 / 12 / 2005$ & 3.1 \\
\hline 55 & MOUDI in Hood & $11 / 12 / 2005$ & 1.8 \\
\hline 56 & MOUDI in Hood & $11 / 12 / 2005$ & 1 \\
\hline 57 & MOUDI in Hood & $11 / 12 / 2005$ & 0.54 \\
\hline 58 & MOUDI in Hood & $11 / 12 / 2005$ & 0.32 \\
\hline 59 & MOUDI in Hood & $11 / 12 / 2005$ & 0.19 \\
\hline 60 & MOUDI in Hood & $11 / 12 / 2005$ & backstop \\
\hline 61 & MOUDI in Hood & $11 / 18 / 2005$ & 18 \\
\hline 62 & MOUDI in Hood & $11 / 18 / 2005$ & 9.9 \\
\hline 63 & MOUDI in Hood & $11 / 18 / 2005$ & 6.2 \\
\hline 64 & MOUDI in Hood & $11 / 18 / 2005$ & 3.1 \\
\hline 65 & MOUDI in Hood & $11 / 18 / 2005$ & 1.8 \\
\hline 66 & MOUDI in Hood & $11 / 18 / 2005$ & 1 \\
\hline 67 & MOUDI in Hood & $11 / 18 / 2005$ & 0.54 \\
\hline 68 & MOUDI in Hood & $11 / 18 / 2005$ & 0.32 \\
\hline 69 & MOUDI in Hood & $11 / 18 / 2005$ & 0.19 \\
\hline 70 & MOUDI in Hood & $11 / 18 / 2005$ & backstop \\
\hline 71 & Worker in Motion & $11 / 18 / 2005$ & 18 \\
\hline 72 & Worker in Motion & $11 / 18 / 2005$ & 9.9 \\
\hline 73 & Worker in Motion & $11 / 18 / 2005$ & 6.2 \\
\hline 74 & Worker in Motion & $11 / 18 / 2005$ & 3.1 \\
\hline 75 & Worker in Motion & $11 / 18 / 2005$ & 1.8 \\
\hline 76 & Worker in Motion & $11 / 18 / 2005$ & 1 \\
\hline 77 & Worker in Motion & $11 / 18 / 2005$ & 0.54 \\
\hline 78 & Worker in Motion & $11 / 18 / 2005$ & 0.32 \\
\hline 79 & Worker in Motion & $11 / 18 / 2005$ & 0.19 \\
\hline 80 & Worker in Motion & $11 / 18 / 2005$ & backstop \\
\hline
\end{tabular}




\begin{tabular}{|c|c|c|c|}
\hline Project ID & Description & Date & Cutpoint $(\mu \mathrm{m})$ \\
\hline 81 & Worker in Motion & $11 / 19 / 2005$ & 18 \\
\hline 82 & Worker in Motion & $11 / 19 / 2005$ & 9.9 \\
\hline 83 & Worker in Motion & $11 / 19 / 2005$ & 6.2 \\
\hline 84 & Worker in Motion & $11 / 19 / 2005$ & 3.1 \\
\hline 85 & Worker in Motion & $11 / 19 / 2005$ & 1.8 \\
\hline 86 & Worker in Motion & $11 / 19 / 2005$ & 1 \\
\hline 87 & Worker in Motion & $11 / 19 / 2005$ & 0.54 \\
\hline 88 & Worker in Motion & $11 / 19 / 2005$ & 0.32 \\
\hline 89 & Worker in Motion & $11 / 19 / 2005$ & 0.19 \\
\hline 90 & Worker in Motion & $11 / 19 / 2005$ & backstop \\
\hline 91 & Worker in Motion & $11 / 22 / 2005$ & 18 \\
\hline 92 & Worker in Motion & $11 / 22 / 2005$ & 9.9 \\
\hline 93 & Worker in Motion & $11 / 22 / 2005$ & 6.2 \\
\hline 94 & Worker in Motion & $11 / 22 / 2005$ & 3.1 \\
\hline 95 & Worker in Motion & $11 / 22 / 2005$ & 1.8 \\
\hline 96 & Worker in Motion & $11 / 22 / 2005$ & 1 \\
\hline 97 & Worker in Motion & $11 / 22 / 2005$ & 0.54 \\
\hline 98 & Worker in Motion & $11 / 22 / 2005$ & 0.32 \\
\hline 99 & Worker in Motion & $11 / 22 / 2005$ & 0.19 \\
\hline 100 & Worker in Motion & $11 / 22 / 2005$ & backstop \\
\hline 101 & Person Sitting in Front of Box & $12 / 5 / 2005$ & 18 \\
\hline 102 & Person Sitting in Front of Box & $12 / 5 / 2005$ & 9.9 \\
\hline 103 & Person Sitting in Front of Box & $12 / 5 / 2005$ & 6.2 \\
\hline 104 & Person Sitting in Front of Box & $12 / 5 / 2005$ & 3.1 \\
\hline 105 & Person Sitting in Front of Box & $12 / 5 / 2005$ & 1.8 \\
\hline 106 & Person Sitting in Front of Box & $12 / 5 / 2005$ & 1 \\
\hline 107 & Person Sitting in Front of Box & $12 / 5 / 2005$ & 0.54 \\
\hline 108 & Person Sitting in Front of Box & $12 / 5 / 2005$ & 0.32 \\
\hline 109 & Person Sitting in Front of Box & $12 / 5 / 2005$ & 0.19 \\
\hline 110 & $\begin{array}{l}\text { Person Sitting in Front of Box - sample } \\
\text { dropped }\end{array}$ & $12 / 5 / 2005$ & backstop \\
\hline 111 & MOUDI in hood & $12 / 9 / 2005$ & 18 \\
\hline 112 & MOUDI in hood & $12 / 9 / 2005$ & 9.9 \\
\hline 113 & MOUDI in hood & $12 / 9 / 2005$ & 6.2 \\
\hline 114 & MOUDI in hood & $12 / 9 / 2005$ & 3.1 \\
\hline 115 & MOUDI in hood & $12 / 9 / 2005$ & 1.8 \\
\hline 116 & MOUDI in hood & $12 / 9 / 2005$ & 1 \\
\hline 117 & MOUDI in hood & $12 / 9 / 2005$ & 0.54 \\
\hline 118 & MOUDI in hood & $12 / 9 / 2005$ & 0.32 \\
\hline 119 & MOUDI in hood & $12 / 9 / 2005$ & 0.19 \\
\hline 120 & MOUDI in hood & $12 / 9 / 2005$ & backstop \\
\hline
\end{tabular}




\begin{tabular}{|c|c|c|c|}
\hline Project ID & Description & Date & Cutpoint $(\mu \mathrm{m})$ \\
\hline 121 & $\begin{array}{l}\text { Person Sitting in Front of Box - exhaust fan } \\
\text { failure }\end{array}$ & $12 / 9 / 2005$ & 18 \\
\hline 122 & $\begin{array}{l}\text { Person Sitting in Front of Box - exhaust fan } \\
\text { failure }\end{array}$ & $12 / 9 / 2005$ & 9.9 \\
\hline 123 & $\begin{array}{l}\text { Person Sitting in Front of Box - exhaust fan } \\
\text { failure }\end{array}$ & $12 / 9 / 2005$ & 6.2 \\
\hline 124 & $\begin{array}{l}\text { Person Sitting in Front of Box - exhaust fan } \\
\text { failure }\end{array}$ & $12 / 9 / 2005$ & 3.1 \\
\hline 125 & $\begin{array}{l}\text { Person Sitting in Front of Box - exhaust fan } \\
\text { failure }\end{array}$ & $12 / 9 / 2005$ & 1.8 \\
\hline 126 & $\begin{array}{l}\text { Person Sitting in Front of Box - exhaust fan } \\
\text { failure }\end{array}$ & $12 / 9 / 2005$ & 1 \\
\hline 127 & $\begin{array}{l}\text { Person Sitting in Front of Box - exhaust fan } \\
\text { failure }\end{array}$ & $12 / 9 / 2005$ & 0.54 \\
\hline 128 & $\begin{array}{l}\text { Person Sitting in Front of Box - exhaust fan } \\
\text { failure }\end{array}$ & $12 / 9 / 2005$ & 0.32 \\
\hline 129 & $\begin{array}{l}\text { Person Sitting in Front of Box - exhaust fan } \\
\text { failure }\end{array}$ & $12 / 9 / 2005$ & 0.19 \\
\hline 130 & $\begin{array}{l}\text { Person Sitting in Front of Box - exhaust fan } \\
\text { failure }\end{array}$ & $12 / 9 / 2005$ & backstop \\
\hline
\end{tabular}




\section{BIBLIOGRAPHY}

ASHRAE, Handbook of Fundamentals, Physiological Principles and Thermal Comfort, Chapter 8, 1993.

Brohus, H., Personal Exposure to Contaminant Sources in Ventilated Rooms, PhD. Thesis, Aalborg University, ISSN 0902-7953 R9741, Trykcenter, Denmark.

Brohus H., and PV Nielsen, Contaminate Distribution around Persons in Rooms Ventilated by Displacement Ventilation, ROOMVENT 94, Fourth International Conference on Air Distribution in Rooms, 1994.

Brosseau, LM, D Vesely, N Rice, K Goodell, M Nellis, and P Hairston, Difference in Detected Fluorescence Among Several Baterial Species Measured with a DirectReading Particle Sizer and Fluorescence Detector, Aerosol Science and Technology, Vol. 32, No. 6, 2000.

Bull, R. K., D. C. Stevens and M. Marshall, Studies of Aerosol Distributions in a Small Laboratory and Around a Human Phantom, Journal of Aerosol Science, Vol. 18, No. 3 99. 321-335, 1987.

Chemistry-Actinide Analytical Chemistry Group, Dissolution and Preparation of Plutonium Material Samples for Analysis of Pu and U Assay, ANC195, R.2.1, 2002.

Cheng, Yung Sung, et al., Characterization of Plutonium Aerosol Collected During an Accident, Health Physics, Vol 87, Issue 6, pp. 596-605, 2004.

Department of Energy Handbook 3010-94, Airborne Release Fractions/Rates and Respirable Fractions for Non-Reactor Nuclear Facilities, Office of Science and Technical Information, 1994.

Dorrian, MD and MR Bailey, Particle size Distribution of Radioactive Aerosols Measured in Workplaces, Radiation Protection Dosimetry, Vol 60, No 2, pp. 119133, 1995.

Fanger, P. O., Thermal Comfort - Analysis and Applications in Environmental Engineering, McGraw-Hill, 1972.

Guffey, Steven E. and Nir Barnea, Effects of Face Velocity, Flanges, and Manikin Position on the Effectiveness of a Benchtop Enclosing Hood in the Absence of Cross-drafts, American Industrial Hygiene Association Journal, Vol 55, pp 132139, 1994. 
Hinds, William C, Aerosol Technology: Properties, Behavior, and Measurement of Airborne Particles, Wiley, 1999.

Inkret, WC, G Miller, ME Schillaci, JNP Lawrence, and G Voelz, Los Alamos National Laboratory Radiological Dose Assessment - Haelth Effects of Plutonium Intake, LA-UR-99-845, 1999.

International Commission on Radiological Protection (ICRP), Cost-Benefit Analysis in the Optimization of Radiation Protection, ICRP Publication 371983.

International Commission on Radiological Protection (ICRP), Human Respiratory Tract Model for Radiation Protection, ICRP Publication 66, 1993.

International Commission on Radiological Protection (ICRP), Individual Monitoring for Internal Exposure of Workers, ICRP Publication 78, 1997.

International Commission on Radiological Protection (ICRP), Optimization and Decision-Making in Radiological Protection, ICRP Publication 55, 1988.

International Commission on Radiological Protection (ICRP), Supporting Guidance 3: Guide for the Practical Application of the ICRP Human Respiratory Tract Model, Elsevier Science, 2003.

Johnson, A. E. and B. Fletcher, The Effect of Operating Conditions on Fume Cupboard Containment, Safety Science, Safety Science, Vol. 24, No. 1, pp 51-60, 1996.

Johnson, A. E., B Fletcher and CJ Saunders, Air Movement Around a Worker in a LowSpeed Flow Field, Annals of Industrial Hygiene, Vol. 40, No 1, pp 57-64, 1996.

Jordan, H, DJ Gordon, JJ Whicker, DL Wannigman, Predicting Worker Exposure from a Glove Box Leak, LA-13833-MS, 2001.

Kotrappa, P, AR Sundararajan, DP Bhanti, and VB Menon, Dynamic Shape Factors for $\mathrm{PuO} 2$ Aerosols Useful in Autoradiographic Particle Size Analysis, Health Physics, Vol. 29, pp. 701-704, 1975.

Kramer, Lutz, lrich Poschl and Reinhard Niessner, Microstructural Rearrangement of Sodium Chloride Condensation Aerosol Particles on Interaction with Water Vapor, Journal of Aerosol Science, Vol. 31, No. 6, pp. 673-685, 2000.

Lan, Ngiam Soon and Shekar Viswanathan, Numerical Simulation of Airflow Around a Variable Volume/Constant Face Velocity Fume Cupboard, American Industrial Hygiene Association Journal, Vol 62, pp 132-139, 2001. 
Lawton, Cindy, Ergonomic Program Manager, Los Alamos National Lab, Personal communication on August 18, 2006.

Los Alamos National Laboratory (LANL), Summary of Radiological Incident Reports, 2004.

Marple, VA, KL Rabow, and SM Behm, A Microorifice Uniform Deposit Impactor (MOUDI): Description, Calibration, and Use, Aerosol Science and Technology, Vol. 14, pp 434-445, 1991.

Maupins, Karen and Dale Hitchings, Reducing Employee Exposure Potential Using the ANSI/ASHRAE 110 Method of Testing Performance of Laboratory Fume Hoods as a Diagnostic Tool, American Industrial Hygiene Association Journal, Vol 59, pp 133-138, 1998.

Memarzadeh, Farhad, National Institutes of Health Methodology for Optimization of Laboratory Hood Containment, 1997.

Myers, JB, MH Hosni, and BW Jones, Interaction of Air Motion with the Human Body, ASHRAE Winter Meeting, 1998, pp. 863-882, 1998.

Qian, Yinge, C Willeke, SA Grinshpun, J Donnelly, CC Coffey, Performance of N95 Respirators: Filtration Efficiency for Airborne Microbial and Inert Particles, American Industrial Hygiene Association Journal, Vol. 59, pp.128-132, 1998.

Potter, Charles A, Internal Dosimetry - A Review, Health Physics, Vol 88, No 6, pp 565$578,2005$.

Press, WH, SA Teukolsky, WT Vetterling, and BP Flannery, Numerical Recipes in C The Art of Scientific Computing, Cambridge University Press, pp 623-630, 1992.

Raabe, OG, GJ Newton, CJ Wilkinson, and SV Teague, Plutonium Aerosol Characterization inside safety enclosures at a demonstration mixed-oxide fuel fabrication facility, Health Physics, Vol 35, pp 649-661, 1978

Shibata, H, S Abe, and T Yamaguchi, New NaCl Aerosol Generator, The Tenth Annual Conference of the Association for Aerosol Research, pp. 242-248, 1990.

Task Group on Lung Dynamics, Desposition and Retention Models for Internal Dosimetry of the Human Respiratory Tract, Health Physics, Vol 12, pp. 173-207, 1966

Thiel, CG, Cascade Impactor Data and the Lognormal Distribution: Nonlinear Regression for a Better Fit, Journal of Aerosol Medicine, Vol. 15, No. 4, pp. 369378,2002 
Wellling, I, IM Andersson, G Rosen, J Raisanen, T Mielo, K Marttinen, and R Niemela, Contaminant Dispersion in the Vicinity of a Worker in a Uniform Velocity Field, Annuls of Occupational Hygiene, Vol. 44, No 3, pp 219-255, 2000.

Wick, OJ, Plutonium Handbook, A Guide to the Technology - Volumes 1 and 2, American Nuclear Society, pp 261-275, 1980. 


\section{VITA}

Cheryl Lynn Olson was born in Waco, Texas on June 4, 1963, the daughter of Beverly Jean Oxley and James Herman Oxley. After completing her work at Reicher Catholic High School, Waco, Texas, in 1981, she entered McLennan Community College in Waco, Texas. In 1983, she enrolled at Texas A\&M University in College Station, Texas. She received the degree of Bachelor of Science from Texas A\&M in May of 1989. After graduation from Texas A\&M, while working as a nuclear engineer, she attended the University of Washington. She received a Masters of Science from the University of Washington in December 1993. During the following years, she was employed as a nuclear engineer at Los Alamos National Laboratory, became certified as a health physicist, and licensed by the State of New Mexico as a nuclear engineer. In May of 2004, she entered the Graduate School of the University of Texas.

Permanent Address: 63B County Road 84B, Santa Fe, NM 87506

This dissertation was typed by the author. 